\title{
WestVirginiaUniversity
}

THE RESEARCH REPOSITORY @ WVU

Graduate Theses, Dissertations, and Problem Reports

2017

\section{Teaching without a Net: Experiencing Mandatory Curriculum Change}

\author{
Stephen Ross Higgins
}

Follow this and additional works at: https://researchrepository.wvu.edu/etd

\section{Recommended Citation}

Higgins, Stephen Ross, "Teaching without a Net: Experiencing Mandatory Curriculum Change" (2017). Graduate Theses, Dissertations, and Problem Reports. 5801.

https://researchrepository.wvu.edu/etd/5801

This Dissertation is protected by copyright and/or related rights. It has been brought to you by the The Research Repository @ WVU with permission from the rights-holder(s). You are free to use this Dissertation in any way that is permitted by the copyright and related rights legislation that applies to your use. For other uses you must obtain permission from the rights-holder(s) directly, unless additional rights are indicated by a Creative Commons license in the record and/ or on the work itself. This Dissertation has been accepted for inclusion in WVU Graduate Theses, Dissertations, and Problem Reports collection by an authorized administrator of The Research Repository @ WVU.

For more information, please contact researchrepository@mail.wvu.edu. 


\title{
Teaching Without a Net: Experiencing Mandatory Curriculum Change
}

\author{
Stephen Ross Higgins
}

\author{
Dissertation submitted \\ to the College of Education and Human Services \\ at West Virginia University
in partial fulfillment of the requirements for the degree of
Doctor of Education in
Curriculum \& Instruction

\author{
Sharon B. Hayes, Ph.D. Chair \\ Mary E. Haas, Ed.D. \\ Sam Stack, Ph.D. \\ G. H. Budd Sapp, Ed.D. \\ Robert Waterson, Ph.D.
}

Department of Curriculum \& Instruction

Morgantown, West Virginia

2017

Keywords: Constructionism, Curriculum, Identity, Narrative Inquiry, \& Social Constructivism Copyright 2017 Stephen Ross Higgins 


\begin{abstract}
Teaching Without a Net: Experiencing Mandatory Curriculum Change
\end{abstract}

Stephen Ross Higgins

This dissertation reports a qualitative study that explored the reconstructed narratives of 4 West Virginia $7^{\text {th }}$ grade social studies teachers. A methodology informed by narrative inquiry guided the research design, including the methods for data collection and data analysis. Two questions served as guideposts throughout the research process: What do the stories of the participants tell us about the ways in which teachers engage as developers of curriculum when curriculum change is mandated? In what ways did their stories of implementing a mandated change impact their professional identities? To explore these questions, I conducted 3 semistructured interviews with each participant. Each interview was recorded and then transcribed. Data analysis of interview transcripts consisted of both structural and thematic approaches.

The layered approach to data analysis provided insight into how the participants navigated complicating events in their professional lives and in turn revealed thematic elements imbedded within their narratives. The temporal findings of this study indicate that, for the participants, mandatory curriculum change provided challenges which produced feelings of uncertainty; however, the participants resolved the challenges via their own initiative and the cultivation of professional relationships among colleagues. The overarching questions and the revealed themes generated two theoretical points: 1) Local, state, and national policy makers cannot take curriculum change lightly, nor can they assume that teaching experience is all that is necessary for successful implementation 2) "Teaching without a net" has the potential to empower educators to assume greater agency over their respective classrooms. 
TEACHING WITHOUT A NET

To

Kim, Claudia, \& Dylan 


\section{Acknowledgements}

Thurgood Marshall once said, "None of us got where we are solely by pulling ourselves up by our bootstraps. We got here because somebody...bent down and helped us pick up our boots." I have been blessed not only by the assistance of somebody, but by the generosity of many individuals on my doctoral journey. I could not have tread the path without the assistance of the following individuals:

Dr. Sharon Hayes, thank you for guiding me through the dissertation process. This project would not have come to fruition without your time and energy. Your insight and suggestions challenged me to improve my craft. Dr. Mary Haas, thank you for mentoring me

through my graduate course work. Dr. Budd Sapp, Dr. Sam Stack, and Dr. Robert Waterson, your contributions to this project were greatly appreciated.

Trina, Katie, Steve, and Jesse, I owe a debt of gratitude to all of you. Thank you for agreeing to not only participate, but to share your reconstructed lives with me.

The phrase "Teaching Without a Net" was inspired by old-timey high wire performers via the Grateful Dead's 1990 album Without a Net (see cover art).

Finally, the love and support of my family has been indispensable in all my endeavors. Kimmie, thank you for cheering me on! 


\section{Table of Contents}

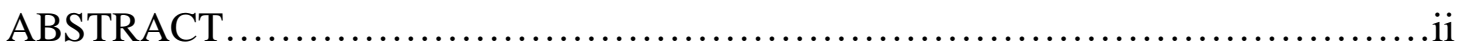



Purpose of the Study \& Research Questions......................................5

Significance of the Study .................................................. 6

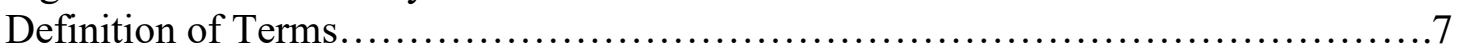

Summary................................................................ 8

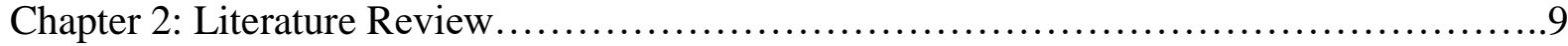

Teachers and Change.......................................................... 9

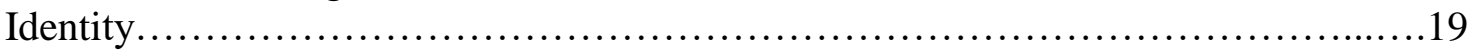

Teachers as Curriculum Makers...............................................23



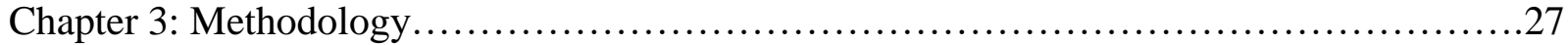

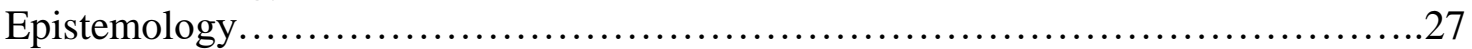

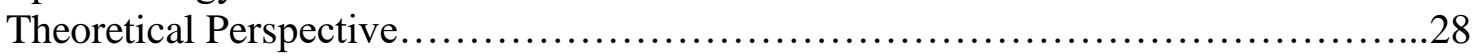

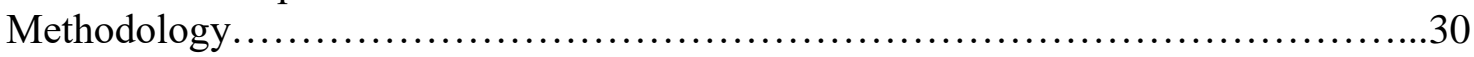

Research Context.................................................. 33

Participants..........................................................

Researcher Subjectivity..........................................440

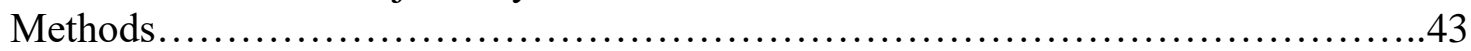

Data Sources \& Collection..........................................44

Data Analysis......................................................46

Thematic Analysis............................................47

Structural Analysis.............................................47

Applying a Layered Approach...................................48

Trustworthiness....................................................49

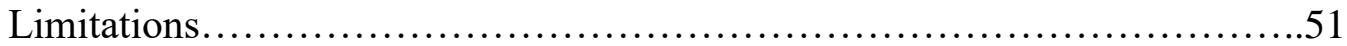



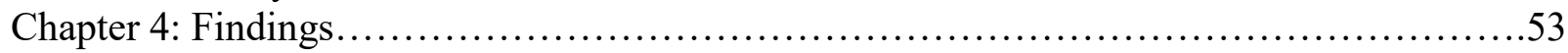

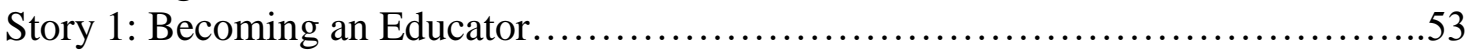

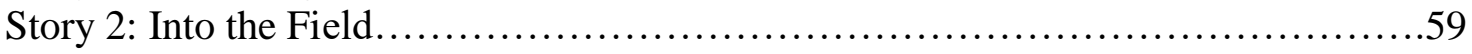

Story 3: Teaching Social Studies............................................64

Story 4: Top Down Mandates................................................. 70

Story 5: NxG CSOs for Social Studies........................................ 77

Story 6: Bridging Past \& Present............................................ 88

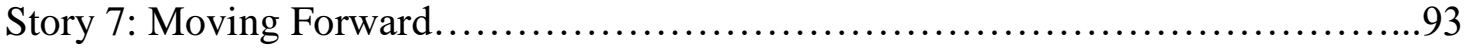

Summary................................................................ 97

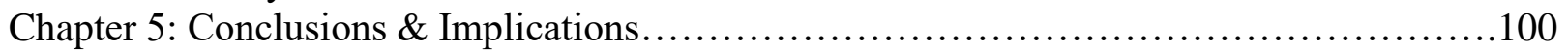



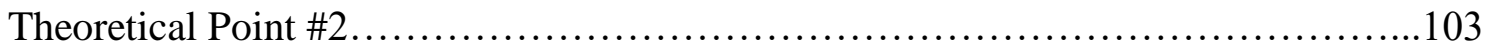

Further Implications................................................... 107

Questions for Further Research............................................ 111 
TEACHING WITHOUT A NET

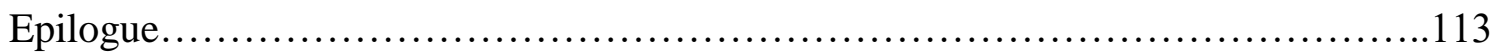

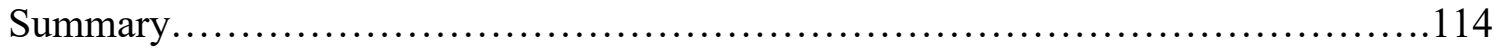

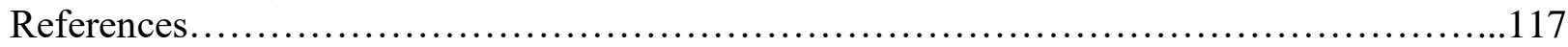

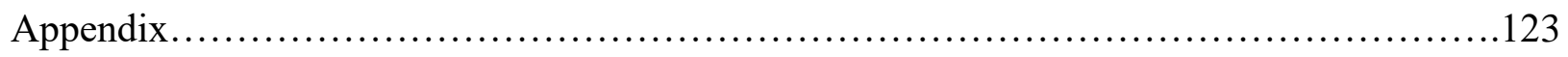




\section{Chapter 1: Introduction to the Study}

As the school year fast approaches an ending our thoughts are already going towards the next year. I just wanted to send a note out to clear up any confusion about the Next Generation Social Studies Standards and Objectives in West Virginia. They were approved by the State Board of Education in February. They will be effective on July 1, 2012. There will not be a roll out as there has been for ELA and Math. The Next Generation Social Studies Standards and Objectives will become effective in grades K-12 during the 2012-2013 school year. They can be found both on the Policy Page of the WVDE site and they can also be found on Teach 21 under the interactive Next Generation Standards and Objectives along with the new ELA and Math (Wiseman, 2012).

Following the chain of command, from the state level social studies coordinator to county level coordinators to building administrators, the above message arrived in my in-box in May of 2012. The subject ("Next Generation Social Studies Standards and Objectives, effective July 1, 2012") of the message caught my eye; however, I did not proceed further than reading the message. Viewing the recommended websites would have to wait as my present situation, concluding the final month of school, took precedence, at least in my mind, over thinking about the forthcoming school year. Until then, the message remained in my in-box as a reminder of something that needed my attention.

My initial thoughts, without consulting the recommended websites, were that the State Board of Education had altered the social studies objectives in some way; perhaps condensing or refining grade level objectives. As a teacher of $7^{\text {th }}$ grade social studies, teaching World Geography, 47 objectives guided my instruction. Upon perusing the West Virginia Department of Education (WVDE) website I learned that the State Board of Education had condensed the required objectives for $7^{\text {th }}$ grade teachers, reducing the number to 24 . However, what astounded me was not the reduction in objectives, but the complete alteration of $7^{\text {th }}$ grade social studies content. Seventh grade social studies had focused on the examination of "people, places and 
TEACHING WITHOUT A NET

events of today" $\left(21^{\text {st }}\right.$ CCSOs, 2009). The adoption of the Next Generation Content Standards

and Objectives (NxG CSOs) by the West Virginia Board of Education (WVBOE) mandated that

the content for $7^{\text {th }}$ grade social studies focus on the ancient world, from the beginnings of

recorded history to about the $16^{\text {th }}$ century. In early September of 2012, the state coordinator of

social studies education made the following statement concerning the change in content:

It is important that people realize the general topics and time periods covered in social studies K-2, 4-5 and 8-12 have not changed. The major changes are in grades 3 and 6-7. The major change in grade 3 is the addition of the introduction to geography. Grade 6 has been streamlined to include the introduction of contemporary US history. Grade 7 provides an introduction to world history from ancient civilizations through Imperialism. Grade 7 continues to focus on geography, but the emphasis is on human geography while teaching about ancient civilization (Wiseman, 2012b).

Under the previous curriculum mandate, $21^{\text {st }}$ Century Content Standards and Objectives ( $21^{\text {st }}$ CCSOs), the ancient world was condensed into one objective (SS.O.07.05.01, Students will analyze the development of early civilizations, e.g., Mesopotamia, Egypt, Greece, China, India.). The content focus for $7^{\text {th }}$ grade social studies teachers, under the NxG CSOs, included the aforementioned cultures plus the Roman Empire, Medieval Europe, the Renaissance, and the Native cultures of the Americas. Scanning further I noticed the inclusion of ten reading and nine writing objectives students should master over the course of $6^{\text {th }}-8^{\text {th }}$ grades.

While examining the state department website, many thoughts went through my mind. Primarily, I was thinking about how I was not going to be able to extend the work I had started in World Geography. Although I had only completed my second year of teaching $7^{\text {th }}$ grade social studies, I felt that from a curriculum perspective my teaching had been more engaging the second year (e.g., better balance between teacher and student centered approaches). Furthermore, I had been able to extend and elaborate my knowledge of the subject matter. However, as I thought about the upcoming school year I realized that, in many ways, I was starting over. Granted, I 
TEACHING WITHOUT A NET

would still work with objectives within the standards of civics, economics, geography, and history, but the context for presenting these objectives had changed tremendously.

Continuing to ponder the content change awaiting the 2012-2013 school year, I questioned my ability to teach without the assistance of a textbook. The World Geography textbook afforded only a brief mention of the ancient world, not of great use to someone attempting to engage young people in a study of antiquity. My prior knowledge of the ancient world was minimal at best; I would need to begin my own study at the most basic of levels. In addition, I thought about my colleagues and wondered how they were reacting to the news. Did the realization that their content had changed prompt questions concerning the upcoming school year? Were they experiencing feelings of uncertainty and uneasiness as they began to prepare for the 2012-2013 school year?

I had not anticipated the content change mandated by the adoption of the NxG CSOs. The emails, cited on the previous pages, were the only directives I received concerning the curricular changes precipitated by the mandate until the second semester of the 2012-2013 school year. Early in the second semester, I was selected to serve on the $7^{\text {th }}$ grade textbook adoption committee, at which time the county level social studies coordinator addressed the changes brought on by the adoption of the NxG CSOs. One half of the school year had passed and I was designing my instruction based on the directives contained in two e-mails, combing the Internet for ideas/activities related to the ancient world, and referring to a World History textbook I used as an undergraduate for assistance in sequencing the content- all the while, staying one day ahead of the students. The circumstances left me feeling like an old-time high wire artist; working, or in this case teaching, without a net. 
TEACHING WITHOUT A NET

Assessing my experience with mandatory curriculum change brought me back to Michael Fullan's The New Meaning of Educational Change, a text I read as a graduate student. I realized that the uncertainty I was experiencing was well documented. Fullan (2001), citing Maris (1975), posits that "loss, anxiety, and struggle" (p. 30) accompany actual change. Similarly, Nolan and Meister (2000), in their qualitative study of teachers and change, found disparate and contradictory storylines; feelings of teacher alienation co-existing with moments of collaboration, ambiguous external initiatives leading to moments of creative thought on the part of the initiative implementers, and student success sometimes growing out of teacher uncertainty.

On one hand, the lack of direction from policy makers in implementing the NxG CSOs could be viewed as an opportunity for educators to assert their creativity and assume greater agency as professionals. This could be a breath of fresh air in an era that Michael Apple (1986) describes as witnessing the de-skilling of educators through the use of "prespecified...procedures and student responses" (p. 199). On the other hand, the body of research suggests that historically, teachers have not fully understood the proposed initiatives mandated by policy making agencies; therefore, classroom practice (i.e., methodology and pedagogy) often remained virtually unchanged (Fullan, 2001; Evans, 2007; Massell, 1994 cited in Hamilton, Shectner, \& Yuan 2009). 
TEACHING WITHOUT A NET

\section{Purpose of the Study}

In celebration of West Virginia's sesquicentennial anniversary, the WVDE published a timeline ("150 Years of Education in West Virginia") plotting the course of education in the state from 1863 to 2013 . One of the plots on the timeline represented the successful adoption of the NxG CSOs. Although administrative and legislative bodies may have considered the adoption of the mandate a success and therefore worthy of notice on the timeline, the timeline plot did not include the thoughts of those assigned the task of implementation. Webster and Mertova (2007) maintain that this kind of "grand narrative" creates "an essentially people-free notion" (p. 33). The WVDE's timeline made the process look easy and hassle free; however, I knew from my own experience that the 2012-2013 school year was far from easy. I had experienced the process of implementing a mandate with only meager resources, scant direction on how to implement the new content, and no explanation as to why the content change was necessary.

Thinking about my experience led me once again to my colleagues and I wondered about their experiences. What stories would they tell concerning the 2012-2013 school year? Would my colleagues' stories mirror the findings of Fullan (2001) and Nolan and Meister (2000) or would their experiences take on a different set of characteristics? By exploring the stories of individual teachers who implemented the curriculum change, we might begin to understand the complexity of the NxG CSO plot on the timeline. As my participants shared their personal experiences of the 2012-2013 school year, other narratives might emerge which could be situated alongside the seemingly static, defined plot on the timeline. Thus, two questions emerged, as I contemplated the events of the 2012-2013 school year, and these questions guided my research. First, what do the stories of four $7^{\text {th }}$ grade social studies educators tell us about the ways in which teachers engage as developers of curriculum when curriculum change is mandated? 
TEACHING WITHOUT A NET

Secondly, in what ways did their stories of implementing a mandated change impact their

professional identities?

\section{Significance of the Study}

This project is unique in that it is devoted exclusively to the experiences of a group of social studies educators. The sharing of stories related to mandatory curriculum change is well documented (see Chapter 2); however, few projects have been devoted solely to the stories of experience as reconstructed by social studies educators. Despite recent educational trends (e.g., NCLB and Common Core Curriculum), which have placed a great deal of emphasis on student proficiency in and the teaching of reading/language arts and mathematics; social studies educators have an important role to play in the social, emotional, and cognitive development of young people. Laughlin and Hartoonian (1995) view social studies education, in addition to reading and the STEM fields (science, technology, engineering, and mathematics), as a necessary component in developing extrinsic and intrinsic goals, "It is difficult, if not impossible, to tell where education for employment ends and education for citizenship begins" (p. 6). This research project brings the stories of social studies educators to the forefront.

Although the primary focus of this study was to provide social studies educators with an outlet to share the stories of their experiences, the project could be of practical and theoretical use to policy makers. This research study has the potential to provide policy makers with insight into how mandatory curriculum changes are interpreted and implemented by classroom educators. Thus, fulfilling Gergen's (1991) claim that the experiences of those within the "hurlyburly of daily life" could "enrich and edify academic debate" (p. x). 
TEACHING WITHOUT A NET

\section{Definition of Terms}

The terms below have been applied in a variety of settings, resulting in a myriad of definitions. For the purposes of this project, the terms will be used as follows:

- Constructionism: An epistemological perspective which contends that knowledge is formed by the interaction of the individual and his/her environment.

- Curriculum: The content a teacher will present in his/her classroom. Goals, objectives, the sequencing of the subject matter, and teacher methodology are components of curriculum.

- Identity: The potentially ever changing formation of the self and closely linked with the question- "Who am I?" Continuous interaction between the individual and the social world greatly impacts the individual and renders identity a fluctuating concept.

- Narrative Inquiry: A methodology which seeks biographical information from participants with the understanding that the researcher and participants are working relationally for a set period of time, resulting in a narrative which should not be considered definitive, but fluid and on-going.

- $\quad$ Social Constructivism: A theoretical perspective based on the premise that an individual's worldview is formed in relationship between the individual and the social world. 
TEACHING WITHOUT A NET

\section{Summary}

The 2012-2013 school year opened with a heightened sense of uneasiness for myself because of the radical change in $7^{\text {th }}$ grade social studies content precipitated by the adoption of the NxG CSOs. The school year commenced without an explanation from either the WVBOE or the WVDE as to why the content change was necessary for $7^{\text {th }}$ grade social studies. The situation was further exacerbated by the lack of guidance concerning the implementation of 19 literacy objectives. The purpose of this qualitative research project was for the participants to share their stories concerning working through mandatory curriculum change. In addition, the project explored the impact the experience had on the professional identities of the participants. 
TEACHING WITHOUT A NET

\section{Chapter 2: Literature Review}

Chapter 2 explores three areas of scholarly interest which informed the study: teachers and change, identity, and teachers as curriculum makers. Teachers and change delves into the literature related to change precipitated by external forces (i.e., national/state/local governing bodies) and how teachers have responded to changes imposed in a top-down manner. Research relating to the implementation process is also presented with scholars identifying factors that led to successful or unsuccessful implementation of mandated change. Next, I address the concept of identity and examine research related to how identity is defined, how it is formed/influenced, and how identities are changed/transformed. Chapter 2 concludes with an examination of the literature related to teachers as curriculum makers.

\section{Teachers and Change}

It has been argued, with the exception of surface changes, that the American public school has changed little over the last 50 years (Ornstein \& Hunkins, 1998; Evans, 2007). Newman (2006) argues that "few educational wheels are brand new" most have been presented "to the public as innovations, [but] they are more like retreaded and recycled tires" (p. 180). Joseph J. Schwab (1969) professed the same sentiment four decades earlier. Among Schwab's "signs" of crisis in educational curricula was the "repetition of old and familiar knowledge in new languages" (p. 125). Despite this assessment, the history of the American public school is marked by various groups clamoring for the adoption of a particular educational ideology.

Social, political, and economic goals have been championed by "federal, state, and local politicians, special interest groups, community organizations, and professional education organizations" (Spring, 2010, p. 3). In some cases, the proponents of certain ideologies have had their proposals adopted by school systems with classroom teachers required to implement the 
TEACHING WITHOUT A NET

mandate. Ross (1997) identified the teacher as the "most critical element in the improvement and transformation of the...curriculum" (p. 4). Yet the body of research suggests that bringing mandates/policies/initiatives to fruition, in the classroom, is a complex process (Sarson, 1966; McLaughlin, 1976; Kennedy \& Kennedy, 1996; Fullan, 2001; Cochran-Smith \& Lytle, 2009). Why is implementation a complex process? The previous paragraph alluded to partisan efforts impacting the public school, creating a difficult atmosphere for the implementation of a particular change effort. The "players" involved in a change effort may include "students, teachers, administrators, consultants, state employees, university professors, parents, lay citizens, and political officials" (Ornstein \& Hunkins, 1998, p. 312). Each of the identified "players" has a role in the successful implementation of a change effort. However, Hahn (1977) maintains that throughout the 1960s and 1970s the developers' viewpoint was considered superior to the needs and values of the implementers'. Ornstein and Hunkins (1998) argue that little has changed in the ensuing years with curriculum change efforts continuing to focus primarily on development (i.e., writing and producing curriculum projects) and neglecting implementation (i.e., how teachers, students, and the community might integrate the materials into the classroom).

Urban and Wagoner (2009) support the notion put forth by Hahn and Ornstein and Hunkins and suggest that the Sputnik launch in 1957 led to an effort to reform the math and science curricula in U.S. schools. Academics and consultants developed projects for implementation by classroom teachers as a means to better prepare U.S. students in the aforementioned fields. However, the effectiveness of the reforms was undercut by the developers" "reluctance to include the insights of school people," thus reducing the new projects to "formula and ritual in the schools" (Urban \& Wagoner, 2009, p. 339). In subsequent years, the lessons from curriculum reform efforts, like those surrounding the Sputnik launch, have 
TEACHING WITHOUT A NET

rarely been heeded. Millions of dollars have been spent, according to Ornstein and Hunkins (1998), in "developing curriculum projects, especially for reading and math, many of these projects have not succeeded" (p. 292). The transition of the curriculum from developer to implementer (the diffusion process) has rarely been "carefully planned and evaluated" (Hahn, 1977, p. 139; Ornstein \& Hunkins, 1998).

The previous paragraph highlighted the absence of communication between those developing or mandating curriculum changes and those implementing the changes.

Communication between all parties is necessary for successful implementation. Expectations expressed via a one-way channel of communication (i.e., from developer to implementer only) are "not sufficient to ensure that communication will be effective"; rather, channels must exist which allow all parties to raise questions (Ornstein \& Hunkins, 1998, p. 295, see also Sarson, 1966). Fullan (2001) argues that to "deny the voice of those who will carry out the changes is to act as if they are puppets" (p. 31). According to Zeichner and Liston (1996), the educational research establishment (e.g., colleges, universities, and research and development centers) views the classroom knowledge of teachers with "a general lack of respect" (p. 5). This contemptuous stance, according to Cochran-Smith and Lytle (2009), stems from the belief that the knowledge of teachers is "bounded by the everyday, local, and particular" (p. 130). The inclusion of all parties involved in implementing the change(s) may assist those developing the changes to better understand the school environment/culture (Sarson, 1990, in Ornstein \& Hunkins, 1998; Lytle \& Cochran-Smith, 1990, in Zeichner \& Liston, 1996). Perhaps the "general lack of respect" afforded classroom teachers by the research establishment is what has led school personnel to take a "dim view of research and researchers" (Sarson, 1966). 
TEACHING WITHOUT A NET

Open communication must be coupled with additional factors for successful implementation to transpire. Support services (i.e., training/in-service opportunities, equipment/materials to carry-out the change, encouragement from leadership, teacher to teacher discussions) and the allotment of reasonable timeframes for implementation to occur are also crucial (Hahn, 1977; Ornstein \& Hunkins, 1998; Fullan, 2001; Colley, 2012). The combination of the aforementioned factors can provide implementers with the necessary knowledge on "how" to implement the mandated change and, more importantly, the listed factors can lead to a better understanding of "why" the change is necessary. Fullan (2001) asserts that learning "why" a change is necessary is just as important as learning "how" to implement a change.

The apparent lack of communication surrounding the Sputnik era curriculum reform efforts resulted in a mismatch between "how" to implement curriculum changes and "why" the proposed changes were necessary. Scholars indicate that, historically, teachers have not fully understood the proposed initiatives brought forth by policy making agencies. Therefore, classroom practice (i.e., methodology and pedagogy) has remained virtually unchanged (Fullan, 2001; Evans, 2007; Massell, 1994 cited in Hamilton, Stecher, \& Yuan, 2009). The changes that occur are often external (e.g., incorporation of new policy resources and materials, imitation of in-service training procedures) and easy to recognize. More difficult to observe are internal changes related to long held beliefs and assumptions (McLaughlin, 1976; Cuban, 1993; Fullan, 2001). For example, Kennedy and Kennedy (1996) support the notion that an educator may support an idea, but have only a superficial understanding of its core beliefs.

Transcripts of the exchanges between instructors of the English language and their nonEnglish speaking students served as the data for Kennedy and Kennedy's research project. The instructors acknowledged that errors are part of what it means to become familiar with a new 
TEACHING WITHOUT A NET

language, and although errors should be corrected, "over-correction can be inappropriate" (p.

352). In one transcript, an instructor continually corrected a student's auditory grammatical

mistakes, before formal instruction commenced, even though the meaning conveyed was

understandable. The researchers saw this as a form of "over-correction" on the part of the instructor; indicating that there is often a discrepancy between an educator's expressed attitude and actual behavior in the classroom (Kennedy \& Kennedy, 1996).

Unlike the actions of the individual in the Kennedy and Kennedy piece, the majority of the participants in Cothran, McCaughty, Kulinna, and Martin (2006) did not proceed with a mismatch between expressed attitude and classroom practice. These participants simply reverted to their long held beliefs and assumptions once they realized they did not have a deep understanding of the curriculum proposal. This study explicitly supports the notion that for successful curriculum change to take place the educator must understand "how" and "why" he/she is implementing a particular initiative.

Set in a large urban school district in Michigan, Cothran et al. interviewed 46 elementary physical education teachers about one month after they attended an initial training. The authors found that the participants were initially supportive of the district's proposal to implement a wellness and physical fitness program as a means to combat youth obesity. The participants attended a one-day mandatory training session and received information pertaining to the philosophy, goals, scope and sequence, and assessment components of the program. The participants also received instructional materials and witnessed the presentation of sample lessons. However, upon returning to the classroom many of the participants realized that they did not fully understand how to implement the curriculum or why they were to utilize certain methods of instruction. The absence of a deep understanding of the proposed curriculum change 
TEACHING WITHOUT A NET

led some educators to incorporate only a few of the elements of the proposal into their current schema, while the majority rejected the new curriculum outright (Cothran et al., 2006).

Through the use of thematic analysis, the researchers identified emerging themes from the transcripts of participant interviews. The participants indicated they were overwhelmed by the amount of information presented at the training session and the information gleaned from the training was at odds with the participants' beliefs about teaching and learning. Follow-up support was not forthcoming and the participants expressed concern that the developers had not considered the environment (e.g., physical education classes held in the school cafeteria or multipurpose space) in which many of the participants were conducting their classes (Cothran et al., 2006). For successful implementation to occur, Maris (1988) (as cited in Fullan, 2001) maintains that the meaning of the change must be shared by all parties (developers and implementers).

Flett and Wallace (2005) found a similar disconnect between implementers and developers in their qualitative study of mandated curriculum change in one secondary school (U.S. equivalent to high school) in Victoria, Australia. Interviews of the participants revealed feelings of resentment towards the Victoria Department of Education (VDOE). The head administrator of the secondary school, where the research was conducted, felt that the VDOE mismanaged the "whole thing" (p. 200) (e.g., top-down approach did not allow for adequate practitioner input thus the elimination of local ownership, unrealistic timetables for implementation, delays in providing support resources, ambiguous language in instructional documents). According to the authors, the school administration and faculty fully implemented only the measures they deemed necessary (e.g., assessments and reporting procedures); classroom practice remained virtually unchanged. 
TEACHING WITHOUT A NET

The studies by Flett and Wallace (2005) and Corthan et al. (2006), highlight the lack of sustained communication between developers and implementers. In both instances the developers provided opportunities for the implementers to become familiar with the mandate, but these opportunities were too limited to provide a deep understanding of the curriculum mandate. Although recognizing the virtues (e.g., efficiency and lower cost) of the "one-shot training" session, McLaughlin (1976) argues that in-service/trainings of this nature are rarely effective.

(One-shot training sessions) ignore the critical fact that project implementers cannot know what it is they need to know until project operations are well underway... There is just so much that a would-be implementer can be taught or can understand until problems have arisen in the course of project implementation... Training programs that attempt to be comprehensive and cover all contingencies at the outset are bound to miss their mark and also to be less meaningful to project participants. (p. 192)

Developers have also offered extrinsic rewards, such as publicity, enhanced reputation, administrative support, and praise to ensure that teachers will implement curriculum mandates (Hahn, 1977). However, the use of extrinsic rewards, on the part of developers or administrative bodies, as a means to foster change has often contributed to educators' lack of deep understanding with regard to change. Desimone (2013) posits that standards-based reform efforts, like No Child Left Behind, have not encouraged teachers to develop a deep understanding of the initiative; instead they have relied on "rewards and sanctions" as the "primary mechanism to foster change" (p. 61). According to this perspective, the proverbial "carrot and stick" only leads to surface changes, not deeper understanding.

Hargreaves (2005) argues that identifying the factors which impact educational change is necessary for understanding the change process, but "age, career stage, and generational identity and attachment matter too" (p. 981). In his qualitative study of 50 Canadian elementary and secondary teachers, Hargreaves divided his participants into three categories: beginning, middle, 
TEACHING WITHOUT A NET

and late career teachers. He maintains that his findings support the "classic studies of how age and career stage affect teacher responses to educational change" (p. 981). Hargreaves argues that in addition to the enthusiasm of youth, many young, beginning teachers do not possess an understanding of the curriculum changes that transpired before their own time in the classroom. Excitement for the field and the absence of history make them more likely to embrace educational change. He elaborates further:

[T] oday's young teachers are enthusiastic and largely optimistic individuals, who have learned the adaptability necessary to their generational survival in an occupational and social environment characterized by increasing insecurity. Towards the end of their careers...experiences of repetitive educational change wear them down...most teachers become resistant to and resilient toward change efforts...In between, in the middle years of teaching, teachers retain but also rein back some of their enthusiasm... with growing confidence, competence and a sense of being established, they feel able to remain open yet also selective about educational change. (p. 981)

The research presented to this point has focused primarily on external forces (e.g., lack of thorough training, insufficient resources, omission of practitioner input) impacting teacher responses to change. However, Hargreaves implies that teachers have a degree of agency in determining whether they accept or resist educational change. From this perspective, teachers are not viewed as passive recipients, but capable of being educational leaders. Zeichner and Liston (1996) insist that teachers "always maintain a degree of control over external influence efforts" (p. 43).

Although not set in a K-12 school environment, Colley (2012) presents the responses of nursing faculty to mandatory change in her qualitative study. Like the examples from Flett and Wallace (2005) and Cothran et al. (2006), the participants in this study did not initiate the purposed changes, but were informed of the changes by administrators in the school of nursing. Based on the recommendation of the National League for Nursing, administrators mandated that 
TEACHING WITHOUT A NET

faculty implement a learner-centered approach to instruction as opposed to the more traditional lecture format. Based on her thematic analysis, Colley’s research suggests successful implementation is "affected by belief in the philosophy, holistic implementation of the philosophical concepts, intrinsic rewards, supportive department leadership, the availability of resources, and previous knowledge and experiences" (Colley, 2012, p. 212). Colley acknowledges the limitations of her study (e.g., homogeneous group, single university, 9 participants); however, her findings are supported by the previously discussed literature in this review, especially the work of Fullan (2001). Unlike the participants in the study conducted by Cothran et al. (2006) or Flett and Wallace (2005), the participants in Colley's study were informed as to the philosophy behind the change and they did not work in isolation to implement the change.

The previously discussed studies from Colley (2012), Flett and Wallace (2005), and Cothran et al. (2006) support the three change interactions put forth by McLaughlin (1976). According to McLaughlin, highly successful change initiatives "involved modification of both the project design and changes within the institutional setting and individual participants" (p. 189). McLaughlin terms these efforts "mutual adaptation" interactions. The research cited by Colley meets the criteria of a mutual adaptation interaction with the participants altering their attitudes, beliefs, and assumptions to meet the requirements of the proposed change and the objectives of the proposed change being altered to meet the needs of both the setting and participants. "Cooptation," the second interaction proposed by McLaughlin, is evident in the study by Flett and Wallace. In this interaction, the implementers enact surface changes without altering their attitudes, beliefs, or assumptions. Flett and Wallace indicated that their participants enacted only the assessment and reporting requirements of the proposed initiative while 
TEACHING WITHOUT A NET

classroom practice remained unchanged. McLaughlin terms the third interaction "nonimplementation." In this situation, the implementers ignore the proposed change initiative. The study by Cothran et al. is a prime example of non-implementation as many of the participants rejected the change proposal.

The study by Colley (2012) presents a productive view of educational change; however, even under ideal conditions, where mutual adaptation is evident, implementers may still experience a wide range of emotions as they struggle to make sense of the mandate. As cited earlier, Nolan and Meister (2000), in their qualitative study of teachers and change, found feelings of teacher alienation co-existing with moments of collaboration, ambiguous external initiatives leading to moments of creative thought on the part of the initiative implementers, and student success sometimes growing out of teacher uncertainty. The ebb and flow of being in a situation like this may seem disorienting. Maris (1975, cited in Fullan, 2001) supports this notion and indicates that "loss, anxiety, and struggle" (p. 30) accompany change. On the other hand, "grappling with the possibilities" (Senechal, 2015, p. 7) may lead to a creative response. In the process of struggling to understand a curriculum mandate, the educator may not only develop a deeper understanding of the initiative, but he/she may also come to a deeper understanding of him/herself; thus, impacting individual identity. 
TEACHING WITHOUT A NET

\section{Identity}

Identity is a term that conjures many definitions and understandings. According to Olsen (2008), the term has been employed in a variety of ways over the last 100 years resulting in a myriad of definitions. From Erikson's stages of identity development (with identity being "achieved") to the anthropological concept of "cultural identity" to the more recent "teacher professional identity" the term has been applied to a number of research fields (Beijard, Meijer, \& Verloop, 2004; Olson, 2008). Establishing a definition may prove difficult, but Beijard et al. (2004), citing the work of Gee (2001), posit that identity "is not a fixed attribute of a person... and can best be characterized as an ongoing process" (p. 108). Related to the continually evolving nature of identity is the question, "Who am I?" (Graham \& Phelps, 2003; Beijard et al., 2004).

When an individual asks "Who am I?" he/she is assessing his/her collected "values, beliefs, and assumptions" (Bennett, 2011, p. 40). How does one acquire this collection? Crotty (1998) places emphasis on the cultural background of the individual, "without culture we could not function...we depend on culture to direct our behavior and our experiences" (p. 53).

Similarly, Beijaard et al. (2004), citing the work of Sugrue (1997), lists family, traditions/cultural archetypes, and observation as sources of personal and professional identity development. The writings of Parker J. Palmer lend further support to the prime role that culture plays in identity development. In The Courage to Teach, Palmer (2007) states:

By identity I mean an evolving nexus where all the forces that constitute my life converge in the mystery of self: my genetic makeup, the nature of the man and woman who gave me life, the culture in which I was raised, people who have sustained me and people who have done me harm, the good and ill I have done to others and to myself, the experiences of love and suffering...identity is a moving intersection of the inner and outer forces that make me who I am. (pp. 13-14) 
TEACHING WITHOUT A NET

Simply stated, individual identity is greatly impacted by a particular cultural

environment. Individuals reflect their surroundings, argues Gergen (1991), and we continue to "incorporate information from the environment throughout our lives" (p. 69). Although culture is learned, it can also be modified or rejected by the individual (Bennett, 2003). At the same time, an individual's identity is not static or incapable of being altered in profound ways. Commenting on the evolving nature of identity and teachers, Beauchamp and Thomas (2009) assert that "identity shifts may occur throughout a teacher's career as a result of interaction within schools and in broader communities" (p. 175).

Connelly and Clandinin (1999) refer to this process, the interaction between the individual and the broader community, as identity formed relationally. Contemporary life is a “swirling sea of social relationships" (Gergen, 1991, p. 61). As a result of these complex relationships, the individual develops his/her identity or "stories to live by" (Connelly \& Clandinin, 1999). Clandinin (2013) offers additional comments on the influential and ever present nature of relationships:

[R]elational between the person and his/her world; a temporal understanding of the relational between past, present, and future, including the relational in the intergenerational; the relational between person and place; the relational between events and feelings; the relational between us as people; the relational between the physical world and people; the relational in our cultural, institutional, linguistic, and familial narratives. (p. 23)

Relationships are also evident in Gee's (2000) four perspectives on identity. Nature (genetics), institutions (schools), discourse (dialogue), and affinity groups (clubs or organizations), according to Gee, "interrelate in complex and important ways" providing us with insight into "how identities are formed and sustained" (p. 101). Relationships are especially evident within the discourse and affinity group perspectives, as individuals directly communicate with one another, and are latently apparent within the institution and nature perspectives. As to 


\section{TEACHING WITHOUT A NET}

the former, Gee maintains that before an institution can sustain and underwrite a particular identity, dialogue and discourse must occur. The latter is impacted by relationships via "people's historically and culturally different views of nature" (p. 107). If identities are to exist, according to Gee, then "human beings must see each other in certain ways and not others" (p. 109).

The late Frank McCourt seemed to capture the correlation between relationships, identity, and the always pertinent "Who am I?" question in his memoir Teacher Man (2005). In the text, McCourt recounted his experiences as an English teacher at various high schools in New York City. Far more than a collection of humorous anecdotes, McCourt was forthcoming with his struggle to not only engage young people in the curriculum, but also his own struggle to define himself as an educator. When discussing "conceptions of the self," Gergen (1991) includes not only a variation of "Who am I?" (Who are we?), but also how we are constituted, and how we should perform (p. 19). McCourt's journey to define himself (who we are/how we are constituted) as an educator involved his efforts to justify his work (how we should perform) in relation to colleagues and expected societal notions of what it means to be an educator.

For example, McCourt recalled how teachers are advised to make the curriculum relevant for their students. Yet, as he considered how to connect the curriculum to the lives of his students, his colleagues "were teaching solid stuff, analyzing poetry, assigning research papers, and giving lessons on the correct use of footnotes and bibliography" (p. 213). McCourt acknowledged that the assignments of his colleagues were designed to prepare high school students for higher education, but he sensed a lack of excitement in the delivery of the content and the absence of joy in the learning process. Knowing that food naturally piques the interest of the young and old alike, McCourt had his students bring a recipe to his creative writing class. In the course of a week, the assignment evolved from students reciting their recipes to some 
TEACHING WITHOUT A NET

students singing their recipes with musical accompaniment. The exercise provided the students with an opportunity to talk about their cultural backgrounds while McCourt injected "a little teaching" (p. 212), drawing attention to the writer's need to recognize the significance of events. This exercise brought McCourt into conflict with his assistant principal and his colleagues, but he found that the experience "called for a new kind of thinking" (p. 213). Through unorthodox methods, like the aforementioned experience, McCourt was finding his own voice and style of teaching.

McCourt was not unique in his struggle to define himself as an educator. In fact, research indicates that individuals continually negotiate, reflect, and reassess their understandings of who they are (Coldron and Smith, 1999, cited in Beijaard et al., 2004; Gee, 2000). The process of continually revising individual identity appears common place for many people in most contemporary societies. Gee (2000) posits that advancements in communication technologies have greatly expanded the number of people an individual can have contact with, thereby "outdating some identities and offering ever more opportunities for the creation of new ones" (p. 114).

Gergen (1991) refers to the aforementioned scenario as "populating of the self," a process through which the individual acquires "multiple and disparate potentials for being" (p. 69). Like Gee, Gergen (1991) views advancements in technologies (both in communication and travel) as the means by which people have become ever more connected; "time and distance are no longer such serious threats to a relationship" (p. 62). In this age of instant global communication and wide spread mobility, answering the "Who am I?" question may become increasingly difficult. Gergen (1991) theorizes that as "new and disparate voices are added to one's being, committed identity becomes an increasingly arduous achievement” (p. 73). 
TEACHING WITHOUT A NET

\section{Teachers as Curriculum Makers}

Teachers are not exempt from Gergen's "multiple and disparate potentials for being."

The lives teachers lead in- and outside of the classroom impact who they are and who they will become. Gergen (1991) maintains that socialization is a lifelong process with individuals continuously incorporating information from the environment into their lives. Frank McCourt (2005) recalled how quickly his view of what it meant to be a classroom teacher changed after entering the field. The romanticized image of the teacher skillfully lecturing while the students compiled copious notes quickly gave way to the realities of the classroom. McCourt found himself becoming more than a teacher of literature. Among other things, he became a disciplinarian, a singer, a low-level scholar, a clerk, a referee, a clown, a counselor, an apologist, a collaborator, a politician, and a critic (p. 19). Although teachers assume many identities and wear multiple "hats" in the classroom, is curriculum developer one of them?

Zeichner and Liston (1996), citing Darling-Hammond and Berry (1988), report a shift in educational rhetoric from one of controlling teachers to positioning teachers as empowered educational leaders. The degree of educational leadership assumed by teachers varies among those in the field. Ornstein and Hunkins (1998) insist that in "most cases" teachers and curriculum creators "should be the same individuals" (p. 294). Research cited in the first section of this chapter indicates that, historically, outside "experts" serve as the developers of curriculum while teachers serve as implementers. Others contend that a more cooperative environment is necessary for change proposals to come to fruition in the classroom (Zeichner and Liston, 1996; Hargreaves and Shirley, 2009). These theorists envision a partnership between educators, the local community, and governing agencies. In Reflective Teaching An Introduction (1996), Zeichner and Liston state: 
TEACHING WITHOUT A NET

Our alternative is not that teachers should dictate what should go on in the classroom, but rather that teachers and others who work in schools should work together with concerned and involved parents and community to give direction and purpose to the education of the school's students. (p. 20)

Zeichner and Liston (1996) maintain that teachers can and need to take a more active stance in considering educational changes. By thinking reflectively teachers can develop a greater understanding of the "how" and "why" components of curriculum change. Like Fullan (2001), they acknowledge that the classroom is an unpredictable and exhausting environment, often resulting in limited time for reflection and feelings of isolation. This constraining environment may lead many educators to develop a perspective that focuses solely on the short term, immediate challenges of the classroom with long term planning the priority of policy makers (Lortie, 1975, cited in Hargreaves and Shirley, 2009). However, the realities of the classroom cannot be used as a reason for teachers to fully acquiesce to the whims of those outside of the classroom. For teachers to be leaders, Zeichner and Liston (1996) propose that teachers must look "internally on their own practices, and externally on the social conditions of their practice" (p. 19).

Unless hemmed in by, what Apple (1986, p. 199) refers to as "technical control procedures...pre-specified teaching competencies, procedures, and student responses," the classroom teacher has a degree of agency he/she can exercise over the development of the curriculum in his/her own classroom. As discussed earlier, administrative bodies may determine grade level objectives, but McLaughlin (1976) posits that classroom teachers have agency over how the objectives will be presented in the classroom. "Local material development" (p. 191), McLaughlin's phrase for the materials teachers develop either from scratch or from commercially produced products, has the potential to instill within educators a sense of ownership over the curriculum. Working in tandem with a heightened sense of ownership is the 
TEACHING WITHOUT A NET

opportunity educators have, when creating local materials, to think critically about "how" and "why" they are selecting certain resources to complement their instruction. McLaughlin (1976) maintains that creating local materials appears to be a "critical part of the individual learning and development necessary for significant change" (p. 192).

\section{Summary}

This chapter reviewed the literature related to teachers and change, the concept of identity, and the need for teachers to take on a greater role in curriculum development. Historically, teachers have been relegated to the role of curriculum implementers while outside experts have assumed the role of curriculum developers. Scholars indicate that curriculum mandates have often been unsuccessfully implemented because teachers have not fully understood the implementation process. Single day training sessions, lack of follow-up support services, underfunded resources, and unreasonable timeframes for implementation have often resulted in, at best, partial implementation. Fullan (2001) maintains that teachers must not only understand how to implement a particular mandate, but they must also understand why the mandate is necessary. Teachers often do not understand the deeper theoretical aspects of a mandate due to a lack of communication between developers and implementers, the use of extrinsic rewards by developers to entice teachers to implement, which fosters surface changes and depthless understandings, and the exhaustive nature of the classroom, which leaves many teachers feeling isolated with little time for reflection.

Based on Erikson's work, some psychologists view identity as achieved in stages and within a particular timeframe (Slavin, 1997). However, within this chapter identity is viewed in a more fluid manner, capable of being modified as individuals interact with their environment. Associated with the concept of identity is the "Who am I?" question. When exploring this 
TEACHING WITHOUT A NET

question, individuals reflect and reassess their understandings of who they are and who they are becoming. Teachers have a number of potential identities; however, curriculum developer has typically not been an identity embraced by teachers. Zeichner and Liston (1996) propose that teachers need to engage in deeper reflection. By thinking about their own practice(s) and the social dimensions of the school, teachers may become better suited for the role of educational leader. Moreover, as educational leaders, teachers could think more critically about curriculum proposals and mandates. 
TEACHING WITHOUT A NET

\section{Chapter 3: Methodology}

Crotty (1998) demonstrates, visually and through text, that qualitative research projects contain four elements (methods, methodology, theoretical perspective, and epistemology). These aspects of a research study are connected, forming what he calls a "string" or "arrow" between and among each of the elements (p. 5). This chapter describes the connections among the aforementioned elements; beginning at the macro level with epistemology (constructionism), moving to the theoretical perspective (social constructivism), then to the methodology (narrative inquiry), and finally to the micro level with methods of data collection (interview) and analysis (structural and thematic). The chapter also includes an introduction to the participants, a description of the research context, as well as the trustworthiness, and limitations of the study.

\section{Epistemology}

Epistemologically, this qualitative research project is oriented within a constructionist framework. Constructionism refers to the making of meaning "in and out of our engagement with the realities of this world" (Crotty, 1998, p. 8). Unlike objectivism, which maintains that meaning exists outside of human consciousness, and subjectivism, which adheres to the premise that meaning resides solely within the individual, constructionism takes up a position between these poles (Crotty, 1998, pp. 8-9). The polarity created by objectivism (outside the mind) and subjectivism (inside the mind) creates, in Gergen's opinion, "an inherently intractable problem in determining how the former is accurately registered in the latter" (Gergen, 2001, p. 117). Thus, while constructionism requires human consciousness, it also requires the individual to interact with his/her environment. When human consciousness 
TEACHING WITHOUT A NET

interacts with objects in the environment meaning is constructed and the meanings emerge through this interaction (Crotty, 1998).

No attempt was made to deduce objective truth from the participants and their statements, nor did this project make any claim as to reporting the stories of all $\mathrm{WV} 7^{\text {th }}$ grade social studies teachers regarding mandatory curriculum change. The aim of the project was to collect and study the stories, related to curriculum change, of four individuals. The participants' interpretations of the events which occurred during the 2012-2013 school year varied slightly. At the same time, the participants brought a variety of prior experiences to the project and viewed their current understandings of professional identity from varying perspectives. The uniqueness of the participants and their responses to events in their teaching lives created spaces in which they, as diverse individuals, "construct[ed] meaning in different ways, even in relation to the same phenomenon" (Crotty, 1998, p. 9).

\section{Theoretical Perspective}

Crotty (1998) states that a theoretical perspective "refers to how one views the world" (p. 11). The previous section outlined the epistemological orientation of this qualitative project and situated it within constructionism. Under the banner of constructionism, knowledge/meaning is constructed via the relationship(s) between the individual and his/her environment. In a similar way, the concept of identity, as discussed in Chapter 2, relies on the relationship between the individual and his/her culture for continuous re-shaping of personal and professional identities. As I reflect on questions such as, "Who am I? What are my values, beliefs, and assumptions as a spouse, parent, community member, person of faith, and educator?" I am forming/transforming my identity. However, I am not acting alone. My relationship with the culture, which surrounds me and includes other human beings, institutional practices, 
TEACHING WITHOUT A NET

linguistic forms, influences the possibilities for who I become. There is "continuous interaction of human thought" with the "personal, social, and material environment" (Clandinin, 2013, p. 52). This notion of relationship is crucial as I situate this project within a social constructivist theoretical perspective.

Schwandt (2001) refers to constructivism as an "elusive term" which appears in the literature of a variety of fields (e.g., mathematics, experimental psychology, social research) (p. 30). In relationship to this project, it seems that Schwandt's most basic or general definition of constructivism will suffice; humans "invent concepts, models, and schemes to make sense of experience, and we continually test and modify these constructions in light of new experience" (p. 30). A relational or social component enters when we begin to "construct our interpretations" of experience "against a backdrop of shared understandings, practices, language" (p. 30).

At this point, scholars diverge in various directions with regard to how they will apply the basic principles of social constructivism (Phillips, 2000). Crotty (1998) posits that "constructivism is primarily an individualistic understanding of the constructionist position" ( $p$. 58). This perspective is appropriate for this project considering the importance of narratives in understanding mandatory curriculum change and identity. Elaborating further, Crotty indicates that constructivism relates to the personal or "unique experience of each of us" resulting in an individual worldview that "is as valid and worthy of respect as any other" (p. 58). Patton (2002) concurs when he states that constructivism emphasizes the "capturing and honoring of multiple perspectives" (p. 102).

As previously stated, the aim of this project is twofold: to explore the stories told by a group of $7^{\text {th }}$ grade social studies teachers with regard to working through mandatory curriculum change and to investigate the impact that responding to the curriculum change had on the 
TEACHING WITHOUT A NET

participants' professional identities. From a social constructivist standpoint, the stories told by the participants represent only a fraction of the possible "voices" available to explore the events surrounding the mandatory implementation of the NxG Social Studies CSOs. Yet, these voices, according to the social constructivist perspective, are just as valid as those emanating from the WVDE, WVBOE, or any other individual. Gay, Mills, and Airasian (2009) maintain that the practitioner's voice is crucial to better understanding issues related to the field and necessary when discussing educational policy. Unfortunately, the individuals (e.g., students, teachers, counselors, administrators, service personnel) who comprise the school environment are often neglected in the research process (Seidman, 1998). However, individuals working in the field, according to the social constructivist perspective, have accumulated experiences and stories to share which could benefit the performance of the entire system.

\section{Methodology}

Considering the emphasis on relationships in the epistemology and theoretical perspective components of the study, I made the decision to employ narrative inquiry to guide the research design, methods for data collection, and analysis. Clandinin (2013) indicates that narrative inquiry is a "relational methodology" which operates from the assumption that relationships exist between "the person and his/her world" (p. 23). The relationship between the individual and his/her environment as well as "the inner workings of a person's mind" and can be accessed "via the stories an individual tells" (Sparkes \& Smith, 2008, p. 297).

Stories have been with human beings for millennia and provided preliterate people with a means to preserve ideas, customs, and experiences (McKay, Hill, Buckler, and Ebrey, 2000; Webster \& Mertova, 2007)). Even with the advent of literacy, stories continued to serve an important role in conveying information about who we are as individuals and as a society 
TEACHING WITHOUT A NET

(Patton, 2002; Bammberg, 2008; Sparkes \& Smith, 2008). Reismann (2008) posits that many researchers are turning to narrative inquiry because of its potential to provide insight into the human experience. She suggests that in order to make sense of events we often tell "stories about difficult times in our lives" which "create order and contain emotions, allowing a search for meaning and enabling a connection with others" (p. 10). Seidman (1998) also indicates that storytelling is a "meaning-making process" (p. 1). According to this perspective, meaning develops via the selection of certain details from a particular experience. The individual reflects on the selected details and orders them, providing a beginning, middle, and end to the story. Simply stated, this process allows the individual to make sense of his/her experiences (p. 1). However, according to narrative inquirers, shared narratives should be considered temporal, rather than final understandings of events (Clandinin, 2013). The details one selects to include in his/her narrative may not be the same as those he/she may include in the future, because as individual perspective changes, so will the selected details of the narrative (Seidman, 1998).

Narrative inquiry is a twentieth-century development, despite its use of one of the oldest methods (the story) to share and collect information (Reissman \& Speedy, 2007, quoted in Clandinin, 2013, p. 11). Scholars indicate that narrative inquiry is a diverse field which has drawn heavily from the disciplines of history, sociology, and anthropology (Schwandt, 1997; Chase, 2008; Clandinin, 2013). Yet, at its center is "an interest in biographical particulars as narrated by the ones who live them" (Chase, 2008, p. 651). Stories, told by participants, are of the utmost importance to a researcher employing narrative inquiry; however, researchers are encouraged to go beyond simply “valorizing individuals” experience” (Clandinin, 2013, p. 18).

Attention must be given to the "social, cultural, familial, linguistic, and institutional narratives within which individuals' experiences were, and are, constituted, shaped, expressed, 
TEACHING WITHOUT A NET

and enacted" (Clandinin, 2013, p. 18). Once again the relational is apparent. Chase (2008) maintains that the researcher must balance the "narrator's active construction of self... and the social, cultural, and historical circumstances that constrain and enable" the narrative (p. 667). The use of a "layered approach" (Johnson, 2011, p. 56) to data analysis allowed me to demonstrate my understanding of the participants and their stories in relationship to the two overarching research questions guiding this research project.

Clandinin (2013) succinctly describes narrative inquiry as "a way of studying people's experiences" (p. 38). Central to this project is the idea of studying teachers' stories of working through mandatory curriculum change. However, as the previous paragraph indicated, researchers employing narrative inquiry as a methodology want to move beyond the "merely anecdotal" (Clandinin, 2013, p. 35) and explore the experience to a greater depth. Clandinin and Connelly (2000) term the process of engaging research participants in a more in-depth look at experience as moving within the three-dimensional inquiry space. In the three-dimensional inquiry space, researchers think about temporality (past, present, and future), sociality (the conditions under which events unfold), and place (location of events) (pp. 38-42). 
TEACHING WITHOUT A NET

\section{The Research Context}

Located in Northcentral West Virginia, the county school system in which the participants currently teach operates 9 elementary schools (K-4), 5 middle schools (5-8), 2 elementary/middle schools (K-8), and 3 high schools (9-12). According to the WVDE (2015) website these 19 schools serve the educational needs of 8,036 students $(4,141$ males/3,895 females) with a racial/ethnic composition of $90.52 \%$ White (7,274 students), $6.18 \%$ Black (497 students), 2.12\% Multi-Racial (170 students), 0.65\% Hispanic (52 students), 0.39\% Asian (31 students), and $0.14 \%$ Native American (11 students).

The 8,036 students served by the county school system represent $14 \%$ of the total population for the county $(56,418)$ (US Census, 2015). The US Census (2015) reports that $87 \%$ of the residents in the county have a high school diploma or higher and $20 \%$ of the residents have attained a bachelor's degree or higher. Median household income is $\$ 42,152$ with the top three categories for employment being education/health care/social services (27\%), retail (12\%), and arts/entertainment/accommodations/food services (9\%). Sixteen percent of the population has been identified as living below the poverty level (US Census, 2015).

\section{Participants}

The four participants ( 2 white females and 2 white males) in this qualitative research project met the criteria for participation in the study: they were all teaching $7^{\text {th }}$ grade social studies in West Virginia during the 2012-2013 school year. Based on their teaching assignments, during the 2012-2013 school year, all of the participants experienced the WVBOE mandate altering the content for $7^{\text {th }}$ grade social studies teachers. The sample size (4 participants) was small, but appropriate for qualitative research. Gay et al. (2009) indicates that the qualitative researcher can select a smaller sample size because he/she is studying individual experience and 
TEACHING WITHOUT A NET

is less concerned about generalizing his/her findings to a larger audience. The participants, along with additional identifying proper nouns (e.g., colleges or universities, places of employment), were provided pseudonyms.

Trina. Trina came to the field of social studies education almost by accident. At the urging of her husband, she began pursuing a college degree almost 20 years after graduating from high school. She explained that, as an undergraduate, she could never see herself teaching students, but she always loved the library. The college, where she completed her undergraduate degree, only offered library science as a minor, requiring Trina to declare a major. "All along I had been taking history classes and they (her college advisor) told me that I was close to having the necessary social studies requirements...so, to get my library degree I had to get a social studies degree."

Upon graduating from college, Trina worked locally as a substitute teacher for 2 years, developing a "bag of tricks" to assist her in being a successful substitute and eventually a successful full-time teacher. Inspired by Trina's return to school, her husband returned to graduate school and upon his graduation the couple moved to Kansas because he secured a job there. Initially, Trina found work as a substitute teacher (working everything from elementary grades to high school foreign language); however, a high school library science job eventually opened and Trina was hired. While in Kansas, Trina assisted in the development of her district's initial media/library K-12 curriculum standards and in addition to her duties as a high school librarian she was assigned to collaborate with a $12^{\text {th }}$ grade History teacher. She had this to say about the collaboration:

We had an energy for what we were doing. So it was fun working with her. When your job is no longer fun then don't do it anymore. That is just me... I started to develop 
TEACHING WITHOUT A NET

activities for the class and I had a social studies degree. I was working collaboratively to try and help kids who could not pass the class the first time. I don't want to say that we were "dumbing down" the curriculum, but we wanted to find a way for the kids to get through the class.

In 2004, Trina and her husband returned to Northcentral West Virginia. The hiring difficulties Trina had faced twelve years before were no longer an issue. She quickly found employment as the librarian at a $5^{\text {th }}-8^{\text {th }}$ grade middle school. For the $2005-2006$ school year, she taught $6^{\text {th }}$ grade social studies in addition to her duties as the school librarian. By 2010, Trina had transferred to a junior high school $\left(7^{\text {th }}-8^{\text {th }}\right)$ in the county, serving as the school's librarian. Her move to $7^{\text {th }}$ grade social studies came after attending a meeting between the county's librarians and local board office personnel. Trina remembered being informed, at the meeting, that the "librarian was going by the wayside." Concerned about the possibility of being reassigned to another school, Trina applied for a social studies job within the school where she served as the librarian. Trina recalled, "My administrator asked me why I was doing this, I had no accountability in the library, no testing, and no curriculum map to follow... but it was job preservation!" Presently, Trina teaches 3 sections of Ancient Civilizations ( $7^{\text {th }}$ grade) and 3 sections of WV Studies ( $8^{\text {th }}$ grade). Through consolidation efforts, the school in which Trina presently teaches is now a $5^{\text {th }}-8^{\text {th }}$ grade middle school. The school is located in the county's most populated center and serves the needs of 670 students (WVDE, 2015).

Katie. Prior to her retirement, after the 2012-2013 school year, Katie taught in Northcentral West Virginia for 43 years. Unlike Trina, who entered the field of social studies education almost by accident, Katie knew she wanted to teach the subject matter that she enjoyed as a student. "I thought it would be wonderful to help students learn social studies and have the love for it as I had," she stated during one of our interviews. Her career began in the late 1960s teaching physical education and history classes at the high school level. Over the next four 
TEACHING WITHOUT A NET

decades, Katie taught a variety of social studies classes (e.g., geography, economics, history, sociology) to students in grades 7-12 and she earned a Master's Degree (secondary education with an emphasis on social studies). Continually refining her own knowledge of the field of social studies education was only one aspect of her professional life. Katie understood that her professional knowledge needed to include an understanding of her students and their communities. She had this to say, "As I changed teaching positions from community to community the students had their own set of values which was related to a community and as a teacher I had to relate to that to meet the student needs."

Although a connection between the school and community existed, to some degree, at all of Katie's teaching placements, she spoke fondly of the connection between the community and the high school which provided her with her initial teaching position.

In 1972, my daughter was born and I remember many of the seniors coming to see me in the hospital. They had placed bets on the date I would deliver! Parents brought me baby gifts. I know that some of the parents didn't have much, but they still wanted to do something. That community high school was very special.

Prior to the start of one of our interview sessions, Katie reminisced about the sense of community which existed within the schools where she taught. She felt fortunate to have worked with many great people, especially her colleagues in the field of social studies. She recalled social studies department meetings, at the high school level, where educators engaged in thought provoking conversations about the field. There were light-hearted moments too, good natured pranks which only heightened the sense of family between the co-workers. It was a friend and teacher who encouraged Katie to return to the junior high school level.

In the summer of 2000, a friend told me that a social studies job was opening at the junior high school where she taught. She liked the school and the administrator. I applied for the 
TEACHING WITHOUT A NET

job and got it. This was the final school I would teach at, I spent the next 13 years teaching $7^{\text {th }}$ grade social studies.

The school in which Katie concluded her teaching career has an enrollment of 628

students (WVDE, 2015) and is one of two recently consolidated schools serving students in grades 5-8. Like Trina's school, the school in which Katie concluded her teaching career is within the most populated center of the county school system. Katie taught $7^{\text {th }}$ grade social studies exclusively during her final 13 years in the classroom.

Steve. Like Katie, Steve had an intrinsic interest in the field of social studies from a young age. "I was always interested in history, studying the past, and finding out where places are," he recounted, adding "it's the one field (as a student) I was always interested in." At the college level, Steve earned a BA in secondary education with a certification in 5-12 social studies. Upon graduating from college, Steve found full-time employment within his home county school system, but his initial job was not in the field of social studies education. He was hired as the In-School Suspension (ISS) supervisor at a junior high school. He elaborated:

Well, it wasn't so much a classroom. Under the gym they had set-up a classroom for the kids that were in ISS and this was the first job that I had...It was get their work for them, make sure they have everything done, walk them to the bathroom, walk them to lunch, and sadly, usually someone was in there. So instead of suspending the kid and the kid going home for three days and not getting any work from them; they came to ISS. Most of the kids did not want to be there, I made it so that they didn't want to be there.

Steve's opportunity to teach social studies came two years later when a teaching position opened at a middle school in the county. He was hired to teach World Geography ( $7^{\text {th }}$ grade) and WV Studies ( $8^{\text {th }}$ grade). Although excited about the opportunity, Steve essentially walked into a bare classroom with only student textbooks on the shelf. The lack of resources concerned him, “There were no maps, I was hired to teach WV History and World Geography, no teacher's manual. I didn't have anything!' Understanding Steve's situation, his administrator, along with 
TEACHING WITHOUT A NET

his administrator's wife, secured additional funds for him to begin purchasing items for his

classroom. Steve recalled, "They took care of me and hooked me up pretty well."

Like Trina and Katie, Steve acknowledged the benefits of fostering positive

conversations and dialogue among the school's staff. He commented further, "All three

principals that I have worked for have gone out of their way to support the teachers" and "the

ideas, resources, and advice" from colleagues has been wonderful. In reconstructing the past,

Steve also spoke of two assertive and resolute women (identified by pseudonyms) who

influenced him greatly.

Sister Stewart at South School... To this day, she is probably the best teacher I ever had. She was, from the way you would figure being a nun, very strict, very regimented...she cared about the way we learned. She did her best to get the information across to us. She is just someone that I have always looked up to...As far as college, once again I'm going to choose a woman, Miss Vance. She was the public school version of Sister Stewart. It was a flashback, she was the hardcore, no nonsense public school teacher. And it was kind of like déjà vu. She was probably an influence as well, the only woman who has ever frightened me. She made me a nervous wreck every time she came to observe. And it was more of "I don't want to disappoint her" than me not liking her.

Since 2004, Steve has continued to teach $7^{\text {th }}$ and $8^{\text {th }}$ grade social studies at the middle school level. In addition to his teaching and family responsibilities, Steve has coached football at the high school level as well as basketball and track/field at the middle school level. The middle school where Steve teaches serves 208 students in grades 5-8 (WVDE, 2015).

Jesse. In many ways, Jesse's background encompasses many of the experiences shared by the other participants. Like Katie, Jesse has a close relative, his mother, who taught school. Just as Trina reconstructed her move from West Virginia to Kansas and back, Jesse had a story to share about leaving West Virginia for Tennessee before returning to his home state. Jesse's background is similar to Steve's in two ways: 1.) they both have experience coaching sports teams and 2.) they both found initial school employment as ISS supervisors before being 


\section{TEACHING WITHOUT A NET}

hired to teach middle/junior high social studies. However, unlike the other participants, Jesse

left the field of education for 10 years due to a tight job market for teachers in Tennessee.

What happened was I graduated in 1991 from ETU and I substituted for 2 years.

Unfortunately, they paid substitute teachers $\$ 30.00$ dollars a day and I was working odd jobs. It got to the point where it was very difficult, I was working all the time. Tennessee was experiencing educational cut-backs and I knew some people at the board office and they told me that there was a hiring freeze and that it was going to be a while before I got on full-time. Around this time, I was offered a full-time job from a printing company and I took it. I thought it would be short term, but I ended up staying there for 10 years. I definitely missed teaching. My mom was still teaching at the time and we would talk about it and I was going back to renew my license, but I was out of the classroom. It was tough because you go to school to do one thing and your heart is in it, but you can't get in and you are forced to do something else because of finances. By the time 2001 rolled around I had come to the conclusion that I was never going to be a teacher.

Jesse and his wife returned to Northcentral WV, after a brief period in Pennsylvania, in

2001 due to his wife being transferred by her employer. Upon his return to WV, Jesse worked as a substitute teacher in various counties. He commented, “If I had stayed in Tennessee I don't think it (teaching) would have happened," but "some doors began to open" once back in WV. An opportunity for full-time employment presented itself in 2003 with Jesse being hired as the ISS supervisor at a middle school.

I got my foot in the door, but not teaching social studies. I had been trained to teach social studies, but wasn't. I was thankful to have a full-time job and I did the best I could with it, but it was not what I went to school to do. I had to come to terms with the fact that there are steps to the process, to get where you want to go it takes time. You can't always start out where you want to be.

Jesse's opportunity to teach social studies came two years later when he was hired to teach $6^{\text {th }}, 7^{\text {th }}$, and $8^{\text {th }}$ grade social studies and $8^{\text {th }}$ grade health at a small K- 8 elementary/middle school. Like the other participants, Jesse spoke of the sense of community among faculty and staff at the school. A willingness, among faculty, to assist others was evident early in Jesse's first year teaching social studies. Classroom reassignments forced Jesse to change classrooms the day before school started. As Jesse and two other teachers moved classroom furniture, two 
TEACHING WITHOUT A NET

other teachers prepared his "homeroom packets," enabling him to open school with the necessary paperwork he needed to distribute to his students. The experience impacted Jesse greatly, "I try to make myself available, paying it forward, because I remember what it was like when I first started and how helpful those teachers were to me." Jesse remains at the elementary/middle school where he was first hired 13 years ago. According to him, he is now the most senior middle school teacher at the school. Presently, the school serves the educational needs of 333 students (WVDE, 2015).

\section{Researcher Subjectivity}

Clandinin (2013) reminds the researcher that he/she does not stand outside of the research topic when engaging in narrative inquiry. The researcher works in relationship with the participants, "stepping into the midst" (p. 43) of lives that are unfolding. In fact, the research topic for this project is of great importance to me because I, too, was teaching $7^{\text {th }}$ grade social studies when the WVBOE adopted and mandated the NxG CSO. Therefore, I have my own story of the events which occurred during the 2012-2013 school year and thoughts on how my professional identity was shaped and continues to evolve as a result of this experience.

As indicated in Chapter 1, I was taken aback by the complete alteration of the content for $7^{\text {th }}$ grade social studies. Although I later read that there had been a public comment period prior to the legislature's adoption of the NxG CSOs, the email citied on page 3 of Chapter 1 informed me of the change. The summer months concluded and a new school year (2012-2013) was set to begin; yet, no further information was released by the county coordinator or state director of social studies education with regard to the content change for $7^{\text {th }}$ grade social studies. I felt like I was in a precarious position, unsure of how to move forward. Inquiring into the 
TEACHING WITHOUT A NET

situation only left me feeling isolated as local administrators were aware of the mandate, but not specific aspects such as the content change for $7^{\text {th }}$ grade.

In the process of assessing my situation I thought back to the journey I had traveled in the field of education. I had been a novice, first year teacher once, excited about applying what I had learned in a teacher preparation program, but at the same time, unsure of my abilities to effectively engage young people in a topic of study. As the 2012-2013 school year approached, I was now a veteran teacher with twelve years of teaching experience. The decade plus that I had spent in the classroom had not diminished my enthusiasm for the field. Differences were apparent as I compared my present self to the person I was as a first-year teacher, but an excitement for teaching and learning still remained.

I had also changed teaching assignments over the course of my journey, effectively starting over more than once. My initial teaching position was in a third grade classroom. Although I spent 3 years teaching third grade and made many friendships among my colleagues, I was on a one-year contract each year (the conclusion of each successive school year brought with it the uncertainty of not being offered another contract because the position was funded through federal grant money). A full-time teaching position in gifted education came open in my county and I applied for the job. I interviewed and was hired with the stipulation that I work towards certification in the field within a two-year timeframe. At the time, I was pursuing my master's degree, along with an additional teaching certificate in middle school social studies, and was able to obtain the gifted certification simultaneously.

As the 2012-2013 school year neared its opening date, a question continued to hound me, "What was I going to do with a classroom of 20-25 students without resources (no textbook or supplementary materials) and only a minimal understanding of the content?" I had been in 
TEACHING WITHOUT A NET

this position before, my initial year with the gifted program, and had succeeded in creating a foundation for future educational endeavors. My first year with the gifted program was a struggle as I learned to write and submit Individualized Education Plans (IEPs), coordinate and conduct yearly IEP review meetings with administrators, teachers, and parents, and design (often with student assistance) and present engaging units for the students on my caseload. Like my first year with the gifted program, the 2012-2013 school year proved to be a struggle. However, the lack of direction from state and county administrators did not impede my creation of a foundation from which to build future classes. Excitement for the profession, interest in the material, and a willingness to study and improve my craft carried me through a trying year.

Prior to the first interview I informed the participants of my work as a teacher of $7^{\text {th }}$ grade social studies. The interviews were not designed to be confrontational (my perspective vs. the participants' perspectives or male perspective vs. female perspective), but in-line with a qualitative stance. Kvale and Brinkmann (2009) define the qualitative stance as "focusing on the cultural, everyday, and situated aspects of human thinking, learning, knowing, acting, and ways of understanding ourselves as persons" (p. 12).

My close connection to the research topic could be viewed as a liability with my preconceived notions influencing everything from the proposed interview questions to the ways in which the participants' stories were reported. Kvale and Brinkman (2009) advise the researcher to report all interpretations, even those that are in opposition to the researcher's stance. They conclude that "multiple perspectival interpretations will then not be a weakness, but testify to the fruitfulness and vigor of interview research" (p. 213). At the same time, the constructionist epistemology maintains that individuals gain knowledge in relationship to their environment. Therefore, it is possible for all involved to gain insight from one another. Crotty 
TEACHING WITHOUT A NET

(1998) insists that interpretations, from a constructionist perspective, "may be judged fulfilling and rewarding" or even oppressive, but never "true or valid" (p. 48). My background experience with the research topic does not render my interpretation(s), at least from a constructivist lens, to be of greater (or lesser) worth than those of the participants.

Although the individual stories of the participants with regard to mandatory curriculum change and identity may vary, Bennett (2011), quoting Kraemer (1973), recognizes the dominant role Anglo-Western European culture has had in shaping the collective worldview of Americans and the US educational system. She acknowledges individuality, but maintains that people "who share a culture develop similar styles of cognition; similar processes of perceiving, recognizing, conceiving, judging, and reasoning; and similar values, assumptions, ideas, beliefs, and modes of thought" (p. 40). As a white male and native of the county where the research is being conducted I have a particular way of viewing the world. The participants, 2 white females and 2 white males, have also been influenced by this predominant Anglo-Western culture.

\section{Methods}

Working from a constructivist perspective, I hoped to learn "not the way things are," but the "sense individuals make" of their world (Crotty, 1998, p. 64). Therefore, the stories told by the participants are of the utmost importance. Narratives may be obtained in several different ways; they may be "oral or written and may be elicited or heard during fieldwork, an interview, or naturally occurring conversation" (Chase, 2008, p. 652). For this project, I employ interviews as the method for making the "perspectives (of my participants) meaningful, knowable... and explicit” (Patton, 2002, p. 341). 
TEACHING WITHOUT A NET

\section{Data Sources and Collection}

The use of the interview in qualitative research is more dynamic than portrayed in popular culture (Patton, 2002; Riessman, 2008). Although conversation is paramount, Kvale and Brinkmann (2009) argue that the qualitative research interview transcends "everyday conversations, and becomes a careful questioning and listening approach with the purpose of obtaining...knowledge" (p. 3). The term, interview, covers a wide range of structures and approaches (Seidman, 1998; Kvale \& Brinkmann, 2009). However, the structure favored by many qualitative researchers is in-depth interviewing with the utilization of open-ended questions, providing a space for the participant to construct an expanded narrative in his/her own words (Seidman, 1998; Patton, 2002; Reismann, 2008).

The interview structure for this qualitative research project was semi-structured. The interview guide (see Appendix), composed of open-ended questions, was designed to elicit the narratives of the participants in their own words. The interview guide utilized predetermined questions; however, follow-up, probing, or specifying second questions were proposed when necessary. Kvale and Brinkmann (2009) advise "actively following up on the subjects' answers, seeking to clarify and extend the interview statements" (p. 7). These authors indicate that secondary questions require familiarity with the interview topics and the ability to actively listen on the part of the researcher (p. 134). Thus, a qualitative research interview does not necessarily follow a linear trajectory, but is often full of surprises and reformulations of concepts (Kvale \& Brinkmann, 2009, p. 100). Similarly, Riessman (2008) contends that narrative interviewing cannot be reduced to a series of techniques. Thus, the interview guide assisted in developing an understanding of the interview topics and served as a means to anticipate secondary questions. However, unanticipated probing questions did emerge as the interviews commenced. 
TEACHING WITHOUT A NET

For this research project, 3 semi-structured interviews were conducted with each

participant. Based on the format discussed by Seidman (1998) and designed by Shuman (1982)

and Dolbeare, the three-interview series allows the "interviewer and participant to plumb" (p. 11)

the stories of the participants and place them in context. Seidman (1998) explains further:

The first interview establishes the context of the participants' experiences. The second allows participants to reconstruct the details of their experiences within the context in which it occurs. And the third encourages the participants to reflect on the meaning their experience holds for them. (p. 11)

Seidman (1998) terms the first interview "focused life history" with the objective being to place the "participant's experience in context by asking him or her to tell as much as possible about him or herself in light of the topic up to the present time" (p. 11). For this project, the participants "reconstructed" their life histories up to the 2012-2013 school year, focusing on those experiences which influenced their teaching. Instead of asking participants to "remember" or "recall" past experiences, Seidman (1998) asks participants to reconstruct the past.

Reconstruction, according to Seidman, "is based partially on memory and partially on what the participant now senses is important" (p. 74). Citing the work of Tagg (1985), Seidman argues that the use of the terms "remember" and "recall" often result in "impediments to memory" (p. 74) with the participant not being able to recall long-term information. Kvale and Brinkmann (2009) encourage the researcher to seek "spontaneous, rich, specific, and relevant answers" (p. 164) from participants; in this way, Seidman's reconstruction of the past may facilitate this goal. Examples of the types of questions I asked the participants, in interview 1, included: How did you come to the field of education? What did you find challenging about your first full-time teaching position? and What experience did you have with implementing mandates prior to the NxG CSO mandate? (see Appendix). These questions were relevant to the study as 
TEACHING WITHOUT A NET

the topics of change and identity were being explored from a focused life history perspective. In addition, the questions created spaces for each participant to share his/her unique perspective.

Interview two provided opportunities for the participants and researcher to delve into the "concrete details" of the "topic area of the study" (Seidman, 1998, p. 12). In the case of this research project, interview two encouraged the participants to reconstruct their experiences during the 2012-2013 school year. The participants shared stories regarding learning about the mandatory curriculum change, preparing for the opening of the 2012-2013 school year, as well as how they implemented the mandate over the course of the school year. Interviews one and two provided the foundation for interview three which, according to Seidman (1998), encourages participants to "reflect on the meaning of their experience" (p. 12). In order to make sense of experience, Seidman posits that the participants must "look at how the factors in their lives interacted to bring them to their present situation" (p. 12). The relationship between the past and present is evident in interview three. For this research project, interview three culminated with the participants thinking about how the experience of working through mandatory curriculum change impacted their identities as professional educators and their current practices as teachers and curriculum developers.

\section{Data Analysis}

Analysis, according to Kvale and Brinkmann (2009), involves 'bringing the subject's own understanding into the light as well as providing new perspectives from the researcher" (p. 196). Working from this foundation, two forms of qualitative data analysis were selected for this research project- thematic and structural. Johnson (2011) refers to the use of multiple "analytic angles" as a "layered approach (p. 56)" to interpreting stories. Riesmann (2008) encourages the researcher to employ more than one analytic method because the additional methods have the 
TEACHING WITHOUT A NET

potential to strengthen the other methods and provide further insight into the topic of study. The combination of analytic methods positions the researcher to "describe broad patterns, but also variation in meanings for individuals" (p. 90).

Thematic Analysis. Thematically organizing interview data is one of the more conventional methods of qualitative analysis (Seidman, 1998; Riesmann, 2008). In this analytic form, the content or what the participant said is paramount and becomes the topic of inquiry (Riesmann, 2008). Thematic analysis requires the researcher to identify repeated patterns or phrases that emerge from what the participants have said (Gay et al., 2009). Although Clandinin (2013) does not use the term "themes" in her description of how she analyzes field texts (her term for data, which includes interview transcripts, p. 46), she does make reference to "resonant threads or patterns" (p. 132). She indicates that "threads" are "particular plotlines threaded or woven over time and place through an individual's narrative account" (p. 132). In terms of analyzing multiple transcripts, Clandinin looks for "resonances across the accounts" (p. 142).

Structural Analysis. Riesmann (2008) indicates that although content (what is said/ "told") is important when pursuing structural analysis, greater emphasis is placed on the "telling" or narrative form/sequence (p. 77). The structural analytic approach for this project was based on the model developed by Labov and Waletzky (1967), with further discussion by Labov (1972), and pertains to "a chronologically told story, with focus on how its elements are sequenced" (Kvale \& Brinkmann, 2009, p. 223). When we tell stories, we order the events, creating a plot. A closer review of the plotline could reveal, according to Labov, 6 elements: an abstract (title), orientation (to time, place, characters, situation), complicating action (events, often includes a crisis), evaluation (narrator comments/reflects on events), resolution (outcome of reflection), and coda (ending of the story) (Riesmann, 2008, p. 84). 
TEACHING WITHOUT A NET

An application of Labov's structural analysis has the potential to inform the researcher or audience of the steps an individual went through to navigate an event of concern. Yet, this model does not need to work in isolation. As indicated earlier, analytic methods can work in tandem to produce greater insight into the meaning(s) the participants make of an experience. Riesmann (2008) argues that, in developing this approach, Labov wanted "to identify sequences and structural parts of the narrative that recur across stories of experience" (p. 84). In this way, Labov's model assisted me in developing the thematic elements of the participants' narratives. The broad themes resonated across the participants' narratives while the structural analysis allowed for a more personalized understanding of the thematic elements.

Applying the Layered Approach. Seven "stories" were selected for analysis from the participants' interview transcripts. The seven "stories," with each participant providing one narrative for each "story," related to the two overarching questions guiding the research project. The contours or "peaks and valleys" (structural telling) of the participants' narratives yielded patterns (emerging themes) within individual accounts and across the participants (Riessman, 2008). Simply stated, as the participants responded to various interview questions they structured their narratives in certain ways, often including most, if not all, of Labov's elements. Themes emerged from the identified complicating actions, the resolutions, or from the participants' evaluations of the issues of concern. An application of a layered approach to data analysis is the focus of Chapter 4. 
TEACHING WITHOUT A NET

\section{Trustworthiness}

Riessman (2008) indicates that research projects involving narratives must strive to confirm the story told by the participant (s) and the story reported by the researcher. If both the former and latter are confirmed then the reported research could persuade the reader to consider the work "plausible, reasonable, and convincing" (Riessman, 2008, p. 191). In an effort to ensure trustworthiness, Kvale and Brinkmann (2009) recommend continuous checking, questioning, and interpreting of findings, which should include the researcher playing "devil's advocate toward his or her own findings" (p. 249). Although an audience or group of readers will decide on the trustworthiness of the research project, it is the researcher's responsibility to accurately conduct the research and report the findings.

In an effort to substantiate the trustworthiness of a qualitative research project, Riesmann (2008) advises the establishment of fluid boundaries. This was evident, for this research project, in the criteria (see Participants) developed for inclusion. Secondly, the interview guide contained questions designed to evoke open-ended responses from the participants and the proposed questions were relevant to the topic of study. Efforts were also taken to ensure the reliability of the participant's stories. Kvale and Brinkmann (2009) recommend the use of leading questions as a means to "repeatedly check the reliability of the interviewee's answers, as well as to verify the interviewer's interpretations" (p. 172). Each interview session was recorded and the dialogue exchanged between the researcher and participants transcribed. Disfluencies in speech (pauses, "ums") were omitted from the transcripts because the project focused on how the participants structured their stories and the themes which emerged from the reconstructed narratives not on the participants' use of language as a means to construct a particular identity. In addition, each participant was provided a copy of 
TEACHING WITHOUT A NET

each transcript of the interview in which he/she participated. The participants were encouraged to engage in member checking the transcripts and to voice any concerns they had about the transcription or audio recording of the interview. Any objections the participants had to the manner in which they were represented in the written transcript was considered.

Riesmann (2008), like Crotty (1998), maintains that a clear connection between epistemology and theoretical perspective lends credence to the trustworthiness of a research project. Working from an epistemology framed by constructionism and a social constructivist theoretical perspective, this project sought the varying and unique perspectives of four individuals who experienced the same event (mandatory curriculum change). Crotty (1998) reminds us that, from a social constructivist perspective, each of us has a unique way of viewing the world. We share our views on the world through stories or narratives. However, Riesmann (2008) argues that "narrators interpret the past in stories rather than reproduce it as it was; investigators, in turn, interpret the interpretations" (p. 188). The relativistic nature of the aforementioned ethos is not viewed as a liability, as it would be in a theoretical perspective informed by positivism; instead it is viewed as necessary when attempting to bring multiple perspectives to the forefront. The narratives of the four individuals participating in this research project have the potential to open vistas in which those with the power to enact mandates have perhaps never envisioned. 
TEACHING WITHOUT A NET

\section{Limitations}

As recently indicated, narratives are selectively composed (Reismann, 2008). Earlier, in this chapter, Seidman's (1998) thoughts on the reconstruction of memories supports the selectivity stance. Clandinin (2013), citing her work with Rosiek (2007), lends further support by indicating that, "Every representation, therefore, no matter how faithful to that which it tries to depict, involves selective emphasis of our experience" (p. 15). Qualitative researchers, engaged in narrative inquiry, understand this and many view the meaning individuals make of an experience to be of greater importance than verifying facts (Riesmann, 2008; Seidman, 1998).

However, as individuals share their selectively composed narratives, it is possible that the audience is not only gaining insight into the individual, but also into the many influences which shape and are shaped by the individual. Crotty (1998) contends that "even in telling our own story, it is the voice of our culture -its many voices, in fact -that is heard in what we say" (p. 64). Words, according to Gergen (1991), "are not mirrorlike reflections of reality, but expressions of group convention" (p. 119). Possible discrepancies in the source of the narrative being presented must be considered. As Crotty (1998) posits, "narration can no longer be seen as straightforwardly representational of reality" (p. 64); perhaps this is why Clandinin (2013, p. 207) strongly urges researchers to explore the social, institutional, familial, and cultural storylines which emerge from the stories told by participants. 
TEACHING WITHOUT A NET

\section{Summary}

Kvale and Brinkmann (2009, p. 324) liken the qualitative researcher to a craftsman; an individual in possession of special skills, gained through training, practice, and personal know-how. This chapter, described my craftsmanship in designing a research study, encompassed both the theoretical and practical aspects of the research project, and demonstrated how they were connected. The relational was evident at the macro levels (constructionist epistemology and social constructivist theoretical framework), as well as the micro levels (narrative inquiry as the research methodology and interview as the research method). In each instance, individuals interacted with others to form knowledge (constructionism), to explore the meaning of an experience (narrative inquiry), and to gather data (interview). The interview data was analyzed via a layered approach (structural and thematic), with each analytic form working to provide further insight into the elements and possible interpretations of the participants' stories. The chapter introduced the participants ( $47^{\text {th }}$ grade social studies teachers), their schools, and provided a description of the research context (Northcentral WV). Furthermore, the chapter concluded with a thorough examination of trustworthiness, researcher subjectivity, and limitations of the study. 
TEACHING WITHOUT A NET

\section{Chapter 4: Findings}

Chapter 4 is divided into 7 subsections with each section corresponding to a particular "story." As previously stated, the selected "stories" relate to the two overarching questions that guided the research project. The "stories" emerged as the participants reconstructed narratives in response to the interview questions. The narratives, which were structured in particular ways, revealed themes (sometimes referred to as patterns or resonant threads) (Patton, 2002; Reissman, 2008; Clandinin, 2013). Therefore, each subsection explores the themes which emerged from the participants' stories, as well as an analysis of the contours or “peaks and valleys" (Reisman, 2008, p. 78) which provided structure for the narratives. Included with each "story" is a table providing a visual representation of both the structural and thematic approaches to analysis.

\section{Story 1: Becoming an Educator}

Prior to engaging the participants in open-ended questions related to mandatory curriculum change or the purpose of social studies education, I asked each of the participants to reconstruct how they came to the field of education. Because I was working within a social constructivist theoretical frame, I was interested in the influences which impacted the participant's decision to enter the field of education. As discussed in chapter 3 , individuals are influenced by the culture that surrounds them, which includes other people, institutional practices, and linguistic forms. According to Gee (2000), the various components of culture "interrelate in complex and important ways" providing direction into "how identities are formed and sustained" (p. 101). From a social constructivist perspective, relationships are paramount for identity development. This seemed to be the case as I listened to my participants reconstruct 
TEACHING WITHOUT A NET

narratives of their respective decisions to enter the field of education. Based on their narratives, relationships emerged as a theme from story 1.

When asked how she came to the field of education, Katie indicated she chose a career in education because of the influence of some of her friends from high school. She said, "I had some friends that were going to college and they were planning to major in education. So, I decided to try the teacher education program." Although Katie's peers may have influenced her decision to enter the field, she spoke at greater length about the influence of her grandmother on her decision to enter education.

My grandmother was a school teacher and she attended a Normal School and I always admired her and hoped that I could follow in her footsteps. My grandmother began teaching in 1916 and started a summer school in the mine camp where she lived. She was only able to teach a few more years because when my grandfather returned from WWI they married. At that time female teachers were to be single. My grandmother would go on to have 7 kids, one of which was my mother. Although she never taught in a formal setting again she always remained someone who valued education.

The dual influence of her grandmother's legacy and peer support combined with

Katie's own love of learning coalesced to inform her decision to enter teacher education.

However, her pursuit of a college degree was a costly endeavor. Katie explained that she worked during the summer months to help pay for her tuition and books. As Katie shared her reconstructed narrative, she identified the challenges related to reaching her goal with the relational being central to Katie's resolution.

Advice from my dad actually kept me in college... While in college I had a summer job at a glass plant doing secretarial work. The money I made from this job really helped pay for my tuition and books. At the end of one summer I was asked to stay on as a full-time employee. The money was outstanding and I struggled with the decision to stay in school or work full-time at the plant. My dad told me to finish my degree and then I could decide if I wanted to stay in education or go back to the plant. It ended up closing for good in 1987. I'm glad I listened to dad's advice and got my degree. 
TEACHING WITHOUT A NET

Katie's reconstructed narrative concerning the role her father played in encouraging her to finish her undergraduate degree not only provided further evidence of the relational in her decision-making process, but also brought to light the "turning points, peaks, and valleys" (Riesman, 2008, p. 78) that provided the structure of her narrative. Katie began her narrative, "Advice from my dad...," with what Labov referred to as the abstract or point of the story. The complicating action or issue of concern arose when Katie stated that she "struggled with the decision to stay in school or work full-time at the plant." Katie's evaluation of the situation was that the "money was outstanding" at the plant and its allure almost persuaded her to forgo her undergraduate degree. However, Katie resolved the situation by adhering to the advice of her father and finishing her degree. The narrative came to a conclusion or coda when Katie indicated that the glass plant terminated its Northcentral WV operations in 1987 (see Table 1).

Table 1

Becoming an Educator

\begin{tabular}{|c|c|c|c|c|c|}
\hline Participant & Orientation & $\begin{array}{l}\text { Comp. } \\
\text { Action }\end{array}$ & Evaluation & Resolution & Coda \\
\hline Trina & $\begin{array}{l}20 \text { yrs. after } \\
\text { High School } \\
\text { (H.S.) }\end{array}$ & $\begin{array}{l}\text { Tight job } \\
\text { market }\end{array}$ & $\begin{array}{l}\text { Skeptical } \\
\text { about teaching }\end{array}$ & $\begin{array}{l}\text { Husband's } \\
\text { advice to } \\
\text { pursue degree }\end{array}$ & \\
\hline Katie & After H.S. & $\begin{array}{l}\text { How to pay } \\
\text { for college }\end{array}$ & $\begin{array}{l}\text { Summer work } \\
\text { paid well }\end{array}$ & $\begin{array}{l}\text { Dad's advice } \\
\text { kept her in } \\
\text { college }\end{array}$ & $\begin{array}{l}\text { Plant closed in } \\
\text { late ' } 80 \mathrm{~s}\end{array}$ \\
\hline Steve & After H.S. & $\begin{array}{l}\text { Unsure of } \\
\text { college major }\end{array}$ & $\begin{array}{l}\text { Impact of a } \\
\text { teacher }\end{array}$ & $\begin{array}{l}\text { Major in Soc. } \\
\text { St. educ. }\end{array}$ & \\
\hline Jesse & After H.S. & $\begin{array}{l}\text { Unsure of ed. } \\
\text { field }\end{array}$ & $\begin{array}{l}\text { H.S. history } \\
\text { teachers }\end{array}$ & $\begin{array}{l}\text { Major in Soc. } \\
\text { St. educ. }\end{array}$ & \\
\hline
\end{tabular}

The relational was also evident in Trina's reconstructed narrative of how she came to the field of education. Like Katie, Trina indicated that she "loved school" as a K-12 student. However, her enjoyment of school did not lead her into a teacher education program 
TEACHING WITHOUT A NET

upon graduating from high school. Twenty years after graduating from high school (orientation)

and encouraged by her husband (relational), Trina enrolled in college as a non-traditional

student.

I had always worked in the private sector. I worked as an office manager, a realestate secretary, a title insurance closer, a loan officer at a bank...a lot of experiences in the business field. My husband said that since we were going to be moving around, and we had already moved, he thought that it would be great if I had a degree that I could use wherever we went. He said, "You have always been good at teaching people so why don't you go and become a teacher." I looked at him and laughed!

Faced with the prospect of moving and the need to find employment (the complicating action), Trina resolved the issue of concern by enrolling in college, but not before she evaluated the situation with obvious skepticism ("I looked at him and laughed!"). Familial relationships were also evident in Jesse's reconstructed narrative of how he came to the field of education. As previously discussed, Jesse's mother was a school teacher.

Probably the biggest influence on me becoming a teacher is my mother... My mom jokes with me saying that she tried to talk me out of it (entering the field of education)! My mom taught for 32 years before she retired. My mom was a teacher, I became a teacher, and my brother was a teacher and now an administrator, so there is a family history.

Jesse acknowledged the role his mother played in his career choice; however, when he began school, he was not certain as to the content area he would choose as a specialization. Making this choice proved to be a complicating action.

For a long time, I didn't know whether I wanted to go into physical education and health, social studies, or science. Those were my three choices, but a few teachers at at the high school level swayed me to social studies... They were great!... They made history come alive, their classes were fun. They made me feel like I was involved, they made the class interesting. They made me want to do more research; they gave me a ton of positive feedback. They were very demanding, but very fair. They told you when you did something wrong, but they also told you that you did a really nice job when you did something right... We did a lot of projects, what we would term higher depth of knowledge, it wasn't just filing out worksheets and turning them in. They would really push you to think. 
TEACHING WITHOUT A NET

His decision to major in social studies education (resolution) was also closely linked

to the relational, as Jesse stated that two of his high school social studies teachers "swayed" him to pursue a social studies degree because, among other characteristics, "they made history come alive." Relationships formed within the K-12 or higher education settings (institutional) also appeared in the narratives of Steve, Katie, and Trina.

Steve indicated that his family was supportive of his decision to pursue an undergraduate degree in education. However, he came to the field of education primarily through the influence of a teacher.

Originally, I wanted to be a dentist...The more I thought about people and their mouths...it eventually turned me off! A lot of it (becoming a teacher) goes back to Sister Stewart. I wanted to do for other people what she did for me...To this day, she is probably the best teacher I ever had...It was the way she approached things. She was, from the way you would figure being a nun, very strict, very regimented, but she cared about learning. She did her best to get the information across to us. She is just someone that I have always looked up to.

Steve's evaluation of her teaching that "she cared about learning" influenced his decision to become a teacher and "do for other people what she did for me," providing a coda for the narrative. For Steve, relationships not only influenced his decision to become a teacher, but they also informed his experience as a prospective teacher. In particular, Steve spoke about a professor he had as an undergraduate. Whereas Sister Stewart had influenced Steve's decision to enter the field of education, a professor at the college level greatly impacted his pedagogical perspective.

Professor Vance... She was the public school version of Sister Stewart. It was a flashback, she was the hardcore, no nonsense public school teacher...She was about taking command of the classroom, projecting your voice. The kids needed to know that you knew your material and that you were in charge. She wanted you to be confident in your delivery... And it was kind of like déjà vu. She was probably an influence as well, the only woman who ever frightened me. She made me a nervous wreck every time she came to observe. And it was more of "I don't want to 
TEACHING WITHOUT A NET

disappoint her" than me not liking her...I wanted her to see that I was putting to use what she had showed me.

The observations by Professor Vance served as a complicating action for Steve, which he resolved by "putting to use what she had showed me," even as she was "the only woman who ever frightened [him]" (evaluation). Steve positioned this professor as the "public school version of Sister Stewart," and her expectations that he "take command of the classroom" and "know [his] material" influenced not only his performance in the classroom, but also the ways in which he was constructing a teacher identity ("putting to use what she had showed me").

Trina and Katie also made reference to a college professor who they both had for class, although 20 years apart. In reconstructing the stories of their past, both participants noted the encouraging words and insight of this particular professor. Katie stated that, "Dr. Preston had a large impact on my teaching career...He was always so positive and encouraging." As a preservice teacher observing licensed teachers, Trina found herself observing many "sit and get" classrooms with direct instruction being the primary means of content delivery. Trina wanted to develop a more engaging classroom where each child would feel important. Dr. Preston reminded Trina that developing a personal relationship with her students would take time, but he encouraged her pursuit of a more student centered classroom. Trina remembered him saying that, "Your methods will work the way you prefer to do it, but it will take time". For Trina, Dr. Preston's confirmation of her methods not only influenced her practice, but also informed her nascent teacher identity. In fact, the significance of this narrative is still evident today as Trina explained that building a good rapport with her students is still something she strives for each year. She stated that, "It's taking the child with the dirtiest reputation and finding a way to get him or her on your side." 
TEACHING WITHOUT A NET

Relationships, both familial and institutional, were evident as the participants shared their reconstructed narratives concerning their initial steps toward careers in education. This theme emerged as a result of the complicating actions the participants encountered in making a career choice that were mediated by the relationships they had developed with family and educators in public schools and higher education.

\section{Story 2: Into the Field}

Story 2 emerged out the participants' reconstructed narratives concerning their initial full-time teaching positions. Keeping the overarching, guiding questions in mind, I was interested to see how at an early stage in their respective careers the participants responded to developing and implementing a curriculum with limited prior experience. At the same time, I was interested to learn how their initial teaching experience impacted the development of their teacher identities. The relational again appeared as a theme, but the participants' search for stability in the face of uncertainty dominated these narratives.

Each of the participants situated their reconstructed narratives within a particular school, grade level, and content area (orientation). For Steve and Jesse, the orientation of their narratives was a junior high school setting, supervising $7^{\text {th }}$ and $8^{\text {th }}$ grade In-School Suspension (ISS). Trina and Katie situated their narratives within a $9^{\text {th }}-12^{\text {th }}$ grade setting with Trina working as a high school librarian and Katie teaching U.S. History and physical education.

In the process of reconstructing narratives of their first full-time teaching positions, each of the participants made reference to an event or events which caused concern (complicating action) and required their attention. For Steve, the complicating action was manifest in the fact that as ISS supervisor he had to have an understanding of multiple subjects, not just social studies content, in order to assist the students assigned to ISS. 
TEACHING WITHOUT A NET

Instead of suspending the kid and the kid going home for three days and not getting any work from them, they came to ISS... The challenges were that it was just not social studies, if the kids had questions about math or English I had to be able to help them. I had to go back and learn, refresh myself. I didn't want to be the person that didn't know how to do that! I had to brush up on sentence diagraming, that type of thing.

Steve not only identified a complicating action (needing knowledge of multiple

subjects) in his reconstructed narrative, but he also evaluated the situation and stated his

resolution to the event of concern. Steve's admission that he "didn't want to be the person that didn't know how to do that" represented his evaluation and he resolved the situation by taking it upon himself to relearn the material that his students were learning (see Table 2).

Table 2

Into the Field

\begin{tabular}{|c|c|c|c|c|c|}
\hline Participant & Orientation & $\begin{array}{l}\text { Comp. } \\
\text { Action }\end{array}$ & Evaluation & Resolution & Coda \\
\hline Trina & H.S. librarian & $\begin{array}{l}2 \text { broadcast } \\
\text { journalism } \\
\text { classes }\end{array}$ & $\begin{array}{l}\text { Facilitator of } \\
\text { knowledge }\end{array}$ & $\begin{array}{l}\text { Encourage } \\
\text { students to } \\
\text { take resp. }\end{array}$ & \\
\hline Katie & $\begin{array}{l}\text { H.S. history \& } \\
\text { PE }\end{array}$ & $\begin{array}{l}\text { Discipline } \\
\text { issues }\end{array}$ & Proactive stance & $\begin{array}{l}\text { Found ways to } \\
\text { relate \& } \\
\text { comm. w/ } \\
\text { students }\end{array}$ & \\
\hline Steve & ISS Supv 7/8 & $\begin{array}{l}\text { Content } \\
\text { knowledge } \\
\text { beyond soc. } \\
\text { st. }\end{array}$ & $\begin{array}{l}\text { Didn't want to } \\
\text { appear } \\
\text { unknowledgeable }\end{array}$ & $\begin{array}{l}\text { Relearned } \\
\text { material to } \\
\text { assist students }\end{array}$ & \\
\hline Jesse & ISS Supv 7/8 & $\begin{array}{l}\text { Not teaching } \\
\text { soc. st. }\end{array}$ & $\begin{array}{l}\text { Pros/Cons } \\
\text { Considered }\end{array}$ & $\begin{array}{l}\text { Did best he } \\
\text { could }\end{array}$ & \\
\hline
\end{tabular}

Like Steve, Jesse's first full-time job in education was supervising ISS. Jesse also recognized that his assignment required more than just knowledge of social studies content, creating a complicating action.

I got my foot in the door, but not teaching social studies. I had been trained to teach social studies, but wasn't. I was thankful to have a full-time job and I did the best I could with it, but it was not what I went to school to do. I had to come to terms with 
TEACHING WITHOUT A NET

the fact that there are steps to the process, to get where you want to go it takes time. You can't always start out where you want to be.

In evaluating the situation, Jesse seemed to weigh the pros and cons of his initial teaching assignment. Finding full-time work, after more than a decade out of the field, was a positive; however, he was not teaching subject matter that he was passionate about. He resolved the situation by doing the best he could, given the circumstances, and vowed to move forward, trusting that an opportunity to teach full-time social studies would emerge. Although neither Steve nor Jesse found initial employment in a social studies classroom, their tenure as ISS supervisors, from a social constructivist perspective, influenced their emerging identities as educators. Gergen (1991) maintains that individuals "incorporate information from their environment" throughout their lives (p. 69).

Unlike Steve and Jesse, Trina and Katie found initial employment in the field of education teaching subject matter that reflected their undergraduate training and their interests. However, teaching subjects that they were passionate about did not render them immune to events of concern. In reconstructing her initial full-time teaching position, Trina spoke of how her role as a high school librarian extended beyond overseeing the media center.

It was interesting. I had to teach two classes of broadcast journalism and I had never done that before. The students, thankfully, had some experience running the editing equipment so they taught each other. I was there for guidance, I would throw some ideas at them, and I was a censor because high school students need a censor sometimes.

Trina's first year of teaching was complicated by the assignment of two broadcast journalism courses. Although not explicitly stated in this narrative, Trina referred to herself as a "facilitator" in another interview. Her evaluation of the aforementioned event seemed to support the notion that even at an early stage in her career she saw herself as a facilitator of knowledge. By assuming the role of facilitator, Trina resolved the complicating action by recognizing her 
TEACHING WITHOUT A NET

own limitations and encouraging her students to build on their strengths which moved Trina

beyond the "sit and get" classroom she observed as a pre-service teacher and toward the

development of a student-centered classroom. Here Trina was beginning to construct the identity

she had envisioned for herself as a teacher. Developing positive teacher/student relationships

with her students was a key component to this transition.

Upon earning her undergraduate degree, Katie was immediately hired at the same

high school in which she had completed her student teaching requirements. Although excited

about the opportunity, Katie made reference to challenges that both novice and veteran teachers

face on a daily basis.

My initial teaching position was a good experience because I was placed in the same school that I did my student teaching, giving me the opportunity to...become familiar with the school rules, administration, staff members and students... Discipline sometimes hindered or interrupted with what I wanted to accomplish in a lesson. Now that I think back, some of the issues I thought were discipline problems early in my career were pretty minor to what I would encounter during the latter part of my career...I had to learn to respond to each challenge as it was presented and ultimately the challenges in teaching all go back to relating to and communicating with the people involved.

In Katie's narrative, of her initial teaching experience, discipline issues emerged as the complicating action. Although student behavior did not keep Katie from evaluating her initial teaching assignment as "a good experience", her reconstruction of this particular school year also indicated that she needed to find a means to proactively respond to the various challenges she faced in the classroom. In order to minimize behavioral interruptions, she resolved to find ways to relate and better communicate with her students. Katie felt that developing these relationships was an important aspect of her identity and practice, even at this very early stage in her career. 
TEACHING WITHOUT A NET

An application of a layered approached to data analysis revealed the relational (most evident in the narratives of Trina and Katie) and feelings of uncertainty as the participants reconstructed their initial teaching positions. As teachers, all of the participants were required to engage their students in a particular curriculum corresponding to an academic field. The complicating actions that they faced, during their initial year in the classroom, created feelings of uncertainty. For Jesse and Steve, feelings of uncertainty emerged from the fact that they were teaching in educational environments that did not reflect their undergraduate training. Although Trina found employment in a field which reflected her undergraduate degree, like Jesse and Steve, her teaching assignment required familiarity with concepts outside of her area of expertise. Katie, teaching content she enjoyed, faced the uncertainty of behavioral disruptions. Faced with events which created feelings of uncertainty (complicating actions), the participants sought ways to stabilize their respective situations (resolution). Steve resolved to relearn concepts so he could confidently assist students assigned to ISS. Jesse also acknowledged that ISS was more than social studies content and he resolved to make the best of the situation. Essential to Trina and Katie's resolutions was the theme of relationships. Trina resolved her issue of concern by acknowledging her own limitations and encouraging her students to take an active role in the learning process; while Katie saw communication, between teacher and students, as a key component to resolving behavioral disruptions. 
TEACHING WITHOUT A NET

\section{Story 3: Teaching Social Studies}

Like story 2, story 3 emerged from an interest in following the "peaks and valleys" of the participants' stories in relation to the overarching question of how teachers engaged as curriculum developers when curriculum change was mandated. As previously indicated, the participants, with the exception of Katie, worked in other capacities within the field of education before finding employment in social studies education. Again, I wanted to pay attention to how the participants developed their respective approaches to curriculum at a relatively early stage in their careers. Thematically, the participants again talked at length about relationships and they noted the many challenges of stepping into a classroom for the first time with uncertainty looming over head. For story 3, Steve and Jesse oriented their reconstructed narratives in a middle/junior high school classroom setting while Trina situated her narrative in a high school setting (because Katie's first teaching position included teaching social studies content her narrative is not included in Story 3).

As previously stated, Trina's first full-time job in education came when she was hired as a high school librarian. Two years into her tenure as a librarian, her administrator approached her about the possibility of collaborating with a social studies teacher for one class period.

[T]he last 2 years I was there they asked me to team teach with another teacher, of social studies, working with seniors who had failed social studies their junior year. The teacher was way up here (motions upward) and I had some special education classes and a social studies degree so I could bring what the teacher was teaching down and help the students graduate on time...I don't want to say that we were "dumbing down" the curriculum, but we wanted to find ways for the kids to get through the class... So we just looked for ways to apply the information. We had the students draw maps of say New York City...We had them create a supply list of items they would need to go west during Westward Expansion... We had an energy for what we were doing. So, it was fun working with her.

Trina's reconstructed narrative of her initial foray into social studies education contains both external and internal complicating actions. The former was evident in the 
TEACHING WITHOUT A NET

circumstances surrounding the students (needing credit to graduate) who were enrolled in the class. The latter surfaced when Trina seemed to question her methods of engaging the students and was concerned that others might view her methods as soft or merely a "dumbing down" of the curriculum. Ultimately, Trina wanted to see her students graduate, but she did not want to simply pass them on. She resolved to "look for ways (for the students) to apply the information," which was aligned with the identity she wished to constructed as a teacher who created student-centered learning environments.

Out of necessity, she encouraged her students, in story 2 , to take an active role in the technical components of creating a news broadcast. In story 3 , she encouraged her students to take a more active role in the learning process while relinquishing some of the "power" associated with the in loco parentis role of the classroom teacher. In another portion of our first interview, Trina spoke of the astonishment that her administrators have often had when they witnessed the academic success her students achieved via differentiated instruction. She stated, "My administrators always seemed surprised that I could take troubled students and get some kind of results." Trina's evaluation of this particular vignette not only included her decision to differentiate her instructional techniques, but she also recognized the positive working relationship she fostered with her co-teacher. In commenting on their rapport, Trina provided a coda to her narrative, allowing the storyline to bridge the past, present, and future. She stated, "So it was fun working with her. When your job is no longer fun then don't do it anymore. That is just me (see Table 3)." 
TEACHING WITHOUT A NET

Table 3

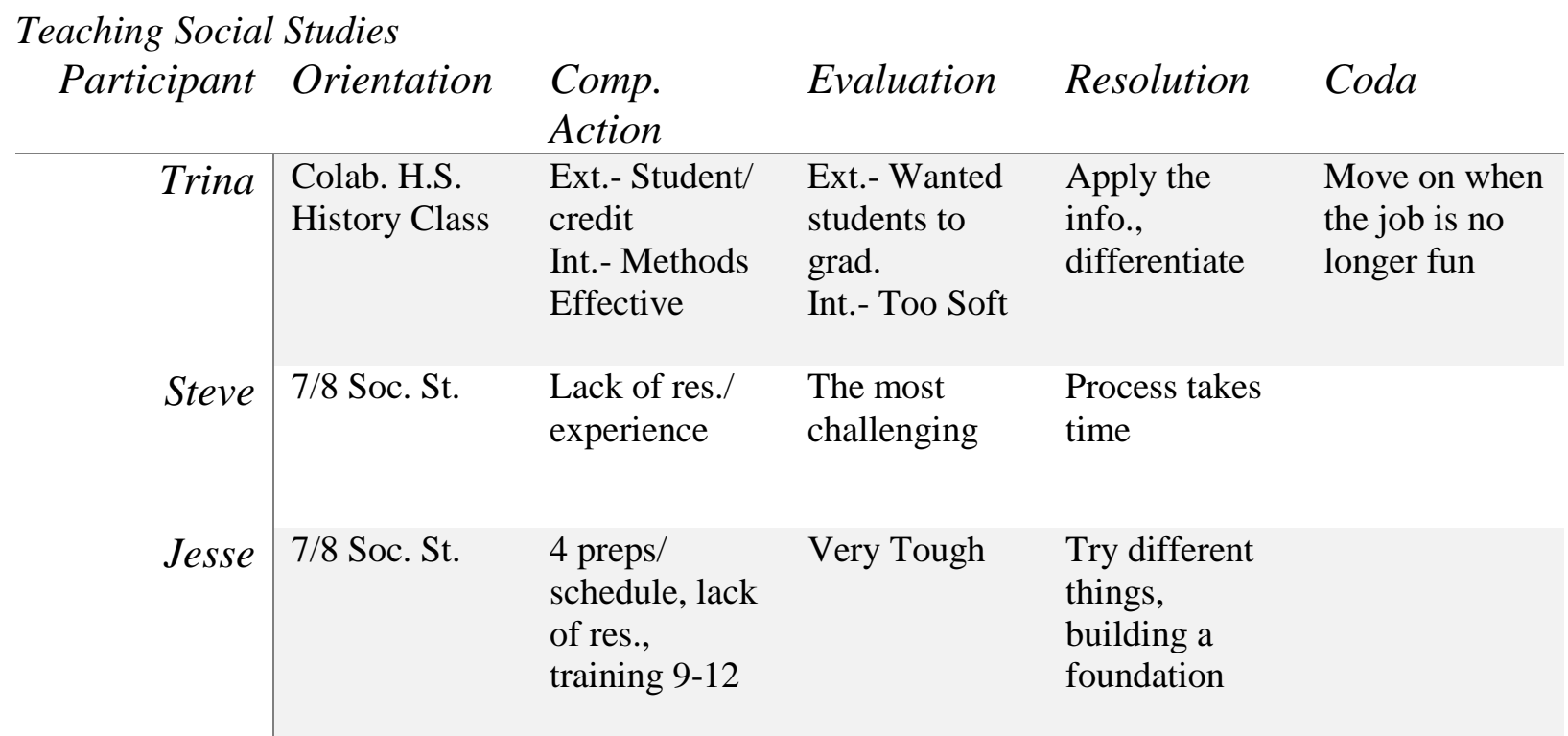

As previously stated, Jesse left the field of education not long after earning his

undergraduate degree. Upon returning to the field he found employment, outside of his preferred area of interest, as an ISS supervisor. His opportunity to teach social studies arrived in the early 2000's. However, Jesse experienced his share of complicating actions his first year in the social studies classroom.

The first year in the social studies classroom was very tough. We had a unique schedule, of course I taught $6^{\text {th }}, 7^{\text {th }}$, and $8^{\text {th }}$ grade social studies and $7^{\text {th }}$ grade health, one semester I saw half the kids and the second semester I saw the other half. It was like block scheduling. I had to plan, then implement, and now I was doing preps for 4 classes. As a first year teacher you do not have any materials on hand, so in many ways you are learning as the kids are learning. My training in college was 9-12 and now I'm teaching middle school. I tried a lot of things and then the second year you change a lot of things... The teacher that was there before me was well-liked, so the kids had to get to know me and understand what I expected...The $8^{\text {th }}$ graders I had had previously had him for $6^{\text {th }}$ and $7^{\text {th }}$ grade. So they knew him and he knew the students. That was tough to get over at first...The first day before students reported to class for the first time they decided to move my room from the one I am in now to the math room. This was my first year ever teaching social studies and I'm moving my classroom the day before school starts! 
TEACHING WITHOUT A NET

Preparing for 4 different classes, working within the framework of a "unique

schedule," lacking materials, instructing middle school students after focusing on grades 9-12

during undergraduate training, succeeding a well renown teacher, and moving to another

classroom the day before school started all presented Jesse with issues requiring his attention.

He succinctly evaluated his first year in a social studies classroom by stating that it "was very

tough." His resolution to the various complicating actions was to "try different things" knowing

that he was creating a foundation from which to build in subsequent years. Jesse's willingness to

"try different things" in regard to how he approached the curriculum, during his first year in a

social studies classroom, is markedly different from the reconstructed narrative he shared

concerning his tenure as an ISS supervisor ("I did the best I could"). Perhaps being comfortable

with the content allowed Jesse to exert a greater degree of agency over his classroom and in turn

begin developing a more pliable approach to the classroom.

In further conversation, Jesse spoke of how his first year in the social studies

classroom required him to stay late many evenings and arrive early the next day; straining his

time and home life. He had a responsibility to make the class as informative and engaging as

possible, but as Jesse further evaluated the year he recognized that it was not entirely a solitary

experience.

I was very fortunate, I had a couple of teachers here, they are now retired, and they were mentors to me. I don't think I could have made it without them...Those two teachers got all my homeroom packets together for me while I was changing rooms. They helped me, anytime I needed something they helped me. Now as I am the senior middle school teacher I try to make myself available, paying it forward, because I remember what it was like when I first started and how helpful those teachers were to me.

Any K-12 educator who has ever opened the school year knows that there are several administrative forms distributed to students on the first day of school; ranging from school code 
TEACHING WITHOUT A NET

of conduct guidelines to emergency contact information. As Jesse scrambled to re-locate his classroom, two teachers were preparing the administrative packets necessary for his homeroom students to take home the opening day of school. This selfless act impacted Jesse greatly as he now strives to "pay it forward." This portion of Jesse's narrative, like the conclusion of Trina's Story 3 narrative, represented the coda to the story. Jesse commented on the past, but he also provided insight into his present situation and what he plans to do in the future.

Like Jesse, Steve's initial teaching position consisted of supervising students assigned to ISS before finding employment as a social studies teacher. Although Steve's initial foray into social studies education did not commence like Jesse's (e.g., changing classrooms the day before school started), he still experienced a number of complicating actions which make teaching, especially for the uninitiated, stressful.

The first year was by far the most challenging because the teacher that was there previously left only the textbook. There were no maps. I was to teach WV History and World Geography, no teacher's manual. I didn't have anything! That was the toughest thing, trying to get some resources- videos, other books... My lack of experience and the process of doing lesson plans, wondering "Will this work?" You can write up the greatest plan in the world and when you get there it falls flat. Just the process of keeping what works and getting rid of what doesn't work.

Steve began his narrative by evaluating his first year in the social studies classroom as "the most challenging" of his career. Stepping into an essentially bare classroom, lacking prior experience, and engaging in the process of writing weekly lesson plans all presented Steve with issues of concern. Like Jesse, he resolved to move forward with the understanding that gaining greater insight required time. Comparing his journey forward to a "process," Steve acknowledged the paramount role time plays in the learning process. However, the resolution of some issues required less time than others.

Fortunately, I was blessed at the time because the school was part of a collaborative 
TEACHING WITHOUT A NET

project with a local university. Through this partnership each teacher could spend $\$ 200$ on classroom supplies. My principal and his wife, who served as the school coordinator, knew about my situation and they gave me their allotment. So, I ended up with about $\$ 800$ to spend. Plus, the partnership bought me a set of classroom maps. They took care of me and hooked me up well. I still have the maps.

And the teachers were wonderful as well. The $5^{\text {th }}$ and $6^{\text {th }}$ grade social studies teachers were helpful with ideas, resources, and advice.

Steve received an unexpected resolution to his resource deprived classroom in the form of money allotted to him via a university/public school partnership. Perhaps, just as important as the financial assistance was the assistance from colleagues in overcoming the challenges of his initial year in a social studies classroom. Steve's reconstructed narrative highlighted the role his peers in social studies education, as well as his administrator and his administrator's wife, played in assisting him during his initial year teaching social studies. The relational was also evident in Trina and Jesse's storylines regarding the role colleagues played in assisting them in resolving various complicating actions.

The "loss, anxiety, and struggle" which, according to Maris (1975), accompanies change was apparent in the participants' reconstructed narratives of their first year teaching social studies. Jesse described (or evaluated) the year as being "very tough"; Steve referred to the year as being "challenging." Their respective narratives contained a number of anxiety producing complicating actions resulting in feelings of uncertainty. Although Katie stated that she had fun working with her co-teacher, her narrative indicated that she struggled to justify her teaching methods. The various complicating actions described by the participants could produce, according to Nolan and Meister (2000) feelings of alienation. However, based on their study of teachers and change, Nolan and Meister also indicated that the uncertainty change may provoke can also produce opportunities for collaboration. These findings are supported by the reconstructed narratives of the participants. Collaborative relationships with their colleagues 
TEACHING WITHOUT A NET

greatly assisted Trina, Steve, and Jesse in resolving the various complicating actions that they encountered during their first year teaching social studies. Challenges, in one form or another, uncertainty, and peer relationships were also components of story 4.

\section{Story 4: Top Down Mandates}

Prior to engaging the participants in conversation related to their stories about implementing the mandated NxG CSOs for Social Studies, I wanted my participants to create narratives that reconstructed their memories of implementing previous mandates. By exploring the past, I succeeded in gaining insight into how the participants interpreted, implemented, and were influenced by mandates required during their respective teaching assignments. Prior experiences with interpreting and implementing mandatory changes could have influenced the way the participants approached the NxG CSOs implementation process. In fact, my participants' narratives indicated that the various mandates they were required to implement posed challenges and generated feelings of uncertainty.

To resolve the feelings of uncertainty, my participants indicated that they took the initiative/demonstrated agency to remedy the complicating action that they experienced; often turning to colleagues and even their students for advice and guidance. The lack of support services for successful implementation is well documented and Ornstein and Hunkins (1998) argue that policy makers often pay greater attention to the development of programs than to how the programs will be implemented. All of my participants had a story to share regarding implementing a mandate/requirement. The orientation of their narratives was within a junior high school setting $\left(7^{\text {th }}-8^{\text {th }}\right.$ grades $)$ teaching social studies.

When asked to discuss his prior experience in working with a required mandate, Jesse spoke about a situation which occurred during his first year teaching social studies. As a 
TEACHING WITHOUT A NET

teacher of $6^{\text {th }}-8^{\text {th }}$ grade social studies, one of Jesse's responsibilities was to administer the WV Golden Horseshoe test to his $8^{\text {th }}$ grade students. The Golden Horseshoe test was given annually to $8^{\text {th }}$ grade students and measured their understanding of WV's history, geography, economy, and government. The students with the highest scores from each county were "dubbed either Knight or Lady of the Golden Horseshoe Society" (WVDE, 2015) at a ceremony in Charleston, WV. As a first-year teacher, Jesse had no prior experience with administering the test or assisting his students with study preparation. Jesse's unfamiliarity with the test created a complicating action.

I had never administered it and I don't even remember taking it as an $8^{\text {th }}$ grader. After the test was over I felt I could have done a better job for the students that chose to take it... Of course you are always concerned about messing something up during the test...It is one of those things where you show up and they tell you to give the test. And you try to make a few phone calls; I talked to one of my former teachers and he pretty much got me through it. He is an outstanding WV History and another teacher that I knew in the county gave me some advice as well. I believe that if you are going to be a successful teacher then you need to find the most successful teachers and pick their brains.

While discussing this event, Jesse noted that one "can never assume" that policy makers or those in administrative roles will offer direction when it comes to implementing grade level policies or mandates. This perspective was evident in Jesse's resolution to the complicating action of administering a state test without training. Jesse resolved the situation by personally contacting veteran teachers and seeking their guidance on how to administer and best prepare his students for the test. Although a touch of despondency was evident in his evaluation of the situation ("I could have done better...", “...concerned about messing something up...”), Jesse's coda to the situation was optimistic. Continuous dialogue between colleagues (the relational) enabled Jesse to improve his craft and become more confident with his role as a social studies teacher (see Table 4). 
TEACHING WITHOUT A NET

Table 4

Top Down Mandates

\begin{tabular}{|c|c|c|c|c|c|}
\hline Participant & Orientation & $\begin{array}{l}\text { Comp. } \\
\text { Action }\end{array}$ & Evaluation & Resolution & Coda \\
\hline Trina & 7/8 Soc. St. & $\begin{array}{l}\text { Assigned a co- } \\
\text { teacher }\end{array}$ & $\begin{array}{l}\text { Not a true } \\
\text { collab. }\end{array}$ & $\begin{array}{l}\text { Located } \\
\text { necessary } \\
\text { resources }\end{array}$ & \\
\hline Katie & 7/8 Soc. St. & TechSteps & $\begin{array}{l}\text { Theory/prac. } \\
\text { disconnect, } \\
\text { dicomfort }\end{array}$ & $\begin{array}{l}\text { Located } \\
\text { necessary } \\
\text { resources }\end{array}$ & \\
\hline Steve & 7/8 Soc. St. & TechSteps & $\begin{array}{l}\text { Not great w/ } \\
\text { tech., } \\
\text { discomfort }\end{array}$ & $\begin{array}{l}\text { Explore on } \\
\text { own, advice of } \\
\text { colleagues \& } \\
\text { student }\end{array}$ & $\begin{array}{l}\text { Mandate no } \\
\text { longer } \\
\text { required }\end{array}$ \\
\hline Jesse & 7/8 Soc. St. & $\begin{array}{l}\text { Golden } \\
\text { Horseshoe } \\
\text { Test }\end{array}$ & $\begin{array}{l}\text { No prior } \\
\text { experience }\end{array}$ & $\begin{array}{l}\text { Advice from } \\
\text { experienced } \\
\text { teachers }\end{array}$ & $\begin{array}{l}\text { Talk to } \\
\text { successful } \\
\text { teachers }\end{array}$ \\
\hline
\end{tabular}

Like Jesse, Trina's narrative concerning the implementation of a mandate prior to the NxG CSOs occurred during her first year teaching $7^{\text {th }}$ grade social studies. Trina's class schedule included a class period where a special educator worked collaboratively with her. Based on a statewide mandate, students with mild learning disabilities would no longer be "pulled out" of the general education classroom for instruction, but would remain in the general education setting with the special educator coming to them. The classroom teacher and the special educator were expected to work collaboratively to meet the educational needs of the student in a general education setting. Based on her prior experience with co-teaching in Kansas, Trina welcomed the opportunity to work collaboratively with another educator.

For one period a special education teacher was in the classroom with me, but it was different from when I collaborated in Kansas. In Kansas, I was more like the special educator, finding ways to support the students and my co-teacher was discussing the higher level content. Now it was a role reversal, I was the regular teacher working with a special educator. But, it wasn't a true collaboration. We did not have time to plan together, it was more like, "So, what are we doing today?" I would give her my plans for the next week thinking that she would modify the material for the students, 
TEACHING WITHOUT A NET

but this did not happen...So, I had to charge right in!...I got on the Internet and found resources, located what I needed. For the higher-level students, I found ways to challenge them through projects and for the non-readers and non-writers I found ways for them to make something, looking at an art aspect.

The complicating action, in Trina's narrative, stemmed from the absence of collaborative planning time available, during the instructional day, for her co-teacher and herself. The situation was further exacerbated by her co-teacher's unwillingness to modify Trina's weekly lesson plans; electing instead to improvise (“So, what are we doing today?") once in the classroom. This led to Trina's evaluation that this co-teaching experience "wasn't a true collaboration." To resolve the situation, Trina took the initiative of locating materials which would be suitable for students of various cognitive levels.

Interestingly, both Katie and Steve cited the required use of a program called TechSteps as a mandate they both implemented prior to the NxG CSOs for Social Studies. The TechSteps program was a county adopted computer based program which contained technology related projects for students in elementary through high school grades. The program not only offered grade level projects, but offered a project for each of the core disciplines within each grade level. Therefore, students could complete up to 4 TechSteps projects per year. Steve admitted that "the material was good," but both participants identified complicating actions due to initial unfamiliarity with the program, the time required for students to complete the projects, and issues with students being off-task while completing the projects. Katie reconstructed the following narrative about her experience with TechSteps.

As a teacher, I was responsible for completing a TechStep assignment. It was a very time consuming assignment, each student was to complete a computerized assignment. Students were to go into the computer and read the directions and complete this assignment independently. The students were totally confused and not focused on what needed to be done. They had to be monitored very closely because they would go into game sites. 
TEACHING WITHOUT A NET

In her narrative, Katie referenced a perceived disconnect between theory and practice which, in her opinion, contributed to the cited complicating actions (e.g., assignment time consuming, students off task). The teacher and student "screens" within each TechSteps project contained detailed directions pertaining to the successful completion of each project. In theory, the directions allowed the students to progress through the assigned projects at their own pace. In addition to directions in text form, embedded within each page were pictures and videos designed to assist students in completing the project. Once familiar with the directions and overall objective of the project, students opened another tab outside of the TechSteps program to access the technology necessary to complete the project (e.g., Microsoft Power Point, an Excel Spreadsheet). A third tab provided an outlet to the Internet for research purposes. Ultimately, the project required reading comprehension skills, familiarity with various computer technology applications, navigation between tabs, and research skills. In practice, Katie found that many of her students were overwhelmed by the various aspects of this assignment and quickly became off-task.

Although her own unfamiliarity with the program and the possibility for off task student behavior may have influenced Katie's unfavorable opinion of TechSteps, she indicated that she was uncomfortable working in a computer lab in a "less structured learning environment." For Katie, the teacher was the center of the classroom with the students responding "solely to the instruction of the teacher." The components of the TechSteps program required the students to assume greater responsibility for their learning and for the teacher to take on the role of guide and supervisor. Student-centered approaches to teaching and learning were at odds with the position Katie had held since her formative years in public education and initial teacher training. Katie admitted that "it was difficult to give up the role of a teacher instructed 
TEACHING WITHOUT A NET

classroom," but she wanted to "keep growing" and explore the possibilities available through student-centered learning. Although a difficult situation to resolve, it seems that the TechSteps mandate presented Katie with the opportunity to reassess her values, beliefs, and assumptions. This reassessment, according to Bennett (2011), is related to the "Who am I?" question, essential to the ongoing process of identity development.

Steve also indicated that he felt a sense of uncertainty in with the various components of the TechSteps mandate. Again, like Katie, his uneasiness may have derived from multiple sources.

TechSteps was required. I was not the greatest technology person at the time, but I've gotten better. At that point I wasn't very good at it and it made me more nervous than just teaching the class because I didn't want the kids to think that I didn't know how to do the technology based things.

Steve's self-applied moniker, "not the greatest technology person," lent credence to the uncertainty he felt in attempting to engage young people in an application of the technology based mandate. However, Steve's image of the teacher as "one who knows all," akin to Katie's position regarding the teacher-centered classroom, was jeopardized by the mandate. Previously, Steve had expressed a similar sentiment when discussing his initial teaching position, as an ISS supervisor, and his need to become familiar with multiple subjects. Steve wanted to be able to assist the students, but he also did not want "to be the person who didn't know how to do that."

To resolve the situation, Katie and Steve, like Trina and Jesse, recognized that they would need to take it upon themselves to become more familiar with the requirements of the mandate. However, instead of working in isolation, they both utilized the knowledge of colleagues (the relational) to become better acquainted with TechSteps. Katie explained that she was not prepared to implement this mandate, but "through struggling" on her own and 
TEACHING WITHOUT A NET

"discussing the program with other teachers" she became more comfortable, but it took time.

Steve reconstructed a similar narrative.

I went in before I took the class in (to the computer lab) and figured it out myself. Mr. West is the tech guy at our school and anything that I wasn't sure about he would write down how to use the program. So, that was big. After the first year or two it got to the point where I did it without even thinking about it.

Katie and Steve developed a greater understanding of this mandate not through training sessions provided by county administrators, but through the combined efforts of exploring the program on their own and seeking support from colleagues. Steve, despite his admission that he did not want to appear unknowledgeable in front of his students, recognized that his students can provide insightful instruction into a variety of topics, especially technology.

Many of the kids can do more with a computer than we can. They can tell you what to do. The first time I was working with hyperlinks (a TechSteps objective) I was able to get it right about half the time. There was a student in the class that really knew how to do it so I had him help as well. He was almost done with the project, so I had him go around and help people. I could watch him and learn how to create the links.

By recognizing the insight and assistance students can provide, Steve appeared to be reassessing his image of the teacher as the "one who knows all." Despite being influenced by two teachers who both stressed the need for the educator to "take command of the classroom," Steve indicated that to better serve his students he would need to create a space for his students to serve themselves. Like Katie, his reconstructed narrative, concerning implementing a mandate, supports the notion that identity development is an ongoing process (see Gee, 1991).

Steve provided a coda to his narrative concerning his experience with implementing a mandate prior to the NxG CSOs. He simply stated, "We don't have to do that (TechSteps) anymore, it has been phased out!" Steve's coda connected an experience from the past to his 
TEACHING WITHOUT A NET

present situation; as one mandate is being phased out, a new mandate is often being implemented; thus, implementing the NxG CSOs for Social Studies was the focus of story 5.

\section{Story 5: NxG CSOs for Social Studies}

Stories 1-4 explored events prior to the 2012-2013 school year. These narratives were elicited because they provided insight into how the participants interpreted, implemented, and reflected on various changes in their respective teaching careers and how these narratives influenced their current professional practice and identity. Like stories 1-4, story 5 was also set in the past; however, story 5 focused on the 2012-2013 school year. For WV $7^{\text {th }}$ grade social studies teachers, the 2012-2013 school year was particularly interesting because the mandated NxG CSOs completely altered the $7^{\text {th }}$ grade social studies curriculum. This school year provided the impetus for the overarching questions which guided the research project. To gain some degree of understanding into how teachers engaged as developers of curriculum when curriculum change was mandated, at least for this project, the 2012-2013 school year needed to be reconstructed.

In reconstructing the events of the 2012-2013 school year, all the participants oriented their narratives within a $7^{\text {th }}$ grade social studies classroom setting. Thematically, relationships and taking the initiative/demonstrating agency emerged from the participants' reconstructed narratives. All the participants were able to resolve the complicating actions

created by the NxG mandate. However, Katie and Steve found themselves in unique situations which greatly impacted their resolutions while Trina and Jesse constructed similar narratives when discussing their respective resolutions.

By the conclusion of the 2011-2012 school year all the participants were informed, by their individual building principals, that the 2012-2013 school would commence with new 
TEACHING WITHOUT A NET

social studies standards and objectives. Katie, Steve, and Jesse were informed verbally, by their respective administrators, of the move from the $21^{\text {st }}$ CCSOs to the NxG CSOs while Trina's administrator printed her a copy of the new standards. Although the participants were all aware of the termination of the $21^{\text {st }}$ CCSOs and the adoption of the NxG CSOs, they varied in their understanding of why the changes were mandated by state administrators and the WV legislature. Fullan (2001) maintains that knowing "why" a change has been mandated is just as important as knowing "how" to implement the mandate. Trina had perhaps the greatest grasp on the precipitating factors leading to the change.

It was my understanding or it was explained to us, while I was on the Common Core committee, that WV was not going to be last, we were going to be one of the first states in the nation to implement this endeavor (Common Core). So, ready or not here it comes!

Like Trina, Jesse indicated that the Common Core movement precipitated the adoption of the NxG CSOs. However, his response revealed a touch of apprehension as to why state officials mandated the change.

I was never given the information, but I think that it related to Common Core and to make the curriculum more in-tune with what other parts of the country were doing. Sixth grade and seventh grade were similar (regarding social studies content in WV under the $21^{\text {st }} \mathrm{CCSO}$ ), but I think it was mainly about all the states getting on the same page.

Katie indicated that she was not informed nor did she inquire into the motivation behind the NxG CSO mandate. Steve also admitted not knowing why the change was mandated; however, he indicated that it was something he had thought about.

I've thought about it, but I've never asked why. Sixth grade social studies was always the world and it was similar to World Geography. But, I don't know why. They want me to teach this and I am able to do it. My degree says that I can teach any type of social studies. 
TEACHING WITHOUT A NET

Although none of my participants were aware beforehand of the imminent changes to their curriculum, 19 WV social studies teachers served as external education consultants for the development of the NxG CSOs (Next Generation, 2012). Of the participants, Trina had the earliest introduction to the pending changes. This may explain why she was more attuned to the reasoning behind the mandate, yet she was not fully aware of the curriculum changes precipitated by the NxG CSOs for social studies.

My principal had been informed that the CSOs would be changing, the state was going Common Core. Six of us from the school went to a training; two English teachers, two math teachers, a science teacher, and I was the social studies teacher. The team then came back to the school and we would tell them (the faculty) what the differences were and what the changes were going to be as far as Common Core. We had professional days in the afternoon to discuss the changes with the faculty. We were not told that the specific social studies curriculum might be changing, we were just informed about the additional literacy components.

Unbeknownst to the participants (and this researcher), the WVBOE filed a notice with the WV Secretary of State's office in January of 2012 indicating a proposed change to repeal and replace Policy 2520.4 ( $21^{\text {st }}$ CCSOs for Social Studies). In the notice, the WVBOE stated that the proposed changes were "being recommended due to the adoption of and alignment with the Common Core Standards for English/Language Arts and Literacy in History/Social Studies, Science and Technical subjects, as well as to create a more developmentally appropriate alignment across all pragmatic levels" (Next Generation, 2012). A month long, statewide comment period, devoted to the proposed repeal of the $21^{\text {st }}$ CCSOs and the pending adoption of the NxG CSOs, followed with only 9 teachers submitting questions, concerns, or comments.

The submitted queries pertained to various components of the proposed $\mathrm{NxG}$ mandate; however, the first entry, submitted by a high school teacher, inquired as to why the WVDE planned to alter the $7^{\text {th }}$ grade curriculum in such a way as to make it almost identical to 


\section{TEACHING WITHOUT A NET}

the $9^{\text {th }}$ grade social studies curriculum. The WVDE response did not directly address the question, but indicated that the study of geography (which had been the focus of $7^{\text {th }}$ grade social studies) was still incorporated within the K-12 social studies curriculum (Next Generation, 2012). Another inquiring teacher stated that he found the "lack of publicity surrounding the $\mathrm{NxG}$ CSOs for Social Studies disturbing" with the situation leaving him with the feeling that the mandate was being "sneaked" in (Next Generation, 2012). Based on the latter comment, Trina, Katie, Steve, and Jesse may not have been the only teachers surprised to the NxG mandate.

The content change became apparent as Trina began to prepare for the 2012-2013.

Despite having the summer months to prepare, Trina encountered numerous complicating actions as the 2012-2013 school year unfolded.

Working over the summer helped and having been informed about the inclusion of the literacy standards prior to implementation helped...I had a lot of work to do up front, ahead of the students because I had to build the tasks that I wanted the students to do...Personally, the year (2012-2013) was stressful because I was trying to teach material that I was not familiar with and I had few resources to complement my teaching...I found it difficult to incorporate as much writing as they wanted. This was especially difficult for students that struggle with reading and writing.

Being unfamiliar with the content, lacking materials to support her teaching, and attempting to integrate literacy standards into an already precarious understanding of the curriculum created a series of complicating actions for Trina. Issues related to the mandatory implementation of the NxG CSOs continued to crop up even as the 2012-2013 school year neared its conclusion. Trina shared:

I was told to base my instruction on the new standards, but the textbook I had was World Geography and it corresponded to the old standards... There was no common ground, the history component definitely didn't meet, the geography component wasn't great; these were two totally different animals. It was very frustrating for me as well as my students to know that we were going to be learning the Next Gen. material, but that the assessment was still going to be the WESTest which was the old World Geography CSOs. I prepared them the best I could. I said, "Hey, this is going 
TEACHING WITHOUT A NET

to stink, don't expect to have good scores (on the social studies portion of the WESTest). Just do the best you can."

Trina resolved the complicating action created by a lack of resources by going out and locating what she needed. She said, "I was used to having to go out on my own to get what I needed and the library skills didn't hurt. The previous curriculum experience, from other places, didn't hurt." Even though materials/resources were not provided by her county school system, based on prior experience, Trina knew she possessed the ability to locate materials and plan engaging lessons. Based on the circumstances, Trina's resolution to the complicating action created by the disconnect between the $\mathrm{NxG}$ content and the end of the year assessment took on a more somber outlook. She resolved the situation by attempting to prepare her students for the end of the year assessment, but the grim reality of the situation could not be denied ("Hey, this is going to stink..."). Trina succinctly evaluated the year as being "stressful" and "frustrating" (see Table 5).

Table 5 NxG CSOs for Social Studies

\begin{tabular}{|c|c|c|c|c|c|}
\hline Participant & Orientation & $\begin{array}{l}\text { Comp. } \\
\text { Action }\end{array}$ & Evaluation & Resolution & Coda \\
\hline Trina & 7/8 Soc. St. & $\begin{array}{l}\text { Unfamiliar w/ } \\
\text { content, lack } \\
\text { of res., } \\
\text { increased lit. } \\
\text { objective, } \\
\text { testing } \\
\text { discrepancy }\end{array}$ & $\begin{array}{l}\text { Stressful \& } \\
\text { frustrating }\end{array}$ & $\begin{array}{l}\text { Located } \\
\text { materials to } \\
\text { begin building } \\
\text { curriculum }\end{array}$ & \\
\hline Katie & 7/8 Soc. St. & $\begin{array}{l}\text { Unfamiliar w/ } \\
\text { content }\end{array}$ & Overwhelmed & $\begin{array}{l}\text { Did not } \\
\text { implement }\end{array}$ & $\begin{array}{l}\text { Next teacher } \\
\text { can implement }\end{array}$ \\
\hline Steve & 7/8 Soc. St. & $\begin{array}{l}\text { Unfamiliar w/ } \\
\text { content }\end{array}$ & $\begin{array}{l}\text { Jerk the rug } \\
\text { out }\end{array}$ & $\begin{array}{l}\text { Worked w/ } \\
\text { student } \\
\text { teachers }\end{array}$ & $\begin{array}{l}\text { Kept student } \\
\text { teacher ideas }\end{array}$ \\
\hline
\end{tabular}


TEACHING WITHOUT A NET

\begin{tabular}{l|lllll} 
Jesse & $7 / 8$ Soc. St. & $\begin{array}{l}\text { Unfamiliar w/ } \\
\text { content, lack } \\
\text { of res., testing }\end{array}$ & $\begin{array}{l}\text { Not best year } \\
\text { teaching, } \\
\text { tough }\end{array}$ & $\begin{array}{l}\text { Internet \& } \\
\text { other sources } \\
\text { for info. }\end{array}$ & $\begin{array}{l}\text { Build on what } \\
\text { you do right }\end{array}$
\end{tabular}

Although the participants were placed in an extremely difficult situation (e.g., teaching without sufficient resources, content not commensurate to statewide assessment) by local and state level administrators, Jesse's evaluation of the 2012-2013 school year provided evidence of the coupling between his professional practice and identity. His evaluated the year by stating, "I don't think that it was my best year teaching." However, a bit of optimism appeared in his next statement, as he positioned these events for opportunities for learning, "You can build on what you do right, but you can also learn from what you do wrong." Jesse had much to consider as the 2012-2013 school year progressed. His unique schedule (teaching $6^{\text {th }}$, $7^{\text {th }}$, and $8^{\text {th }}$ grade social studies) complicated matters.

It was tough! I went from teaching $6^{\text {th }}$ grade World History and $7^{\text {th }}$ grade World Geography which were very similar to teaching $6^{\text {th }}$ grade US History and $7^{\text {th }}$ grade Ancient Civilizations. I had almost no materials except the limited information I could pull from the old textbooks. I had to basically adopt all new material for both classes. Again, the (new) textbook would not be adopted until the next year. I know that the textbook is just one resource, but the text usually provides resources for instruction and that helps.

Like Trina, Jesse took it upon himself to resolve the complicating action created by

the lack of resources available to actively engage his students. He elaborated:

(I went to) the Internet and past sources... I did a lot of my own planning and incorporated projects, hands-on stuff. The kids made their own study booklets, I would give them a rubric and they would make a booklet on Rome or a monotheist religion. I did a lot of class notes which I usually don't like to do, I like to keep the kids engaged. I printed off information and we would work on highlighting information and note taking skills.

Jesse resolved the day-to-day complicating action of not having sufficient resources by combing the Internet to locate supplemental material, devising projects, or resorting to lecture 
TEACHING WITHOUT A NET

as the primary means to convey information, but the end of the year assessment presented an

exponentially greater complicating action. Like Trina, Jesse wanted his students to score well on the state assessment; however, the disconnect between the content for $7^{\text {th }}$ grade social studies under the NxG CSOs mandate and the content tested by the year-end summative assessment seemed to place, in Jesse's opinion, teachers and students in a no-win situation.

I didn't think it was fair that the kids would be tested on the World Geography CSOs after having worked all year with the NxG CSOs. When the school year started I didn't know if they would have a test ready which reflected the new CSOs. It was presented to us much later in the school year that we would be tested on the old CSOs. It was very stressful for me as a teacher and I felt that the kids were getting cheated. Sometimes when you try too hard you end up over teaching and I think I threw too much at them trying to prepare them for the test. I don't think that it was my best year teaching. You can build on what you do right, but you can also learn from what you do wrong.

Whereas Trina resolved to prepare her students for the WVDE's summative test from a brutally honest perspective ("Told them this is going to stink..."), Jesse attempted to fuse the $21^{\text {st }}$ CCSOs with the NxG CSOs (i.e., the old set of standards with the new set) as the test date approached. Jesse evaluated his resolution by stating that his attempt to fuse the old and new standards only resulted in him "over teaching" and over whelming his students ("I threw too much at them"). Again, Jesse evaluated the entire 2012-2013 school year as not his "best year teaching."

Considering the numerous complicating actions (e.g., working through curriculum change, implementing NxG mandate with limited resources, and addressing standardized test pressure by fusing old and new standards) of the 2012-2013, one can sympathize with Jesse in his assessment. As mentioned previously, an optimistic outlook (“build on what you do right”) permeated Jesse's more somber assessment of the 2012-2013 school year. Jesse's assertion that he planned to build from the curricular foundation, established during the 2012-2013 school 
TEACHING WITHOUT A NET

year, was similar to the perspective he had regarding the Golden Horseshoe Test. In both narratives, Jesse indicated that only through his own initiative would he be able to further develop his skills as an educator and better serve the academic needs of his students.

Realizing that the NxG mandate replaced World Geography with an Ancient Civilizations curricular focus, Steve thought back to his college course work, "In college the ancient world wasn't my favorite class. I always liked US History more than World History." Despite his preference, Steve knew that he needed to re-familiarize himself with the ancient world (a resolution to the complicating action of curriculum change) before the 2012-2013 school year opened. Steve noted that prior to beginning each new school year he reviewed his lesson plans from the previous year, taking stock of what worked and what needed adjustment. This pattern was interpreted by the NxG mandate, Steve did not have his "previous work to reference" in preparation for the 2012-2013 school year. The NxG mandate caught him by surprise, "they suddenly jerk the rug out from under you and you get something new," and additional surprises awaited Steve as the 2012-2013 school year commenced.

Well, I had a student teacher to start the year! The student teacher did an excellent job, but I had nothing to give her so we worked together. If it had been World Geography, I have folders full of resources, but nothing at this point. I didn't have the chapter 1 test made, so this could have been bad.

In reconstructing the opening of the 2012-2013 school year, Steve referred to a student teacher being placed with him. The arrival of a student teacher had the potential to complicate matters further, especially considering that Steve was still trying to make sense of the new mandate himself ("I didn't have the chapter 1 test made."). Although this scenario "could have been bad," Steve and his student teacher worked together (the resolution) to make the situation manageable. Once again, the theme of relationships emerged as a resolution to a complicating action. Steve continued his narrative: 
TEACHING WITHOUT A NET

About halfway through this student teacher's time, I was asked to take another student teacher for the second placement. And I really didn't want to, but I said, "If the principal says it's okay then I will." So, for the first semester, except for about 8 days, they taught. With WV (Studies $/ 8^{\text {th }}$ grade social studies) I was able to give them everything they needed, but with the new curriculum I couldn't. I was able to collaborate with the student teachers to make it work. I was also able to work ahead; I got six chapters and lesson plans outlined for the second semester while the student teachers were teaching. This was a blessing. I was able to find a lot of great ideas. I had basically the entire day to search for materials and familiarize myself with the material. So, when it was time for me to teach I was ready to go. The next year, I used some of the materials that the student teachers created to open the year with.

Although Trina and Jesse discussed the curricular changes precipitated by the NxG mandate with colleagues, they were solely responsible for planning and delivering the $\mathrm{NxG}$ content. Steve, on the other hand, worked through the uncertainties of planning for and delivering the NxG content (complicating action) with a series of collaborators, thus reducing the stress of implementing the mandate. A sense of relief was evident in Steve's evaluation of the situation. He referred to the collaborative atmosphere as a "blessing" and stated that "the impact (of the content change) probably would have been greater if I had not had the two student teachers...they were helpful in gathering materials and getting resources together." The additional support also enabled Steve to plan beyond the current topic of study and outline future areas of inquiry ("I got six chapters and lesson plans outlined"). Steve also alluded to the lasting imprint his student teachers made on his available teaching resources ("I used some of the materials that the student teachers created to open the next year.") and in his coda he stated that he has "kept some of the things (i.e., study guides, unit ideas) that they did." Steve's coda moved beyond "the next school year" and into the present.

Like the other participants, Katie's administrator informed her of the NxG mandate and directed her to the WVDE website for further information. Katie stated:

I was told that I could find the new CSOs on the state department website. This 
TEACHING WITHOUT A NET

would have been near the end of the 2011-2012 school year. I didn't hear anything else from my principal or the county social studies coordinator about the new CSOs... I was really overwhelmed by the changes... it seemed like they were throwing a lot of information at us at once. This probably shouldn't have surprised me because, like I said earlier, it seemed like every time the state wanted new objectives put into the classroom the process was never smooth. There was always confusion about when to implement and how.

Similar to the narratives shared by the other participants, Katie's reconstructed narrative contained a complicating action in the form of the $\mathrm{NxG}$ mandate. The inclusion of extensive literacy standards and the complete alteration of the $7^{\text {th }}$ grade content "overwhelmed" Katie. However, Katie's resolution to the complicating action created by the NxG mandate differed significantly from the resolutions of the other participants. Whereas the other participants struggled to teach unfamiliar content with limited resources, Katie decided to continue to teach the $21^{\text {st }}$ CCSOs and the World Geography content.

It (the curriculum) was not going to change for me!...I knew going into the 20122013 school year that I was probably starting my final year in the classroom. I was going to finish out my way! We didn't have a textbook, so I thought, "The person coming in after me can start with the new material"...I taught the World Geography content, so I had all of my resources and units ready to go. But, as it turned out, the 2012-2013 school year was without a doubt my most difficult year in the classroom.

Katie indicated that her resolution, not to implement the $\mathrm{NxG}$ mandate, did not raise any concerns from her administrator or county level supervisors. Katie found, after 40 years in public education, that both teachers and administrators often struggle to make sense of new mandates. She stated, "Typically, the new objectives were just set in front of us without any explanation as to how to implement the objectives." The confusion Katie had experienced, over her 40-year career, implementing new objectives coalesced with thoughts of retirement, and her enjoyment of the World Geography content. This triad of factors led her to the decision not to implement the NxG mandate. Despite having ample teaching resources and being confident in 
TEACHING WITHOUT A NET

her ability to teach the World Geography content, Katie still struggled through the 2012-2013

school year.

This was a class that I had heard about since they were in $5^{\text {th }}$ grade. You know, a group where the teachers say, "Wait till you get this group!" Don't get me wrong there were some great kids in the class and my $2^{\text {nd }}$ period that year was outstanding but overall it was just a struggle...It was just one continuous discipline problem. I had never had so many students, in one grade, that were disrespectful to me and each other. Of course I started teaching in another era when the teacher was respected by most of the students and the community... This only finalized, in my mind, my desire to retire. I remember that we had a snow delay day in January and I got up that morning and typed up my retirement letter. On my way to school I dropped it off at the board office. I retired at the end of the 2012-2013 school year.

Katie readily admitted that even before the 2012-2013 school year commenced she was seriously contemplating retirement. Like the participants in Hargreaves' (2005) study, Katie had reached a stage in her career, with retirement looming, which rendered her resistant to mandatory change. Also, impacting her decision was her strong attachment to the World Geography curriculum. She had witnessed numerous curriculum and objective change efforts over her career and found that "there was always confusion about when to implement and how." Perhaps, Katie's years of experience had also informed her not to expect much if any follow-up from administrative personnel regarding the implementation process. Therefore, deciding not to implement would not carry any penalty or consequence. Trina, Jesse, and Steve opted to implement the NxG mandate, but with some reservations. In this way, they seem to mirror the middle stage career teachers in Hargreaves' study; proceeding with implementation, but not with the enthusiasm of an early stage teacher. Regardless of career stage, McLaughlin (1976) posits that classroom teachers have agency over how objectives will be presented in the classroom. McLaughlin's assertion is supported by the stories shared by Trina, Katie, Steve, and Jesse regarding their decisions to implement or not implement the NxG mandate. 
TEACHING WITHOUT A NET

Trina and Jesse shared similar storylines; both realized that to engage their students they would need to become familiar with the content and take the initiative in locating suitable supplementary resources. Steve also spoke of the need to re-familiarize himself with the ancient world content; however, unlike Trina and Jesse, Steve was able to collaborate (the relational) with two student teachers (perhaps resembling the enthusiastic early career teachers from Hargreaves' study). Steve stated that the collaboration was a "blessing," greatly reducing the stress of implementing the new curriculum. Yet, Steve agreed with the other participants that the 2012-2013 school year was, professionally, one of great travail because the NxG mandate created numerous complicating actions for the participants (e.g., teaching unfamiliar material without supplementary resources, incorporation of increased writing objectives, summative assessment not commensurate to material taught). Of course, the aforementioned complicating actions related primarily to "how" to implement the mandate, but the participant's narratives, especially Steve's, stressed a lack of understanding as to the necessity (or "why") of the mandate. Fullan (2001) noted that a philosophical/theoretical understanding ("why") of a mandate is of equal importance to "how" one should implement the change. Just as with story 5, the 2012-2013 school year served as the reference point for story 6 .

\section{Story 6: Bridging the Past and Present}

Whereas stories 1-5 focused primarily on the past, story 6 served as a bridge between the past and the present. The participants were asked to reconstruct the 2012-2013 school year and think about how this school year impacted them as educators. Story 6 related to the second overarching question guiding this research project: In what ways did the participants' stories about implementing a mandated change impact their professional identities? 
TEACHING WITHOUT A NET

As with story 5 , all the participants oriented their reconstructed narratives within a $7^{\text {th }}$ grade social studies classroom and all used words like "stressful," "frustrating," and "sudden change" in their evaluations of the 2012-2013 school year. Yet, for Trina, Steve, and Jesse the experience of working through mandatory curriculum change reminded them that they possessed the abilities and the accumulated knowledge to not only survive, but to also be creative within their uncertainty. In this way, the participants reconstructed narratives supported the assertion by Nolan and Meister (2000) that ambiguous external initiatives can lead to moments of creative thought. Trina, Steve, and Jesse recognized that with no direction forthcoming from county and state administrators, they would need to initiate creative solutions to the $\mathrm{NxG}$ complicating action. The participant's reflections on the 2012-2013 school and their resolutions to the complicating actions are presented in the following paragraphs (see also Table 6).

Table 6

Bridging the Past and Present

\begin{tabular}{|c|c|c|c|c|c|}
\hline Participant & Orientation & $\begin{array}{l}\text { Comp. } \\
\text { Action }\end{array}$ & Evaluation & Resolution & Coda \\
\hline Trina & 7/8 Soc. St. & $\begin{array}{l}\text { Implementing } \\
\text { NxG CSOs }\end{array}$ & $\begin{array}{l}\text { Stressful, } \\
\text { frustrating }\end{array}$ & $\begin{array}{l}\text { Move forward, } \\
\text { build from } \\
2012-2013\end{array}$ & $\begin{array}{l}\text { Will find the } \\
\text { resources to } \\
\text { make it work }\end{array}$ \\
\hline Katie & 7/8 Soc. St. & $\begin{array}{l}\text { Test pressure, } \\
\text { societal } \\
\text { changes }\end{array}$ & Just too much & Retirement & $\begin{array}{l}\text { Teacher } \\
\text { flexible \& } \\
\text { knowledgeable }\end{array}$ \\
\hline Steve & 7/8 Soc. St. & $\begin{array}{l}\text { Implementing } \\
\text { NxG CSOs }\end{array}$ & $\begin{array}{l}\text { Sudden } \\
\text { change }\end{array}$ & $\begin{array}{l}\text { Utilized the } \\
\text { Internet }\end{array}$ & $\begin{array}{l}\text { Energizing, } \\
\text { new \& } \\
\text { exciting }\end{array}$ \\
\hline Jesse & 7/8 Soc. St. & $\begin{array}{l}\text { Implementing } \\
\text { NxG CSOs }\end{array}$ & Tough & $\begin{array}{l}\text { Move forward, } \\
\text { find resources }\end{array}$ & $\begin{array}{l}\text { A jump start, } \\
\text { broadened } \\
\text { horizons }\end{array}$ \\
\hline
\end{tabular}


TEACHING WITHOUT A NET

In reflecting on the 2012-2013 school year, Trina applied both a short and long term

perspective to the $\mathrm{NxG}$ implementation process. In the short term, implementing the required mandate created a stressful situation which resulted in Trina doubting her abilities and her knowledge. However, from a long-term perspective, the 2012-2013 school year created a curricular base from which Trina might build in the ensuing years. Trina stated, "Of course everything is a hassle when you are first learning it, but you learn as you go." Despite the stress and uncertainty of the 2012-2013 school year, Trina resolved to move forward with the understanding that her work as an educator will never be fully complete.

I know what I am teaching now and I'm still adding to it. As I've become more familiar with the material I have thought of other ways to present the content. Give me some time and I'll put lessons together, just don't pull the rug out from under me! (laughs)...I continue to learn and I continue to apply for grants to attend the National Endowment for the Humanities workshops. I am fortunate to have been a recipient of grant opportunities. I recently applied for two and I hope to get one of them. I bring these learning experiences to my classroom...I'm eligible to retire in two years, but right now I'm not planning on retiring because I am not ready to go yet.

Like Trina, Steve also applied a variation of the idiom "to pull the rug out" when describing how he felt about the way state and county administrators handled the inception of the NxG CSOs, especially for $7^{\text {th }}$ grade social studies teachers. He stated, “And then they suddenly jerk the rug out from under you and you get something new." Steve elaborated further, "No one likes, after 8 or 9 years of (teaching) geography, a sudden change." Thus, Steve was not deterred from resolving to engage his students in a study of the ancient world, despite the abrupt nature of the $\mathrm{NxG}$ implementation process.

Sometimes teachers rely too much on the textbook and without it you are forced to expand outside. I did more computer based work that year, we went to the labs to research because we didn't have a book. Thankfully, scheduling time in a computer lab is not a problem here, we have 4 different labs and a mobile laptop lab. I definitely spent more time in the lab than in previous years. 
TEACHING WITHOUT A NET

The resolutions expressed by Trina and Steve, regarding assuming greater agency

over supplementary curricular resources out of necessity, resounded with Jesse. He stated:

We were really on our own. I think teachers did their own thing. Counties may have handled it differently. Unless you had someone at the county level who was able to coordinate it, then teachers were really on their own. There really wasn't any help from the state.

Jesse's statement that teachers, especially those teaching $7^{\text {th }}$ grade social studies, “did their own thing" during the 2012-2013 school year was also supported in Katie's narrative. Whether intentional or not, $7^{\text {th }}$ grade social studies teachers were afforded a heightened level of autonomy; they could proceed under their own volition. Katie elected to go in one direction while Jesse, Trina, and Steve elected to go in another. Regardless of the direction one chose to take, the experience reminded Jesse, as it did Trina and Steve, that classroom teachers must resolve to exercise greater agency over making decisions about the materials they will employ to support the CSOs created by state administrators.

It made me realize that you have to prepare for the unexpected, you can't depend on stuff being there for you. You have to go out and find it. It's like the Golden Horseshoe test, it's such a wide ranging test that you cannot give the kids one study guide. You have to go out and find the best resources. Once you have resources you can guide the students and then they have to do something with it. Every year I learn something different, so I'm still learning.

As previously mentioned, Katie elected not to implement the NxG mandate. From a curriculum standpoint, the 2012-2013 school year did not pose a problem for Katie. She possessed a keen interest in the World Geography curriculum and found it "so now, in the present, and very relatable." However, for Katie the 2012-2013 school year reminded her that the work of the teacher goes beyond merely engaging students in an area of study. Standardized test pressure and societal factors were, in Katie's view, exerting an increasing influence over the function of public education. 
TEACHING WITHOUT A NET

We were required as teachers to show improvement on test scores on the state assessment from the previous year to the current year, but the major focus was on the bottom $25 \%$ to see improvement. So therefore, I was basically required to meet the needs of the bottom of the scores rather than those that were at mastery or above. It seemed like a movement to the middle...Over my career, I worked with students from different income levels, and different academic needs, and I had minor discipline issues, but nothing like that last year...[W]e had parents that couldn't keep up with their kid's medications or just wouldn't keep up with them. There were so many emotional issues with some of the kids that it was just too much. This only finalized, in my mind, my desire to retire.

Katie evaluated her situation in the classroom as becoming "just too much" due to the aforementioned complicating actions. She resolved the situation by retiring at the conclusion of the 2012-2013 school year, which provided a coda to her narrative, connecting the events of the 2012-2013 school year to her present situation.

I continue to read and have a great interest in self learning. I don't see retirement as a time to just sit around. I'm still physically and mentally active. I have a grandson, who is in the $7^{\text {th }}$ grade, and I enjoy talking to him about his school subjects, especially social studies. He will ask me, "Grammie, how do you know so much about Feudal Japan?" And I tell him that, "Grammie spent a long time in the classroom."

As indicated by their reconstructed narratives, the events of the 2012-2013 school year impacted Katie differently than Trina, Steve, and Jesse. Although she did not implement the NxG mandate, the events of the 2012-2013 school year reinforced the notion that an educator's professional identity goes beyond the realm of content specialist. Like Frank McCourt (2005), Katie found herself assuming an ever-increasing number of roles within the classroom partially due, in her opinion, to standardized testing pressures and societal changes. "The teacher of today," stated Katie, "must be prepared for changes, changes in society and technology seem to be happening so much more rapid these days. I guess the teacher must be flexible in addition to knowledgeable." 
TEACHING WITHOUT A NET

As previously stated, Trina, Steve, and Jesse elected to implement the mandate. As a result of working through mandatory curriculum change, these participants confided that the experience was far from hassle free, but it did open a space for them to assume a greater degree of agency over the selection of resources and the presentation of content. Steve indicated that the experience energized him because the change was "something new and kind of exciting." Similarly, Jesse stated that the experience "jump started" him and challenged him to broaden his horizons. Confidently, Trina asserted that, if given the subject, she would find her "own stuff (resources) to make it work." The respective narratives of Trina, Steve, and Jesse indicated that working through mandatory curriculum change impacted the way they viewed themselves as developers of curriculum. The situation created by the NxG mandate allowed the participants to look "internally on their own practices" (Zeichner and Liston, 1996, p. 19) and move forward despite the fact they were "teaching without a net."

\section{Story 7: Moving Forward}

Story 7 , like story 6 , had its impetus in the second guiding question. Although I was primarily interested in how each participant viewed him/herself as a social studies educator (identity related), the nature of our conversations led to narratives related to the general purpose of social studies education and how the field is understood by those at the state administrative level. For the final story, the orientation of the participants' narratives extended beyond their specific teaching assignments to an overarching view of social studies education.

When asked, what does it mean to be a social studies teacher, Trina, Steve, and Jesse all initially responded with some variation of the aphorism, "Those who do not learn history are doomed to repeat it." Yet, this oft repeated phrase gave way to additional ideas, moving the educator from a dispenser of historical knowledge to one encouraging civic/community 
TEACHING WITHOUT A NET

engagement, cultural diversity, and critical thinking/problem solving skills in the classroom.

What follows is a compilation of views from all of my participants.

It's how we got where we are. It's the mistakes we made and the lessons learned, it's having them (students) look to the future and think about how they can make a difference. It's more than history and geography, it's social interaction- how we interact with everything (Trina)...Life skills, work ethic, how to treat others, how to go beyond what you are capable of these are the things I hope to instill. I try to come up with assignments where the kids go beyond what they think they are capable of. That's my whole thing, getting the kids to realize that they are capable of more (Jesse)...I think it is important for people to know where they came from, for them to know what their past was about- the past of the state, nation, or culture (Steve)...As a social studies teacher the world is at your fingertips, we are living social studies everyday. Social studies can help us make global connections and better understand other cultures. It can help us become more tolerant people (Katie).

Based on their narratives, the participants indicated that the identity of the social studies teacher is multifaceted and the benefits of social studies education extend well beyond the student's formative years. Yet, despite the potential benefits for the individual and society, the participants suggested that K-12 social studies education is being relegated to a secondary role with reading/language arts, mathematics, and the sciences prioritized as the focus for curricula. The adoption of the NxG Social Studies Standards, precipitated by the Common Core Sate Standards movement, by the WVBOE, WVDE, and the WV Legislature perhaps contributed to this feeling of secondary status among social studies educators. Jesse shared his perspective on how policy makers view social studies education.

I don't want to say that they (policy makers) don't look at it as important, but right now the focus is on language arts, math, and science. I'm not sure that they (policy makers) have a grasp on how important social studies is to the other core subjects. Maybe they do and I'm just not seeing it. I don't think that social studies should be just swept aside or encompassed in another area like language arts...It (the $\mathrm{NxG}$ mandate) now puts social studies teachers in a situation where we are also Language Arts teachers. We have to start looking at ourselves differently.

Trina concurred with her belief that the state level decision not to require a cumulative assessment for social studies has fostered a message of lesser curricular importance. 
TEACHING WITHOUT A NET

Granted, Trina spoke of her frustration with the end of the year assessment in story 5; however, in that particular narrative the test and the material taught were not commensurate. Trina explained further:

Some of the ideas being bandied about with regard to standardized testing have left out social studies. So, does that mean that social studies is not important? It's not that I particularly want the test pressure, but to be totally left out of the process just doesn't bode well.

The trend to not include a cumulative assessment to measure a student's yearly progress in social studies is not a new development. Over a decade ago, No Child Left Behind required "assessments only in the areas of reading/language arts, math, and science" with states having the discretion to test other subject areas (US Department of Education, 2004). Under NCLB, the WVDE implemented a yearly assessment for social studies. This assessment remained in usage until the $2014-2015$ school year; thereby, requiring $7^{\text {th }}$ grade social studies teachers to endure two years of a lack of continuity between material taught and that which was tested. Since transitioning to the Common Core State Standards and Smarter Balance standardized testing, a state level cumulative test in social studies has not been mandated (see also Table 7).

Table 7

Moving Forward

\begin{tabular}{|c|c|c|c|c|c|}
\hline Participant & Orientation & $\begin{array}{l}\text { Comp. } \\
\text { Action }\end{array}$ & Evaluation & Resolution & Coda \\
\hline Trina & 7/8 Soc. St. & $\begin{array}{l}\text { Soc. St. } \\
\text { Education }\end{array}$ & $\begin{array}{l}\text { Secondary } \\
\text { importance }\end{array}$ & $\begin{array}{l}\text { Doesn't bode } \\
\text { well }\end{array}$ & $\begin{array}{l}\text { Will continue } \\
\text { to engage } \\
\text { students }\end{array}$ \\
\hline Steve & 7/8 Soc. St. & $\begin{array}{l}\text { Soc. St. } \\
\text { Education }\end{array}$ & $\begin{array}{l}\text { Secondary } \\
\text { importance }\end{array}$ & $\begin{array}{l}\text { Test/No test- } \\
\text { still important }\end{array}$ & $\begin{array}{l}\text { Will continue } \\
\text { to engage } \\
\text { students }\end{array}$ \\
\hline
\end{tabular}


TEACHING WITHOUT A NET

\begin{tabular}{l|lllll} 
Jesse & $7 / 8$ Soc. St. & $\begin{array}{l}\text { Soc. St. } \\
\text { Education }\end{array}$ & $\begin{array}{l}\text { Secondary } \\
\text { importance }\end{array}$ & $\begin{array}{l}\text { Look at } \\
\text { ourselves } \\
\text { differently }\end{array}$ & $\begin{array}{l}\text { Make effort to } \\
\text { incorp. Lang. } \\
\text { Arts }\end{array}$ \\
& & & & \\
& & &
\end{tabular}

Steve also interpreted the absence of a state wide cumulative assessment as an indicator that social studies is of lesser curricular importance. However, according to him, the absence or appearance of a yearly standardized test is of little consequence to how he approaches the content.

The fact that they (state level administrators) are not testing social studies does not change the way I approach the class. I treat it (social studies) like it is the most important subject... They may not want to test it anymore, but it will always be important to me.

The assertion that recent trends (e.g., Common Core State Standards) have left social studies educators with the feeling that they are "on the outside looking in" (Hermeling, 2013, p. 51) is supported by the reconstructed narratives of my participants. Despite feelings of being relegated, by policy makers, to secondary status, Trina, Katie, Steve, and Jesse all indicated a strong commitment to the field and acknowledged its multifaceted nature. Common Core heightened the multifaceted nature of the field by emphasizing non-fiction literacy standards within the social studies curriculum. Jesse's claim that he and his colleagues in the field need to "start looking at ourselves differently" seems appropriate considering this recent development. Although the Common Core movement provided educators with an opportunity to reassess their values, beliefs, and assumptions, Zichner and Liston (1996) insist that educators should continually engage in the process of re-evaluation. They advise educators to "reflect internally on their own practice and externally on the social conditions of their practice" (p. 19). Jesse's 
TEACHING WITHOUT A NET

statement ("start looking at ourselves differently") indicated that he is reflecting on his own practice and, in the process, reshaping his professional identity.

\section{Summary}

A "layered approach" (Johnson, 2011, p. 56), comprised of structural and thematic elements, informed the data analysis of the participants' interview transcripts. Through the application of a structural analytic approach the contours in the participant's reconstructed narratives of events occurring before and during the 2012-2013 school year were revealed. The contours or "peaks and valleys" (Reisman, 2008, p. 78) coincided with six elements developed by Labov and Waletsky (1967): abstract, orientation, complicating action, evaluation, resolution, and coda. Reisman (2008, p. 84) likened the six elements to the figures in a musical composition for each hold "an account together, enabling a listener to follow it and determine what is most important." Considering Reisman's use of geographic terminology (i.e., contours, peaks and valleys) a comparison to an elevation profile seems appropriate. Just as an elevation profile allows one to closely view elevation changes across a particular line of latitude or longitude, Labov and Waletsky's elements allowed for the closer inspection of how each of the participants worked their way through various complicating actions.

Thematic analysis represented the second analytic layer of the project. Whereas the sequence of a participant's narrative was the focus of structural analysis, for thematic analysis the content of the narrative became the focus. Reissman $(2008$, p. 77$)$ posits that with thematic analysis the focus shifts from the "telling" to the "told." Simultaneously, the participants sequenced their narratives while verbally sharing their thoughts in response to various openended and follow-up questions. The narratives, structured in a particular manner, began to reveal 
TEACHING WITHOUT A NET

themes (sometimes referred to as patterns or resonant threads) (Patton, 2002; Reissman, 2008;

Clandinin, 2013).

The theme of relationships was interwoven throughout the shared reconstructed narratives. From story 1, with the participants describing the various individuals that influenced their respective decisions to become teachers, to story 7 , where the participants spoke of their understandings of social studies education, my participants acknowledged the presence of other individuals and institutional practices in their professional lives. These components, other individuals and institutional practices, are part of what Gergen (1991, p. 61) refers to as the "swirling sea of social relationships." From a social constructivist perspective, it is within this "swirling sea" that identity shifts occur and knowledge is formed.

Although the participants acknowledged relational elements in their professional lives, their reconstructed narratives also indicated the necessity to take the initiative/demonstrate agency to resolve complicating actions. This thematic element was not only evident in story 5 (where the participants directly addressed working through the $\mathrm{NxG}$ mandate), but resounded throughout the reconstructed narratives. From working with unfamiliar content (e.g., Trina teaching broadcast journalism, Steve and Jesse supervising ISS) to implementing mandates prior to NxG (e.g., Katie implementing TechSteps), all of my participants shared stories related to taking the initiative/demonstrating agency in order to meet the requirements of their respective teaching positions. Outside administrative agencies may issue mandates, like the implementation of grade level objectives, but McLaughlin (1976) posits that teachers have space to determine how required mandates will be brought to fruition in the classroom. Whether utilizing commercially produced products or developing supplemental materials from scratch, 
TEACHING WITHOUT A NET

"local material development" (p. 191) can heighten the educator's sense of ownership of the curriculum.

Although conditions, like those described by Apple (1986), exist where "prespecified procedures" (p. 199) are delineated to teachers, for my participants, the opposite was often the case. Based on their reconstructed narratives, my participants indicated that mandates were often presented with minimal direction regarding implementation. The "Here it is, now go do it!" approach to implementation neglected the "how" and "why" (see Fullan, 2001) components of the initiative, creating feelings of uncertainty among the participants. Although initially uncertain about how to proceed, the participants often began to view their respective situations as challenges that could be overcome. Their resolutions to the situations or complicating actions involved seeking colleague advice (relationships) and moving forward under their own volition (taking the initiative/demonstrating agency). Once the uncertainty of the situation subsided, the participants found that they could work productively within the space generated by the ambiguous change effort. The identified themes (uncertainty, challenges, relationships, and taking the initiative/demonstrating agency) along with the two guiding questions gave rise to two theoretical points. The theoretical points of these findings are discussed in Chapter 5. 
TEACHING WITHOUT A NET

\section{Chapter 5: Conclusions \& Implications}

Unlike quantitative researchers, individuals approaching a research topic from a qualitative perspective do not view the collected data as a means to verify (or refute)

preconceived theories. Instead, qualitative researchers theorize after the data has been collected and analyzed (Patton, 2002; Gay et al., 2009). Because many qualitative studies have a small sample size, the theory generated by qualitative researchers may not be generalizable to all members of a population. However, Patton (2002) contends that "one can learn a great deal" from theory derived by qualitative means and that "new territory for further research" could emerge (p. 46). Thus, the aim of this chapter was not to generalize the findings to the entire population of $\mathrm{WV} 7^{\text {th }}$ grade social studies teachers, but to offer a temporal interpretation of the data and discuss 2 theoretical points. In addition, thoughts pertaining to the burdensome nature of excessive mandates and questions for further research are also presented.

The first theoretical point, Local, state, and national policy makers cannot take curriculum change lightly, nor can they assume that teaching experience is all that is necessary for successful implementation, addresses the intricate connections among the stance(s) taken by policy-makers and the expectations for the enactment of those policies. By introducing the NxG CSOs for Social Studies with little fanfare the WVBOE and WVDE shifted the responsibility of implementation firmly into the hands of local administrators and teachers. Commenting on the transition from development to implementation, Jesse stated, "Unless you had someone at the county level who was able to coordinate it, then teachers were really on their own." The sentiment expressed by Jesse, and corroborated by the teacher cited in story 5 , may encompass the feelings of many local administrators and teachers with regard to implementing the $\mathrm{NxG}$ CSOs for Social Studies. The four participants, in this study, all indicated they experienced a 
TEACHING WITHOUT A NET

sense of uncertainty as they prepared to implement the NxG mandate. The teachers in this study experienced the complete alteration of their content, were required to implement the policy without sufficient resources, and decide how to incorporate a greater language arts emphasis into the social studies curriculum.

Given the situation, one senses that the participants (and perhaps other $7^{\text {th }}$ grade $\mathrm{WV}$ social studies teachers) were "teaching without a net." Of course, any change effort often produces feelings of uncertainty, simply because there is a movement from the familiar to the unfamiliar. Even under the most ideal conditions "reform environments bring frustration and adversity" (Hargreaves and Shirley, 2009, p. 74, see also Maris, 1975, cited in Fullan, 2001; Nolan and Meister, 2000). Although feelings of uncertainty are a natural response to change efforts, measures should be in place which acknowledge uncertainty, but also encourage implementers to move forward. The "Here it is, now go do it!" approach was not effective, at least for the participants in this study, in minimizing their feelings of uncertainty nor have researchers found the "tightening grip of government control" (Hargreaves and Shirley, 2009, p. 71) to be particularly effective.

Steve, perhaps, best summarized the mindset behind the "Here it is, now go do it!" approach when he said, "If they (WVDE) want me to teach this (Ancient Civilizations) then I will...My degree says that I can teach any type of social studies." The assumption, on the part of policy makers, that teaching experience and proper certification will ensure full implementation of a mandate is erroneous. The work of Hargreaves (2005) supports this notion. Veteran teachers, Hargreaves contends, are perhaps more resistant to educational change due in part to the number of, at best, partially implemented mandates they have witnessed over the course of their careers. Further support of this notion is found in Katie's narrative. Although she indicated 
TEACHING WITHOUT A NET

that her pending retirement greatly influenced her approach to the 2012-2013 school year, Katie, nonetheless, did not implement the $\mathrm{NxG}$ mandate despite over 4 decades of teaching experience in social studies education, possessing a permanent WV teaching certificate, and having earned a master's degree. Katie stated, "It seemed like every time the state wanted new objectives put into the classroom the process was never smooth. There was always confusion about when to implement and how."

Whereas critique is easy, offering plausible solutions is a more difficult endeavor. Simple solutions to any change effort are not readily available; however, it does seem that thorough communication among all stakeholders is a step in the right direction to ease the uncertainty associated with any change effort. Fullan (2001), among others (see Ch. 2), supports this claim. Implementers, according to Fullan, must not only understand "how" to bring a particular change to fruition, but they must also understand "why" they are being encouraged (or required) to proceed in a certain direction. The "how" components of a change effort relate to external features (e.g., the employment of certain resources and materials, sequencing of content) while the "why" components relate more to the internal processing of the individual (e.g., values, beliefs, and assumptions). Optimally, "how to get things done" should be preceded by "why to get things done" (Cochran-Smith and Lytle, 2009, p. 121).

For the participants, the "how" and "why" components of the change effort were not initially aligned. All of the participants indicated that they felt a sense of uncertainty with regard to how they would initially implement the NxG CSOs and only Trina expressed any certainty as to "why" the mandatory changes were necessary. Opportunities for continuous, open communication, which extend beyond one-off training sessions and directorial emails, can facilitate the aligning of the "how" and "why" components of a change effort. Hargreaves and 
TEACHING WITHOUT A NET

Shirley (2009) maintain that when stakeholders continuously communicate they generate a "sense of common purpose and shared responsibility" (p. 101). Although not an exhaustive list, it does seem that all stakeholders working with an educational change effort should consider the following: resources needed for implementation, the duration and extent of follow-up training sessions, the impact of the effort on student learning, and how to best align the "how" and "why" component of the change effort. The "Here it is, now go do it!" approach to change does not facilitate a sense of unity, but only fosters feelings of uncertainty and isolation. Open communication among and between stakeholders will not only benefit educational practice and perhaps ease educator uncertainty but, "enrich and edify academic debate" (Gergen, 1991, p. xi) because policy makers and community members will have an opportunity to gain a better understanding of content, pedagogy, and learning environments.

Erroneous assumptions and limited opportunities for discussion may heighten the sense of uncertainty associated with educational change; however, these same impediments could become an asset for the implementer rather than a liability. Hargreaves and Shirley (2009) encourage educators to redefine impediments "as challenges that can be overcome or opportunities to improve" (p. 74). Therefore, "teaching without a net" has the potential to empower educators to assume greater agency over their respective classrooms.

Whether intended or not, by state administrative educational agencies, the absence of a "roll out" for the NxG Social Studies Standards provided opportunities for Trina, Steve, and Jesse to act independently, to assert their creativity, and decide for themselves how they would implement the required mandate. As previously discussed, the "Here it is, now go do it!" approach engendered a sense of uncertainty for all the participants; however, the debilitating effects of the situation began to subside for Trina, Steve, and Jesse as they spent time "grappling 
TEACHING WITHOUT A NET

with possibilities" (Senechal, 2015, p. 7). It was during this time, of "grappling with possibilities", that Trina, Steve, and Jesse began to view the situation as a challenge (or complicating action) in need of a resolution. As the participants were "grappling with possibilities" they were, according to Labov (1972), resolving the complicating action precipitated by the NxG mandate. Their respective resolutions not only pertained to their present situations, but resulted in the formation of a curricular foundation on which they could build. Although "grappling with possibilities" is time and energy depleting, it is likely to pay dividends in the future.

Jesse captured the dualistic nature of the situation when he spoke of how tough implementation was without a firm grasp of the content, sufficient resources to implement, and the inclusion of additional Reading/Language Arts objectives within the social studies framework. Learning that the end of the school year summative assessment would not reflect the NxG CSOs created further stress for Jesse. However, he also said that the experience "jump started" him and broadened his horizons, forcing him to seek sources beyond the traditional textbook. Trina and Steve expressed similar sentiments. "Of course everything is a hassle when you are first learning it", Trina stated, "but you learn as you go." The trial by fire nature of "learning as you go" energized Steve despite the fact it had been years since he had an in-depth study of the ancient world. "I didn't think I would like the change", Steve confessed, "but it was something new and kind of exciting."

Although potentially dangerous, many of us have witnessed the process of jump starting a non-functioning car/truck battery with a functioning car/truck battery and the ensuing energizing process. I am not implying that the intent of the WVBOE or WVDE was to energize the social studies teachers of WV via the inception of the NxG CSOs. I am doubtful that this 


\section{TEACHING WITHOUT A NET}

was a considered consequence. Nor do I believe that policy makers were cognizant of the uncertainty and stress the mandate would generate, especially for $7^{\text {th }}$ grade social studies teachers. State level educational agencies were primarily focused on the creation of standards and objectives which were in "alignment with the Common Core Standards for English/Language Arts and Literacy in History/Social Studies, Science and Technical subjects, as well as to create a more developmentally appropriate alignment across all pragmatic levels" (Next Generation, 2012). The reconstructed narratives of Trina, Steve, and Jesse regarding the unintended consequence of the $\mathrm{NxG}$ mandate jump starting and energizing them professionally is supported by research. Nolan and Meister (2000) maintain that ambiguous external initiatives can prompt creative responses from implementers.

Although on a much smaller scale, the introduction of the NxG CSOs for Social Studies mirrored, at least for the 4 participants, the introduction of curriculum reforms during the Sputnik era (see Chapter 2). In both examples, a lack of careful planning between those requiring the mandate and those assigned the task of implementation was evident. A lack of communication among all stakeholders carries the risk of the reform effort becoming "formula and ritual in the schools" (Urban and Wagoner, 2009, p. 339), something that is easily inserted in place of something else (perhaps, like changing a lightbulb). The formulaic approach may provide insight into "how" to implement, but it lacks the more in-depth "why" components which are necessary for internal changes (i.e., values, beliefs, and assumptions) to occur (see Fullan, 2001; Cochran-Smith \& Lytle, 2009).

Despite the lack of a "roll-out" and little fanfare in introducing the NxG Social Studies Standards, teachers like Trina, Steve, and Jesse moved forward with the implementation process. As previously stated, feelings of uncertainty may have lingered, but the participants all 


\section{TEACHING WITHOUT A NET}

indicated they began to view the implementation process as a challenge that was not

insurmountable. In story 5, the participants discussed how they each resolved (e.g., via

relationships, taking the initiative) the complicating action precipitated by the $\mathrm{NxG}$ mandate.

Trina, Steve, and Jesse indicated that they had to take the initiative themselves to

prepare (i.e., becoming familiar with new content, gathering supplemental resources, unpacking

the new CSOs) for the 2012-2013 school year because assistance from state or local

administrators was not forthcoming. However, the narratives shared by the participants

regarding their preparation for implementation should not be interpreted as classic "pulling

oneself up by one's bootstraps" tales. The theme of relationships clearly indicated that the

participants acknowledged the assistance of their colleagues in helping them resolve the

challenge or complicating action precipitated by the $\mathrm{NxG}$ mandate.

The theoretical position that "teaching without a net" can open a space for educators

to assume greater agency over their respective classrooms and the supporting thematic elements

of taking the initiative and cultivating relationships have a connection to research related to

human happiness. Hargreaves and Shirley (2009) posit that people are more likely to be happy

when they have purpose, power, and relationships.

Teachers feel positive emotions when their purposes are clear, focused, and achievable, and when those purposes belong to them. They become unhappy when purposes are vague, scattered, unrealistic, constantly changing, or are imposed by someone else. Second, teachers like other people, feel happy when they experience being empowered, in control of their work lives and not at the beck and call of others. Last, happiness comes from developing and achieving purposes in positive relationships with colleagues and others, whereas unhappiness springs from a professional life that provides no time to develop or sustain any relationships at all. (p. 73)

Even though "teaching is a complex activity" (Cochran-Smith and Lytle, 2009, p.

120) with many possibilities for complicating actions, Trina, Steve, and Jesse indicated that they 
TEACHING WITHOUT A NET

remain relatively happy in their current teaching positions. Their professional lives appear to encompass the components (purpose, power, and relationships) set forth by Hargreaves and Shirley. Throughout our discussions they spoke of the positive, professional relationships that they have each cultivated with colleagues. These relationships extend beyond mere friendship and have become a source of advice and guidance on a wide range of professional topics (e.g., pedagogy, classroom management, and professional development). As previously mentioned, the narratives of the participants revealed the initiative that they have each taken to better not only their professional lives, but the academic lives of their students. Although disappointed that administrative agencies did not take a more productive stance in communicating the components of the NxG mandate, the participants demonstrated that they were empowered by the ensuing complicating action. Their own initiative, in concert with colleague relationships, enabled them to navigate a stressful academic year. Finally, Trina, Steve, and Jesse each have a sense of purpose regarding their professional lives. Social studies education, according to the participants, extends beyond simply providing a record of past events, but is multi-faceted encompassing civic responsibility, global awareness, problem solving, and critical thinking skills.

\section{Further Implications}

Regarding their professional lives, it appears that Trina, Steve, and Jesse seem to have a sense of purpose, some degree of power/autonomy, and colleague support. These components, according to Hargreaves and Shirley (2009), are necessary for sustaining a sense of personal and professional happiness. However, one may speculate as to the sustainability of my participants' sense of professional happiness, especially in the face of mandates that have the general appearance of being taken lightly by policy makers and introduced without a "roll-out" 
TEACHING WITHOUT A NET

or significant fanfare. At what point, will Trina, Steve, and Jesse no longer view "teaching without a net" as an opportunity for personal and professional growth, but instead view the abdication of responsibility on the part of policy makers to assist with implementation as a signal to listlessly approach the mandate? When/if this occurs, my participants may come to resemble the veteran teachers in Hargreaves' (2005) study, individuals with years of classroom experience, who are wary of mandates. Hargreaves' research supports the notion that witnessing and participating in haphazardly introduced mandates not only encourages teachers to be resistant to change, but also empowers teachers to hold fast to, rather than reexamine, their long held beliefs and assumptions about teaching and learning. Due to an overwhelming influx of policies and mandates, Giroux (1985) asserts that educational reform has "gained the status of a recurring national event" (p. 189).

Trina, Katie, Steve, and Jesse have witnessed their share of reform efforts in relation to the standards and objectives they are required to teach. Since the beginning of the $21^{\text {st }}$ century, 7 amendments to or repeals of the state's social studies standards have occurred (State Rules, 2017). These administrative/legislative mandates have resulted in some form of change, for WV's social studies teachers about every 2.5 years. In this same time period, my participants have no doubt encountered additional mandates emanating from national, state, and local agencies. Given the volume of mandates, one can understand why Trina and Steve both employed the "to pull the rug out" idiom to describe how they felt about the ways in which change efforts were introduced to the classroom. Katie supported the viewpoint of Trina and Steve when she stated "there was always confusion about when to implement and how...the new objectives were just set in front of us without any explanation.” 
TEACHING WITHOUT A NET

For my participants, unpacking mandates and deciding "how" to implement the requirements was a time-consuming task and proved exceedingly frustrating given the quick succession of one mandate replacing another. Granted, deciding "how" to implement is of paramount importance, but the quick succession of mandates left little room for the participants to think about "why" they were proceeding in a certain manner. Fullan (2001) insists that the "why" components of a change effort are just as important as the "how" components because the former touches on the internal (our beliefs and assumptions).

Teacher retention and turnover rates in the US are the subject of debate with the estimated percentage of teachers leaving the field in the next five years ranging from $50 \%$ (Phillips, 2015) to 17\% (Fensterwald, 2015). A number of variables (e.g., low pay, student misbehavior) may explain why teachers are leaving the field in increasing numbers. However, in recent years, a perceived lack of classroom autonomy has driven many educators from the field (Phillips, 2015). Ingersoll maintains that most professions seek employee input when making key decisions, yet this is often not the case in education (Phillips, 2015). Considering that mandates are typically developed by agencies outside of the classroom (Hahn, 1977; Giroux, 1985; Ornstein \& Hunkins, 1998), with little practitioner input, one could theorize that a connection may exist between the continuous barrage of classroom mandates and teachers feeling as though they have little control over matters which directly affect their respective classrooms.

Although some teachers may completely disregard required mandates, like Katie and the veteran teachers in the Hargreaves and Shirley (2009) study, others may robotically acquiesce without thinking critically about "why" they are proceeding in a particular manner. Giroux (1985) identifies the latter group as "high-level technicians carrying out dictates and 
TEACHING WITHOUT A NET

objectives by experts far removed from the everyday realities of classroom life" (p. 189). When teachers are viewed, by policy makers, as "high-level technicians" their function is limited to the role of managers and implementers of curriculum (Giroux, 1985, p. 190). An argument could be made that my participants (and myself) were thought of in this manner by policy makers regarding the NxG CSO mandate. The "Here it is, now go do it!" approach explicitly designated and created a gulf between those charged with developing the mandate and those given the task of implementation.

In contrast to the "high-level technician," Giroux (1985) envisions the classroom teacher becoming a "transformative intellectual," capable of developing and thinking critically about curricula (p. 190). Similarly, Zeichner and Liston (1996) encourage educators to delve into greater professional reflection, focusing "internally on their own practices, and externally on the social conditions of their practice" (p. 19). In both instances, teachers are recognized as autonomous professionals, capable of thinking critically about their practice. Zeichner and Liston (1996) maintain that as autonomous professionals, teachers can "learn from others, and even take direction at times, but in the end are not subservient to those removed from the classroom" (p. 13). Ideally, a balance of power is necessary between practitioners and administrators, at various levels, with both groups working in unison for the achievement of a common goal (e.g., fostering a safe and appropriate student learning environment). A continuous barrage of mandates is not the means to achieve this end. 
TEACHING WITHOUT A NET

\section{Questions for Further Research}

The work of Giroux (1985) and Zeichner and Liston (1996) raised additional questions, for future research, concerning my participants and their experiences in working through mandatory curriculum change. Based on her reconstructed narrative, it might appear as though Katie's decision not to implement the NxG mandate was the embodiment of Zeichner's and Liston's (1996) stance concerning teachers not being "subservient to those removed from the classroom" (p. 13). The argument could be made that after witnessing 4 decades of haphazardly introduced mandates, Katie decided she had had enough and was going to conclude her career on her own terms. Although this may have been the case, Giroux (1985) asserts that teachers are often concerned with "what works" (p. 192) or how best to teach the curriculum (similar to the "how" component discussed by Fullan). Zeichner and Liston (1996), finding inspiration in Dewey (1933), add that the "what works" mindset can deteriorate into a "routine" preventing teachers from "experimenting with alternative viewpoints" (p. 9).

I wonder, did Katie elect not to implement the curriculum change in protest to the haphazard manner in which the mandate was introduced or did she feel that after 10 years of teaching $7^{\text {th }}$ grade social studies she knew "what worked," and created a more convenient, from a curriculum standpoint, final year in the classroom? Katie's reconstructed narratives indicated she was overwhelmed by the required mandate, but she also stated that not having a textbook influenced her decision to let "the next person (taking her position upon retirement) work with the new material." If Katie had had a textbook would she have attempted to implement the mandate?

Although neither of the questions for further research can be definitively answered, an argument could be made which lends credence to theoretical point one (discussed previously 
TEACHING WITHOUT A NET

in this chapter). If Katie's decision not to implement, the NxG CSOs, was based on feelings of uncertainty, protest, or even selecting the path of least resistance, her resolution serves as a reminder that local, state, and national policy makers cannot take curriculum change lightly, nor can they assume that teaching experience is all that is necessary for successful implementation.

One could theorize that Katie's resolution may have been different if she had had greater support in unpacking the objectives and deciding how to implement the mandated changes. As discussed in Chapter 2, Colley (2012) indicates that successful implementation of a change effort can be adversely impacted when implementers work in isolation.

The thoughts of Giroux (1985) and Zeichner and Liston (1996) also generated ideas for further research concerning the resolutions of Trina, Steve, and Jesse regarding the NxG mandate. As previously stated, Giroux's understanding of the teacher as a "high-level technician" involves the educator being reduced to an implementer of predetermined content ( $\mathrm{p}$. 192). Trina, Steve, and Jesse resolved to implement the NxG mandate with its predetermined content. However, I do not think that it is appropriate to refer to them as "high-level technicians." Giroux (1985) indicates that "teachers should be actively involved in producing curricula materials suited to the cultural and social context in which they teach" (p. 193). The reconstructed narratives of Trina, Steve, and Jesse provide evidence that they actively took the initiative to locate materials necessary to bring the $\mathrm{NxG}$ mandate to fruition. McLaughlin (1976), cited previously in this chapter, posits that "local material development," akin to Giroux's thoughts on teachers being actively involved in curriculum development, has the potential to instill a sense of ownership of and responsibility for the curriculum, thereby empowering educators to assume greater agency over their respective classrooms. 
TEACHING WITHOUT A NET

Additional questions for further research emerged pertaining to the materials my

participants self-selected. Specifically, what did they select from the Internet or other sources for use in their respective classrooms? What might the selection of certain materials tell us about the cultural, political, and historical perspectives of the participants and the schools in which they teach? Giroux (1985) maintains that "schools serve to introduce and legitimate particular forms of social life," negating the idea that the school is neutral on ideological and political matters (p. 195). In a similar way, Zeichner and Liston (1996) maintain that there are consequences (personal, academic, \& social/political), for the students, regarding an educator's teaching (which involves the selection of curricular materials). Therefore, I wonder if/how the participants considered both the "how" and "why" components when selecting materials to bring the mandate to fruition?

\section{Epilogue}

The Next Generation Content Standards and Objectives for Social Studies in WV Schools, the mandate which provided the impetus for this research project, was repealed on July 11, 2016 and replaced by the West Virginia College and Career Readiness Standards for Social Studies. Unlike the NxG CSOs there were "no major changes to the social studies content of the current course" (WV College and Career, 2016)) as a result of this mandate. In addition, "performance descriptors (i.e., five levels of competence) and Common Core Literacy Standards from the Next Generation Content Standards and Objectives for Social Studies" (WV College and Career, 2016) were also removed. Simply stated, $7^{\text {th }}$ grade social studies content will continue to focus on Ancient Civilizations with a geography emphasis and the 19 literacy standards, which caused concern for the participants, were reduced to two standards- writing informative/explanatory texts and conducting short research projects. Although these changes 
TEACHING WITHOUT A NET

may seem minor compared to the changes precipitated by the $\mathrm{NxG}$ mandate, the participants and this researcher were not aware of the repeal until well after the comment period. The statewide comment period elicited two comments.

\section{Summary}

Two overarching questions served as guided posts for this qualitative research project: What do the stories of four $7^{\text {th }}$ grade social studies educators tell us about the ways in which teachers engage as developers of curriculum when curriculum change is mandated? In what ways did their stories about implementing a mandated change impact their professional identities? To say that the reconstructed narratives of the participants definitively answered the overarching questions would be inaccurate. The dialogue generated and the stories shared during the interview sessions provided, at best, temporal answers to the overarching questions. Revisiting the project and the participants in the future may yield a new set of questions and conclusions, in addition to those already discussed.

However, for the time being, the reconstructed narratives of the participants offers a lens through which to understand the overarching questions. Their narratives indicated that mandatory curriculum change can produce feelings of uncertainty. Given the perspective that "teaching is a complex activity" (Cochran-Smith and Lytle, 2009, p. 120) it is perhaps safe to say that some degree of uncertainty or the feeling that one is "teaching without a net" will always exist in the classroom. Uncertainty must be acknowledged by policy makers and steps taken (e.g., open channels of communication, discussions related to "how" and "why" components of the change, ample allotment of resources) to reduce the resistance of some implementers to change. Although some individuals may resist change efforts, others view the change as a challenge and embrace the empowering possibilities that uncertainty can produce. For my 
TEACHING WITHOUT A NET

participants, individual initiative was supported by relationships cultivated with colleagues, as teachers often learn best by "watching, listening to, and learning from" their peers (Hargreaves and Shirley, 2009, p. 99).

Trina, Steve, and Jesse readily acknowledged the difficulties (e.g., unfamiliarity with the content, lacking supplemental resources, increased language arts requirements) they faced in implementing the NxG mandate, but they also described the experience as "exciting," "a jump start," and "an opportunity to grow" as an educator. Based on these descriptors, one could infer that their implementation of this mandated change did impact their professional identities and moved each of them to uncover new elements of their respective professional lives. Working without a textbook and the traditional accompanying resources (e.g., worksheets, textbook questions) created spaces for Trina, Steve, and Jesse to become actively engaged in the selection of resources and the CSO implementation process. By assuming greater ownership over the curriculum and its components, my participants became more active developers of curriculum. Trina summarized the transformative process when she stated that after having worked through mandatory curriculum change she could "adapt to almost anything now...give me the subject and I will find my own stuff to make it work."

The silent plot on the sesquicentennial timeline of education in WV, indicating the inception of the NxG CSOs, now has the voices of Trina, Katie, Steve, and Jesse to accompany this point in time. Yet, the perspectives presented in this project are a mere fraction of the available points of view, which could provide additional and perhaps contradictory insight into the development and implementation of the NxG CSOs. Gergen (1991) maintains that the insight of all stakeholders will "enrich and edify academic debate" (p. x). Trina, Katie, Steve, 
TEACHING WITHOUT A NET

and Jesse, through their reconstructed narratives of working through mandatory curriculum change, have no doubt enriched the conversation. 
TEACHING WITHOUT A NET

\section{References}

$21^{\text {st }}$ Century Social Studies Content Standards and Objectives (2520.4),126-044D (2009). Retrieved from http://apps.sos.wv.gov/adlaw/csr/rule.aspx?rule=126-044D

A Snapshot of Education in West Virginia (2013). In West Virginia Department of Education. Retrieved from http://wvde.state.wv.us/downloads.pdf

Apple, Michael (1986). Controlling the work of teachers. In David J. Flinders \& Stephen J. Thornton (Eds.), The curriculum studies reader (pp. 199-213). New York: Routledge.

Bamberg, Michael (2008). Narrative practice and identity navigation. In James A. Holstein \& Jaber F. Gubrium (Eds.), Handbook of constructionist research (pp. 99-118). New York \& London: The Guilford Press.

Beauchamp, Catherine \& Thomas, Lynn (2009). Understanding teacher identity: an overview of issues in the literature and implications for teacher education. Cambridge Journal of Education, 39,175-189. doi: 10.1080/03057640902902252

Beijaard, Douwe, Meijer, C. Paulien, \& Verloop, Nico (2004). Reconsidering research on teachers' professional identity. Teaching and Teacher Education, 20, 107-122. doi: 10.1016/j.tate.2003.07.001

Bennett, Christine I. (2011). Comprehensive multicultural education theory and practice ( $7^{\text {th }}$ ed.). Boston: Pearson.

Clandinin, D. Jean (2013). Engaging in narrative inquiry. Walnut Creek, California: Left Coast Press.

Clandinin, D.J., \& Connelly, F.M. (2000). Narrative inquiry: Experience and story in qualitative research. San Francisco: Jossey-Bass.

Clandinin, D. J., \& Rosiek, J. (2007). Mapping a landscape of narrative inquiry: Borderland Spaces and tensions. In D.J. Clandinin (Ed.), Handbook of narrative inquiry: Mapping a methodology (pp. 35-76). Thousand Oaks, CA: Sage Publications.

Chase, Susan E. (2008). Narrative inquiry multiple lenses, approaches, voices. In James A. Holstein \& Jaber F. Gubrium (Eds.), Handbook of constructionist research (pp. 651675). New York \& London: The Guilford Press.

Cochran-Smith, M., \& Lytle, S. (2009). Inquiry as stance: Practitioner research for the next generation. New York: Teachers College Press.

Coldron, J., \& Smith, R. (1999) Active location in teachers' construction of their professional identities. Journal of Curriculum Studies 31 (6), 711-726. 


\section{TEACHING WITHOUT A NET}

Colley, Sharon L. (2012). Implementing a change to a learner-centered philosophy in a school of nursing: faculty perceptions. Nursing Education Perspectives, 33, 229-233. doi: http://dx.doi.org/10.5480/1536-5026-33.4.229

Connelly, F.M., \& Clandinin, D.J. (1999). Shaping a professional identity: Stories of educational practice. New York: Teachers College Press.

Cothran, Donetta J., McCaughtry, Nate, Kulinna, Pamela Hodges, \& Martin, Jeffery (2006). Top-down public health curricular change: The experience of physical education teachers in the United States. Journal of In-service Education, 4, 533-547. doi: 10. $1080 / 1367458060124556$

Crotty, Michael (2012). The foundations of social research Meaning and perspective in the Research process. London: Sage.

Cuban, Larry (1993). How teachers taught Constancy and change in American classrooms 1880-1990 ( $2^{\text {nd }}$ ed.). New York: Teachers College Press.

Darling-Hammond, L., \& Berry, B. (1988). The evolution of teacher policy. Washington DC: Rand.

Desimone, Laura M. (2013). Reform before NCLB. Kappan, 94 (8), 59-61.

Dewey, John (1933). How we think. Chicago: Henry Regnery.

Evans, Ronald W. (2004). The social studies wars What should we teach the children?. New York: Teachers College Press.

Fensterwald, John (2015, July 16). Half of new teachers quit profession in 5 years? Not true, new study says [Web log post]. Retrieved from https://edsource.org/2015/half-of-newteachers-quit-profession-in-5-years-not-true-new-study-says/83054

Flett, John D., \& Wallace, John (2005). Change dilemmas for curriculum leaders: Dealing with mandated change in schools. Journal of Curriculum and Supervision, 20,188-213.

Fullan, Michael (2001). The new meaning of educational change ( $3^{\text {rd }}$ ed.). New York: Teachers College Press.

Gay, L. R., Mills, Geoffrey E., \& Airasian, Peter (2009). Educational research Competencies for analysis and applications. Upper Saddle River, New Jersey: Pearson.

Gee, James Paul (2000). Identity as an analytic lens for research in education. Review of Research in Education, 25, 99-125. 


\section{TEACHING WITHOUT A NET}

Gergen, Kenneth J. (1991). The saturated self Dilemmas of identity in contemporary life. USA: Basic Books.

Giroux, Henry (1985). Teachers as transformative intellectuals. Social Education, 49(5), 376-379.

Graham, Anne, \& Phelps, Renata (2003). Being a teacher: developing teacher identity and enhancing practice through metacognitive and reflective learning processes. Australian Journal of Teacher Education, 27, 1-13.

Hargreaves, Andy (2005). Educational change takes ages: Life, career and generational factors in Teachers' emotional responses to educational change. Teaching and Teacher Education: An International Journal of Research and Studies, 21, 967-983. doi: 10.1016/j.tate.2005 .06 .007 .

Hargreaves, A., \& Shirley, D. (2009). The fourth way: The inspiring future for educational change. Thousand Oaks, CA: Corwin Press.

Hahn, Carole (1977). Research on the diffusion of social studies innovations. In Francis P. Hunkins, Lee H. Ehman, Carole L. Hahn, Peter H. Martorella, \& Jan L. Tucker (Eds.), Review of research in social studies education 1970-1975 (pp. 137-177). Boulder, CO: Social Science Education Consortium, Inc.

Hermeling, Andrew Dyrli (2013). Social studies on the outside looking in Redeeming the neglected curriculum. District Administration, March, 51-55.

Johnson, Amy Suzanne (2011). Understanding (moral) viewpoints through layered interpretations of teachers' stories. In Lesley A. Rex \& Mary M. Juzwik (Eds.), Narrative discourse analysis for teacher educators Managing cultural differences in classrooms (pp. 55-75). New York: Hampton Press, Inc.

Kennedy, Chris, \& Kennedy, Judith (1996). Teacher attitudes and change implementation. System, 24, 351-360.

Kraemer, A.J. (1973). A cultural self-awareness approach to improving intercultural communication skills. Retrieved from ERIC database. (ED079213)

Kvale, Steinar, \& Brinkmann, Svend (2009). Interviews learning the craft of qualitative research interviewing ( $\left.2^{\text {nd }} e d.\right)$. Los Angeles: Sage.

Labov, W. (1972). Language in the inner city. Philadelphia: University of Pennsylvania Press.

Labov, W. (1967). Narrative analysis. In J. Helm (Ed.), Essays on the verbal and visual arts (pp. 12-44). Seattle: University of Washington Press. 
TEACHING WITHOUT A NET

Laughlin, Margaret A., \& Hartoonian, H. Michael (1995). Challenges of social studies instruction in middle and high schools. Fort Worth, TX: Harcourt Brace \& Company.

Lortie, D. C. (1975). Schoolteacher: A sociological study. Chicago: University of Chicago Press.

Lytle, S., \& Cochran-Smith, M. (1990). Learning from teacher research: A working typology. Teachers College Record, 92 (1), 83-103.

Marris, P. (1975). Loss and change. New York: Anchor Press/Doubleday.

Massell, D. (1994). Achieving consensus: Setting the agenda for state curriculum reform. In R.F. Elmore \& S.H. Fuhrman (Eds.) The governance of curriculum: 1994 yearbook of the association for supervision and curriculum development. Alexandria, VA: Association for Supervision and Curriculum Development.

McCourt, Frank (2005). Teacher man. New York: Scribner.

McKay, John P., Hill, Bennet D., Buckler, John, \& Ebrey, Patricia Buckley (2000). History of world societies $\left(5^{\text {th }}\right.$ ed.). USA: Houghton Mifflin Company.

McLaughlin, Milbrey Wallin (1976). Implementation as mutual adaptation: Change in classroom organization. In David J. Flinders \& Stephen J. Thornton (Eds.), The curriculum studies reader (pp. 188-198). New York: Routledge.

Newman, Joseph W. (2006). America's teachers An introduction to education (5 ${ }^{\text {th }}$ ed.). Boston: Pearson.

Next Generation Content Standards and Objectives for Social Studies in West Virginia (2520.4), 126-044D (2012). Retrieved from http://appa.sos.wv.gov/adlaw/csr/rule.aspx? rule $=126-044 \mathrm{D}$

Nolan, James, \& Meister, Denise G. (2000). Teachers and educational change The lived experience of secondary school restructuring. Albany, NY: State University of NY Press.

Olsen, Brad (2008). Introducing teacher identity. Teacher Education Quarterly, Summer, 3-6.

Ornstein, Allan C., \& Hunkins, Francis P. (1998). Curriculum foundations, principles, and issues ( $3^{r d}$ ed.). Boston: Allyn and Bacon.

Palmer, Parker J. (2007). The courage to teach Exploring the inner landscape of a teacher's life. New Jersey: Jossey-Bass

Patton, Michael Quinn (2002). Qualitative research \& evaluation methods ( $3^{\text {rd }}$ ed.). Thousand Oaks, CA: Sage. 
TEACHING WITHOUT A NET

Phillips, D.C. (Ed.) (2000). Constructivism in education: Opinions and second opinions on controversial issues. Chicago: University of Chicago Press.

Phillips, Owen (2015, March 30). Revolving door of teachers costs schools billions every year. [Web log post]. Retrieved from www.npr.org/sections/ed/2015/03/30/395322012/thehidden-costs-of-teacher-turnover

Riessman, Catherine Kohler (2008). Narrative methods for the human sciences. Thousand Oaks, CA: Sage.

Riesman, C.K., \& Speedy, J. (2007). Narrative inquiry in the psychotherapy professions: A critical review. In D.J. Clandinin (Ed.), Handbook of narrative inquiry: Mapping a methodology (pp. 426-456). Thousand Oaks, CA: Sage Publications.

Ross, E. Wayne (Ed.). (1997). The social studies curriculum Purposes, problems, and possibilities. Albany, NY: State University of New York Press.

Sarson, Seymour B. (1966). The school culture and process of change. In Robert L. Fried (Ed.), The skeptical visionary: A Seymour Sarson education reader (pp. 79-91). Philadelphia: Temple University Press.

Sarson, Seymour B. (1990). The predictable failure of educational reform. San Francisco: Jossey-Bass Publishers

Schwab, Joseph J. (1969). The practical: A language for curriculum. In David J. Flinders \& Stephen J. Thornton (Eds.), The curriculum studies reader (pp. 123-137). New York: Routledge.

Schwandt, Thomas A. (2001). Dictionary of qualitative inquiry $\left(2^{\text {nd }} e d\right.$.). Thousand Oaks, CA: Sage.

Seidman, Irving (1998). Interviewing as qualitative research A guide for research in education and the social sciences $\left(2^{\text {nd }}\right.$ ed.). New York: Teachers College Press.

Senechal, Diana (2015). The paradox of change: How change and stasis combine in education. Arts Education Policy Review, 116, 2-8. doi: 10.1080/10632913.2015. 970093

Schuman, D. (1982). Policy analysis, education, and everyday life. Lexington, MA: Heath.

Slavin, Robert E. (1997). Educational psychology theory and practice ( $5^{\text {th }}$ ed.). Needham Heights, MA: Allyn and Bacon. 


\section{TEACHING WITHOUT A NET}

Sparkes, Andrew C., \& Smith, Brett (2008). Narrative constructionist inquiry. In James A. Holstein \& Jaber F. Gubrium (Eds.), Handbook of constructionist research (pp. 295313). New York: The Guilford Press.

Spring, Joel (2010). American Education (14 ${ }^{\text {th }}$ ed.). New York: McGraw-Hill.

Sugrue, C. (1997). Student teachers' lay theories and teaching identities: Their implications for professional development. European Journal of Teacher Education, 20 (3), 213-225.

Tagg, S.K. (1985). Life story interviews and their interpretations. In M. Brenner, J. Brown, \& D. Canter (Eds.), The research interview: Uses and approaches (pp. 163-199). London: Academic Press.

U.S. Census Bureau. (2015). State \& county quickfacts: Marion County, WV. Retrieved October 1, 2015, from http://quickfacts.census.gov.

U.S. Department of Education. (2004). Testing: Frequently asked questions. Retrieved from http://www2.ed.gov/nclb/accountability/ayp/testing-faq.html

Urban, Wayne J., \& Wagoner, Jennings L. (2009). American education a history (4 ${ }^{\text {th }}$ ed.). New York: Routledge.

Webster, Leonard, \& Mertova, Patricie (2007). Using narrative inquiry as a research method An introduction to using critical event narrative analysis in research on learning and teaching. New York: Routledge.

West Virginia College and Career Readiness Standards for Social Studies (2520.4), 126-044D (2016). Retrieved from http://apps.sos.wv.gov/adlaw/csr/rule.aspx?rule=126-044D

West Virginia State Department of Education. (2015) WVDE public reporting. Retrieved October 1, 2015, from http://wveis.k12.wv.us/nclb/pub/

Wiseman, Robert "Joey" (2012). [Email to county social studies coordinators]. Copy in possession of Stephen R. Higgins.

Wiseman, Robert "Joey" (2012b). [Email to county administrators]. Copy in possession of Stephen R. Higgins.

Zeichner, Kenneth M., \& Liston, Daniel P. (2011) Reflective teaching An introduction. New York: Routledge. 


\section{Appendix}

Dissertation Interview Guide:

Interview One:

- Briefing/Demographic Information:

- How many years have you taught?

- How many years have you taught soc. st.?

- At what grade levels?

- Where have you taught?

- What are your certifications?

- What is the highest degree you have earned?

- Could you tell me about your experiences as a K-12 student?

- What contributed to your success as a K-12 student?

- What proved challenging to you as a K-12 student?

- How did you respond to change as a K-12 student?

- How did you come to the field of education?

- As you entered a teacher education program, what image did you have of the teacher/teaching?

- What kind of teacher did you wish to become?

- How did peers, family members, etc. respond to your career choice?

- Could you tell me about your experience as a student in a teacher education program?

- What promoted your learning?

- What did you find challenging about the teacher education program?

- How did the program influence the image you had of the teacher/teaching?

- Tell me about your initial teaching position...

- How did you respond to the challenges and changes of being a first year teacher?

- What supported you in becoming the teacher you wished to be?

- What interfered with you becoming the teacher you wished to be?

- Could you describe any experiences you have had in implementing mandates prior to the 2012-2013 school year?

○ In what ways were you prepared to implement the mandate?

- In what ways were you not prepared to implement the mandate?

- How did this experience influence your understanding of yourself as a teacher?

- As a first year teacher, what was the image you had of the teacher/teaching?

- Debriefing...Do you have any further comments or questions before we conclude the interview? 


\section{TEACHING WITHOUT A NET}

\section{Dissertation Interview Guide:}

Interview Two:

- $\quad$ Briefing.... Points to revisit from interview one?

- $\quad$ Tell me about the content for $7^{\text {th }}$ grade social studies prior to the 2012-2013 school year?

○ How did you approach the delivery of this content (i.e., methods)?

- What were the academic benefits of this particular curriculum?

- What did you find difficult about teaching this curriculum?

- How did you learn of the Social Studies NxG CSOs?

- What was your initial reaction to the NxG CSOs?

- At what point did you realize that the content for $7^{\text {th }}$ grade social studies had been altered because of the adoption of the NxG CSOs?

- Why was this change mandated?

○ How did you feel as the 2012-2013 school year approached and your content had changed?

- How did you respond to the change?

○ What did you do?... Did you seek clarification from a colleague, your administrator, county coordinator, or a dept. of ed. contact about implementing the NxG CSOs? If so, what did he/she have to say about the new standards?

o How did you implement the new content?

○ (Why did you make the decision not to implement the change?)

$\circ$ (Did anyone question you?)

○ (What was your teaching like the 2012-2013 school year?)

- How would you describe the content for $7^{\text {th }}$ grade social studies under the NxG CSOs?

- Were resources available to assist you in implementing the NxG CSOs?

- What did you do to prepare for the 2012-2013 school year?

○ In what ways were you successful in teaching the new content?

- What did you find frustrating about the 2012-2013 school year?

- Debriefing...Do you have any further comments or questions before we conclude the interview? 
TEACHING WITHOUT A NET

\section{Dissertation Interview Guide:}

Interview Three:

- $\quad$ Briefing...Points to revisit from interview two?

- How did the 2012-2013 school year affect your philosophy of education (beliefs, values, assumptions about education)?

- What advice would you give to policy makers on how to implement a new mandates?

- What does it mean to be a social studies teacher?

- Who is the social studies teacher you will be in the future?

- Any additional thoughts with regard to positive/negative impact of the experience? 
TEACHING WITHOUT A NET 